\title{
STATE OF STRESS, FAULTING, AND ERUPTION CHARACTERISTICS OF LARGE VOLCANOES ON MARS
}

\author{
Patrick J. McGovern \\ Department of Earth, Atmospheric, and Planetary Sciences, \\ Massachusetts Institute of Technology, Cambridge \\ Sean C. Solomon \\ Department of Terrestrial Magnetism, \\ Carnegie Institution of Washington, \\ Washington, D.C.
}

Submitted to Joumal of Geophysical Research

April 1993 


\section{ABSTRACT}

The formation of a large volcano loads the underlying lithospheric plate and can lead to lithospheric flexure and faulting. In turn, lithospheric stresses affect the stress field beneath and within the volcanic edifice and can influence magma transport. Modeling the interaction of these processes is crucial to an understanding of the history of eruption characteristics and tectonic deformation of large volcanoes. We develop models of time-dependent stress and deformation for the Tharsis volcanoes on Mars. A finite element code is used that simulates viscoelastic flow in the mantle and elastic plate flexural behavior. We calculate stresses and displacements due to a volcano-shaped load emplaced on an elastic plate. Models variously incorporate growth of the volcanic load with time and a detachment between volcano and lithosphere. The models illustrate the manner in which time-dependent stresses induced by lithospheric plate flexure beneath the volcanic load may affect eruption histories, and the derived stress fields can be related to tectonic features on and surrounding Martian volcanoes. After an initial load increment is emplaced, flexurally-induced stresses grow with time and the principal stress directions in the volcano rotate as flexure proceeds. Magma is expected to propagate perpendicular to the least compressive stress axis. As a result of flexure, this axis rotates from a horizontal orientation to a nearly vertical one; thus magma propagation paths will tend to rotate from vertical to horizontal orientations. We suggest that at the later stages of flexure, this effect would tend to favor enption sites on to the flanks of the volcano rather than the summit. Such a scenario is consistent with the photogeologically determined evolution of the Tharsis Montes. As a result of flexure there are three regions where stresses become sufficiently large to cause failure by faulting (according to the Mohr-Coulomb criterion): at the surface of the plate just outward of the volcano, and at the base of the elastic lithosphere beneath the center of the volcano, and on the upper flanks of the first volcanic load increment. Normal faulting is the dominant mode of failure predicted for the first region, consistent with circumferential graben observed around the Tharsis Montes and with the scarp at the base of Olympus Mons, interpreted as a large-offset, listric normal fault. Normal faulting, mostly radially oriented, is predicted for the second region. Under the premise that failure 
in the sub-volcano zone may be strongly influenced by pre-existing weak zones or regional stresses, this feature may have a surface expression in the rifting and the bilateral symmetry of the Tharsis Montes. Failure in the third region is predicted to consist of thrust faulting, oriented mostly circumferentially on the upper flanks with an annulus of radially oriented thrust faulting starting about midway downslope. Concentric terraces, interpreted by some workers as thrust faults, on the upper flanks of Olympus Mons may correspond to the predicted circumferential thrust features. For volcanoes detached from the plate, predicted failure in the edifice takes the form of radial normal faulting at the base. Addition of an extensional stress due to regional topography yields a pattern of predicted faulting which closely matches that observed on the Tharsis Montes. This stress state is also consistent with an interpretation of the aureole deposits of Olympus Mons as the result of gravity sliding along a basal detachment.

Our models also suggest explanations for the lack of strike-slip features, predicted by simple flexural models, around the Tharsis volcanoes. For a given load increment, the first mode of nearsurface failure for most of the area immediately outward of the load is circumferential normal faulting and graben formation. As the volcano grows and the flexural response to the increasing load proceeds, the predicted failure mode in a portion of this annular region surrounding the volcano changes to strike-slip faulting. Because normal faulting has been predicted to have taken place earlier, however, it is likely that release of later stresses will occur by reactivation and growth of these normal faults and graben rather than by the formation of strike-slip faults. 


\section{INTRODUCTION}

The major Tharsis volcanoes of Mars (Olympus Mons and the three Tharsis Montes: Arsia Mons, Pavonis Mons, and Ascraeus Mons) are among the largest known volcanic structures in the solar system. An understanding of the formation and evolution of these structures can provide important constraints on the processes that built and maintained the Tharsis Rise. In addition, the Tharsis volcanoes may be analogues to large hot-spot volcanoes on Earth, such as those of Hawaii. For instance, Kilauea and Olympus Mons have very similar ratios of volcano height to diameter and of basal scarp height to volcano height [Borgia et al., 1990]. Thus studies of the evolution of large Martian volcanoes may yield insight into terrestrial volcanic processes as well. In this paper we utilize finite element models to evaluate the evolution in internal stress and deformation within and surrounding the Tharsis volcanoes, and we discuss how the timedependent stress field may be relatable to the eruption characteristics of the volcanoes and to the formation of associated tectonic features.

To date the investigation of the evolution of stresses in large volcanoes has taken two paths: models of edifice stresses alone (usually finite element models with rigid bottom boundary conditions), and investigations of flexural stresses in the lithospheric plate supporting the volcano. As examples of the first category of study, Chevallier and Verwoerd [1988] used an axisymmetric planar finite element code to investigate the effect of magma chamber and external pressures on stress and eruption histories of hot spot volcanoes, Dieterich [1988] modeled stress in volcano rift zones by means of a two-dimensional triangular grid of elements, and Ryan [1988] employed a horizontal planar finite element model of the flank of Kilauea to determine displacements and stresses due to dike emplacement. In an example of the second class of study, Thurber and Gripp [1988] applied a flexural model to constrain the tectonics of volcano flank motions. ten Brink and Brocher [1987] proposed a link between flexural stresses in the lithosphere and eruption history; in their scenario the orientation of flexural stresses beneath a given point on the volcanic chain changes with time as the volcanic load is emplaced and then eroded. Given that magma seeks to propagate along paths perpendicular to the direction of least compressive stress, magma ascent can 
be blocked when both principal horizontal stress deviators are compressional. Thus eruption history depends on location along the volcanic chain or on time since volcano formation.

Recent studies have also been carried out on edifice stresses of large Martian volcanoes. Thomas et al. [1990] investigated the tectonics of the flanks of Martian volcanoes by means of an incompressible finite-element model. Volcano self-loading and magma chamber effects were included, but lithospheric flexure was not. Thomas and coworkers found that stresses on the flanks of a large volcano are sufficient to cause circumferentially oriented thrust faulting, and they suggested that such thrusting produced the concentric terraces observable high on the flanks of Olympus Mons. Zuber and Mouginis-Mark [1992] treated the evolution of the surface of Olympus Mons, using a finite element model to calculate stresses in the summit caldera region caused by different magma chamber locations and geometries for comparison with observed patterns of faulting.

In this paper we study the stress field within a volcano and the lithosphere upon which it rests as a unified system. With such a model formulation we can account explicitly for the interaction between edifice stresses (e.g., due to volcano self-loading) and flexural stresses (a result of the load induced by the volcano on the lithosphere). We include both growth of the volcano and viscoelastic deformation in the asthenosphere, so the problem is intrinsically time-dependent. The calculated displacements yield the subsidence history of the volcano. The orientations of principal stresses and their change with time provide important constraints on possible magma emplacement paths and eruption histories. With the computed stress fields, a failure criterion can be used to predict locations and modes of faulting within and near the volcano. After a short discussion of important geological and geophysical characteristics of the Tharsis volcanoes, we briefly describe the finite element procedure and the modelling assumptions. The results of the numerical computations are next presented, and their potential implications for the evolution of eruption characteristics and the formation of tectonic features are then compared with known constraints on the evolution of the Tharsis volcanoes. 


\section{CHARACTERISTICS OF MAJOR THARSIS VOLCANOES}

The four major Tharsis volcanoes are the largest of the martian shield volcanoes [e.g., Greeley and Spudis, 1981]. Each construct is composed of many overlapping flows and flow units' erupted over a period of activity as much as 2-3 Gy. in duration [Tanaka, 1986]. The approximate heights and basal diameters are given in Table 1.

The largest of the major Tharsis volcanoes is Olympus Mons (Figure 1). The principal tectonic features associated with Olympus Mons are (1) the summit caldera complex, consisting of a series of circular depressions with complex patterns of faulting, (2) concentric terraces seen on the upper slopes of the volcano, (3) the basal scarp, a nearly vertical cliff surrounding the volcano at a radius of about $300 \mathrm{~km}$, and (4) the aureole deposits, which occupy a vast region dominantly to the northwest of the main shield (downslope from the Tharsis rise [U.S. Geological Survey. 1989]). The summit caldera is likely the result of a collapse following withdrawal of magma from a high-level magma chamber [Mouginis-Mark, 1981; Zuber and Mouginis-Mark, 1992]. As noted earlier Thomas et al. [1990] have interpreted the concentric terraces to be thrust faults. The basal scarp has been variously interpreted as a thrust fault [Morris, 1981], a listric normal fault [Francis and Wadge, 1983], and a fault-propagation fold over a subsurface thrust fault [Borgia et al., 1990]. The aureole deposits are generally held to be disrupted landslide material derived from the slopes of the volcano [Harris, 1977; Lopes et al., 1980; Francis and Wadge, 1983]. Tanaka [1985] proposed that gravity sliding and spreading of the aureole deposits is enabled by a weak basal detachment between aureole and substrate. A layer containing about $10 \%$ interstitial or interbedded ice would be sufficiently weak to provide such a detachment.

Tectonic features on the flanks of Hawaiian volcanoes on Earth may provide useful analogues to the Olympus Mons scarp and aureole. Acoustic backscatter images of the Hawaiian Ridge reveal that extensive mass wasting deposits (slumps and debris avalanches) flank all of the major Hawaiian shields [Moore et al., 1989]. A study of focal mechanisms of shallow earthquakes on the southern flanks of Kilauea [Thurber and Gripp, 1988] supports the hypothesis that a detachment surface separates the volcanic edifice and the older oceanic crust. By this hypothesis, 
the volcano can overthrust the underlying crustal layer, sliding on a decollement of weak oceanic sediments. The slides and slumps, driven by intrusions at the rift zones, detach from the volcano along large-offset listric normal faults [Lipman et al., 1985].

Tectonic features observed on and around the Tharsis Montes volcanoes differ somewhat from those of Olympus Mons. The principal tectonic features associated with these volcanoes are (1) circumferential graben on the lower volcano slopes and the surrounding plains, (2) linear embayments or rifts approximately bisecting each volcano along an axis trending $N 40^{\circ} \mathrm{E}$ and serving as sources for flows embaying the northeast and southwest flanks, and (3) lobe-shaped deposits to the west or northwest of the edifice [Scott and Tanaka, 1981; Scott et al., 1981a, b, c]. The Tharsis Montes volcanoes exhibit an approximate bilateral symmetry about a NE-SW-trending axis coinciding approximately with the line connecting their centers. Graben tend to occur on the northwest and southeast flanks of these volcanoes (Figures 2-5), i.e. perpendicular to radial directions broadly orthogonal to the line of the rifts. From photogeological study of Viking Orbiter images, Crumpler and Aubele [1978] proposed the following evolutionary sequence for the Tharsis Montes: (1) construction of the main shield, (2) outbreak of parasitic eruption centers on the volcano flanks along the NE-SW-trending axis, (3) subsidence of the summit and formation of concentric fractures and graben, and (4) formation of a bisecting rift along the NE-SW-trending axis, with rift eruptions leading to flooding of the summit depression and inundation of the rifted flanks. This sequence is most advanced on Arsia Mons; Pavonis Mons has reached stage (3), and Ascraeus Mons stage (2). The morphology and tectonics of the flanks of the Tharsis Montes are described in greater detail by Zimbleman and Edgett [1991]. They propose that the lobate deposits formed by gravity sliding and were further modified by both effusive and pyroclastic volcanic activity.

Prominent rift zones that radiate from the summit calderas are dominant structural features characteristic of Hawaiian shield volcanoes [Peterson and Moore, 1987]. These zones are sites of emplacement of magma drained from the summit magma chamber and indicate an environment of horizontal extension. The rift zones and landslides or slump deposits appear to be causally related, 
as described above. The Hawaiian rift zones may be analogues to the radial rifts of the Tharsis Montes.

The thickness of the elastic lithosphere beneath the Tharsis Montes volcanoes has been inferred from the radial distances of their circumferential graben by Comer et al. [1985] (see Figures 3-5). Preferred values of elastic lithosphere thickness are around $20 \mathrm{~km}$. Concentric graben are not found around Olympus Mons, however, which led Comer and coworkers to conclude that the thickness of the elastic lithosphere beneath Olympus Mons must be much greater $(>150 \mathrm{~km})$ than beneath the Tharsis Montes. Of course, the actual lithosphere does not behave perfectly elastically; rather its strength is limited by frictional failure at shallow depth and by ductile flow at greater depth. From strength envelope considerations for crustal and mantle material [McNutt, 1984], values for elastic plate thickness $T_{e}$ were converted to estimates of mechanical plate thickness $T_{m}$ and lithospheric thermal gradient by Solomon and Head [1990]. For Olympus Mons, flexurally induced curvature is small and $T_{m}$ is approximately equal to $T_{e}$. The lithospheric thermal gradient is then less than $5 \mathrm{~K} \mathrm{~km}^{-1}$. For the Tharsis Montes, flexural curvatures are larger, $T_{m}$ exceeds $T_{e}$, and mean thermal gradients (corresponding to the best fitting values of $T_{m}$ ) are in the range 10-14 $\mathrm{K} \mathrm{km}^{-1}$. Upper and lower bounds on $\mathrm{T}_{e}$ for the Tharsis Montes from Comer et al. [1985] allow a range of thermal gradients from 7-27 $\mathrm{K} \mathrm{km}^{-1}$.

\section{METHOD}

We use the finite element program TECTON [Melosh and Rafesky, 1980, 1983] to model stresses and displacements in a large volcano and in the crust and mantle beneath and around the volcano. TECTON's capability for modeling a viscoelastic rheology in the mantle allows us to model the time-dependent flexural response of an elastic lithosphere to each major increment of load. The program first calculates the elastic (i.e., "instantaneous") response to a load. The stresses and displacements arising from load-induced viscoelastic flow in the mantle are then calculated for a specified number of time steps. The Maxwell time $\left(\tau_{M}\right)$ of the mantle, defined as the ratio of viscosity $\eta$ to shear modulus $\mu$, is used as a convenient reference time scale (in subsequent discussion the term "Maxwell time" will refer to the mantle Maxwell time). Complete 
descriptions of stresses and displacements were obtained at $5,10,15,20,30,40,70,100,200$, 400, 700 and 1000 Maxwell times after emplacement of each load increment.

We assume that the problem is axisymmetric, with cylindrical coordinates $r, \theta$, and $z$. Out-ofplane shear stresses $\sigma_{r \theta}$ and $\sigma_{\theta z}$ are then zero. We solve for $r$ and $z$ displacements and stress components $\sigma_{r r}, \sigma_{\theta \theta}, \sigma_{z z}$, and $\sigma_{r z}$. In axial symmetry, two principal stresses are confined to the $r z$ plane, and $\sigma_{\theta \theta}$, the stress normal to this plane, is also a principal stress. An example of the finite element grid used for this study is shown in Figure 6 . The displacement boundary conditions are that nodes on the side walls $\left(r=0\right.$ and $\left.r=r_{\max }\right)$ are fixed in $r$ but free to move in $z$, and that nodes on the bottom boundary ( $z=-820 \mathrm{~km}$ in the example shown) are fixed in $z$ but free to move in $r$. The lower corners of the box are fixed in both directions. The volcano in the example has a radius of $200 \mathrm{~km}$ and is $25 \mathrm{~km}$ in height, the approximate present dimensions of Ascraeus Mons. In Figure 6 the volcano is the triangular region in the upper left-hand comer. The volcano rests on top of an elastic lithospheric plate of thickness $\mathrm{T}_{e}$. All elements in the volcanic edifice and the plate have a high viscosity appropriate to the lithosphere. These elements behave essentially elastically over the time scales considered here. All elements below the elastic lithosphere have a lower viscosity value, appropriate for an asthenosphere. These elements experience viscous relaxation over the time modeled. Material property values adopted in our calculations are listed in Table 2. Parameters such as density and Young's modulus differ for the crust and mantle. Elements above depth $t_{c}$ are assigned crustal values for these parameters; below this depth mantle values are assigned. For most of the models discussed here, we have chosen $T_{e}=t_{c}$. We do not mean to imply that thicknesses of the Martian lithosphere and crust coincide; this choice serves only to simplify the models. We have performed additional calculations with $T_{e}>t_{c}$ to explore the effect of a strong upper mantle on the flexural solutions. We take $T_{e}$ to be variously 20,40 , and $60 \mathrm{~km}$. These values fall within the range obtained by Comer et al. [1985] for the Tharsis Montes and Olympus Mons. The outer radial boundary of the grid is taken as $r_{\max }=1200 \mathrm{~km}$.

As a check on the use of TECTON for plate flexure calculations, we have compared the stresses and displacements calculated by the code to those from an analytic solution for thick plate 
flexure in axisymmetric geometry [Comer, 1983]. We constructed a model of the plate only, without the volcano elements, similar to analytic models. This was done to avoid local stiffening of the plate due to the added thickness of the volcano near $r=0$, which would change the resulting flexural profile. The load of the volcano was simulated by applying appropriate axisymmetric forces to the nodes on the top surface of the plate. The surface elevation of the plate at the final time step, relative to its value at the right boundary $r=r_{\max }$ is shown in Figure 7a; also plotted is the analytic thick-plate solution. The difference between the two solutions is plotted in Figure $7 \mathrm{~b}$. The TECTON solution closely matches the analytic solution except for errors of less than $1 \%$ near $r=0$ and about $1.5 \%$ near the flexural arch.

We note that for cases in which the volcano is solidly attached to the lithosphere, the deflection given by TECTON at the final time step is less than that of the analytic solution near $r=0$. Radial distances of the zero crossing and flexural bulge are also greater than those for the analytic solution. These effects result from a stiffening of the plate by the volcanic load itself. Near $r=0$, the elements that make up the volcano take up some of the horizontal compressive flexural stresses that would otherwise be taken up by the top half of the plate. This effect may be important when analytic thin-plate flexure models are compared to topography in order to estimate elastic plate thicknesses, in that for welded volcanoes, $T_{e}$ would be overestimated.

An important limitation of analytic models of lithospheric loading is that the load is emplaced instantaneously. This assumption implies a growth time $t_{g}$ much less than the mantle Maxwell time $\tau_{M}$. For Mars, if $\eta \sim 10^{21} \mathrm{~Pa}-\mathrm{s}$ and $\mu \sim 10^{11} \mathrm{~Pa}, \tau_{M}-10^{10} \mathrm{~s}$ or $300 \mathrm{yr}$. A more realistic model would allow the volcano to grow incrementally with time, simulating the way in which many discrete lava flows are superposed to form an edifice. We have implemented a modification to the finite element code that allows us to specify the properties of a given element as a function of time. The finite element grid is set up exactly as in Figure 6a, except that volcano elements are initially given a density of zero and a low but finite value of Young's modulus (the latter to prevent a singularity in the stiffness matrix used to calculate displacements). These elements are considered "off;" that is, for the purposes of the simulation, such elements are considered initially unoccupied 
by volcano material. At the beginning of an appropriate time step, an element can be turned "on" by changing the values of the' density and Young's modulus to normal crustal values. Here we have simulated the incremental growth of a volcano by switching on elements in the volcanic edifice in three stages (Figure 6b), at time zero, at 1000 Maxwell times, and at 2000 Maxwell times. We note here that our attempt to model a growing load is necessarily a coarse one. A typical terrestrial volcanic shield will consist of thousands of units emplaced over about $10^{5}$ to $10^{6}$ years (this timescale may be $10^{8}$ to $10^{9}$ years on Mars). Such units are much lower in volume than those we model. Further, our increments are separated by only 1000 Maxwell times (about 30,000 years for the parameters adopted here). This value was selected to be long enough to complete the flexural response to a given increment, abut is not meant to imply that units are emplaced that rapidly.

In order to explore the hypothesis that volcanoes on Earth and Mars may have similar tectonic structures, we have used special features in the TECTON code to simulate the effect of a detachment between volcano and lithosphere as described by Lipman et al. [1985] and others. The effects of fault slip along such a detachment on the stresses and deformation can be modeled using the slippery node method implemented in TECTON by Melosh and Williams [1989]. We apply slippery nodes to all the nodes originally on the line $z=0$, i.e., along the interface between the volcano and the lithosphere. This modification allows the volcano to thrust outward over the flexed lithosphere.

The evolution of the stress field within and beneath the volcanic edifice in a model is depicted by means of symbols for the principal stresses within each element (Figure 8, symbols after Melosh and Williams [1989]). The first and second symbols denote situations where the azimuthal or hoop stress is the intermediate principal stress $\sigma_{2}$. The third and fourth symbols represent cases where the hoop stress is the greatest extensional stress $\sigma_{3}$. The fifth and sixth symbols represent cases where the hoop stress is the greatest compressive stress $\sigma_{1}$. 
Given stress values, we use the Mohr-Coulomb failure criterion to estimate regions where faulting would occur. The Mohr-Coulonb failure equation relates shear stress $\tau$ at failure to normal stress $\sigma_{\mathrm{n}}$

$$
\tau_{\text {failure }}=c+\sigma_{\mathrm{n}} \tan \phi
$$

where $c$ is the cohesive strength of the rock and $\phi$ is the angle of internal friction. We adopt values for $c\left(3.8 \times 10^{7} \mathrm{~Pa}\right)$ and $\phi\left(49^{\circ}\right)$ appropriate for basalt [Handin, 1966]. Elements where the shear stress has exceeded the Mohr-Coulomb criterion are shaded to indicate failure. Once we have found where failure is expected, the orientations of principal stresses are used to determine the style and orientation of faulting, according to the criteria of Anderson [1951]. Given the principal stress directions, the type of faulting (normal, thrust, or strike-slip) and the orientation (radial or circumferential) can be determined. Figure 8 gives types and orientations of faulting in elements with the given orientations of the stress symbols. This classification scheme holds if the principal stresses approximately correspond to the horizontal $\left(\sigma_{\pi \pi}, \sigma_{\theta \theta}\right)$ and vertical stresses $\left(\sigma_{z z}\right)$ listed here. If the stresses are not aligned in this way, fault geometry may be less simply described. Strike-slip faults do not quite fit the usual definitions of radial and circumferential, because such faults are expected generally to strike obliquely to the principal stress directions. For most situations, strike-slip faults make smaller angles with the $\sigma_{1}$ direction than with the $\sigma_{3}$ direction. Thus, when $\sigma_{1}=\sigma_{\theta \theta}$ we will consider the resulting faults approximately circumferentially oriented, and when $\sigma_{1}=\sigma_{r r}$ we consider them approximately radial. Care must be taken when applying these results to regions at depth, or where principal stresses are oblique to the surface.

For a general state of stress in a plane layer constrained laterally and subjected to self-loading (before the volcanic load is applied), the orientation of the stress symbol will be as in the first line of Figure 8: maximum compression vertical and maximum extension horizontal. The magnitude of the deviatoric stress will increase with depth. This result can be derived from the equations for uniaxial strain (compaction) in the z-direction [e.g., Turcotte and Schubert, 1982 , p. 108]: 


$$
\sigma_{r r}=\sigma_{\theta \theta}=\left(\frac{v}{1-v}\right) \sigma_{z z}
$$

For Poisson's ratio $v=0.25$, the factor $v /(1-v)$ is $1 / 3$. Thus, the vertical stress will be three times as great as the horizontal stress, and with vertical stress equal to the overburden pressure ( $\sigma_{z z}=$ $\rho_{c} g z$, where $\rho_{c}$ is the density of crustal material and $g$ is the gravitational acceleration), the stress difference will increase with depth. The state of stress in the terrestrial crust is still a matter of debate. McGarr [1989] argues that a stress state in which all principal stresses are equal to the overburden load is a better reference stress state than the "Poisson" stress state described by equation (2). However, it seems likely that the state of stress lies somewhere between the two extremes. In general, the stress state described by equation (2) is the initial state in the lithosphere for most of our models. We consider additional models, however, to determine the effects of an isotropic lithospheric prestress (with $\sigma_{\pi}=\sigma_{\theta \theta}=\sigma_{\mathrm{zz}}=\rho_{c} g z$ ). For all models, the prestress in the asthenospheric mantle is taken to be isotropic.

When applying the results of these calculations to actual geologic and tectonic features seen on Martian volcanoes, one must keep in mind the model limitations. The simplest calculations that we perform here start with the instantaneous placement, at time $t=0$, of a significant portion of a volcanic edifice, equivalent to the condition $t_{g} \ll \tau_{M}$. This assumption is valid only for individual flows constituting at most a minor mass fraction of the volcano. While we have modified the finite element code to accommodate changes in element properties with time, as noted above the individual load increments are large fractions of the volcano mass. Other limitations are also noteworthy. It is difficult to determine the geometry of a given volcano load, even at the end of the last major shield-building eruptions, because of subsequent flexure and deformation that may have significantly modified the volcano's characteristics. These calculations are performed under the assumption of axial symmetry; possible effects of nonaxisymmetric loading (such as regional stress) and complex three-dimensional geometry are not incorporated. The effects of magma pressure, transport, and evacuation are not addressed in these models; these processes likely have important influences for caldera and flank tectonic evolution [Thomas et al., 1990; Zuber and Mouginis-Mark, 1992]. Further, lateral variations in material properties (due to 
horizontal temperature gradients, for example) are not included. Our choice that $T_{e}=t_{c}$, while made for convenience, is not necessarily valid for the Tharsis region. Finally, it must be remembered that a viscoelastic model cannot account for relief of stress due to faulting (except for faults modeled a priori such as in the detached volcano models). Once faulting occurs, the stress fields calculated are no longer strictly valid, since faulting would relieve stresses locally and could thus alter the predictions for failure at subsequent times. As discussed below, some of these limitations can be relaxed in future modeling efforts.

NUMERICAL RESULTS: STRESS, DEFORMATION, AND FAULTING

\section{Models with Growing Loads}

An illustrative model for the evolution of volcano-related stresses is shown in Figure 9, which depicts the case of an incrementally grown volcano on a lithosphere with $T_{e}=40 \mathrm{~km}$. At $t=0$ (Figure 9a) deviatoric stresses display the orientations and magnitudes expected from simple selfloading of horizontal layers everywhere but along the top layer of volcano elements, where the stresses are rotated such that the compressive axis is almost horizontal. As the effects of flexure manifest themselves with time, this rotation propagates deeper into the volcano, eventually reaching the upper part of the underlying plate (Figures $9 \mathrm{~b}-\mathrm{f}$ ). These figures also show predicted locations and types of faulting as functions of time. For the initial volcano of $120 \mathrm{~km}$ radius, faulting is initiated in two areas by about 20 Maxwell times (Figure 9b). A subsurface region of normal faulting at a depth of $35-40 \mathrm{~km}$ (at the base of the elastic lithosphere) appears beneath the center of the volcanic load. Faulting also starts at the plate surface just outward of the volcano. In this region, all elements but one are predicted to experience circumferentially oriented normal faulting (the innermost element is predicted to fail by strike-slip). By 100 Maxwell times (Figure 9c), both regions have expanded radially and vertically, and a new zone of faulting appears along the upper volcano flanks. The predicted fault style and orientation on the flanks is predominantly circumferential thrusting. Mostly radial normal faults are predicted for the subsurface failure region. By 1000 Maxwell times (Figure 9d), the area of circumferential normal faulting extends up to $300 \mathrm{~km}$ radius (not shown in figure) and up to $10 \mathrm{~km}$ depth. The area of strike-slip faulting has 
grown in radial extent at the expense of the region of circumferential normal faulting, but each of the elements in this zone has already been predicted to fail by a circumferential normal mechanism at an earlier time step (see Figures 9b, 9c). The upper flanks of the volcano are predicted to fail by circumferential thrust faulting, and the lowermost element on the flank by radial thrust faulting. The failure region at the bottom of the plate now extends slightly beyond the radius of the volcano itself. Near $r=0$, this region includes the entire bottom half of the plate (20 to $40 \mathrm{~km}$ below the original surface).

In Figures $9 \mathrm{e}$ and $9 \mathrm{f}$ we see the effect of the next increment of volcano growth. Notice that most elements on the volcano flank predicted to fail in Figure 9d are no longer predicted to be in failure in Figure 9e, but some of them are predicted to fail again by the time depicted in Figure $9 f$. No failure is predicted, however, in the layer of elements constituting the new surface of the volcano. In Figure 9g, the effects of the final load increment can be seen. Only two elements in the entire edifice have deviatoric stresses sufficiently great to cause failure.

The magnitude of the maximum deviatoric stress (the difference between the principal stresses of greatest and least magnitude) in the vicinity of the volcano is shown versus time in Figure 10. A comparison with the stress orientation symbols of Figure 9 indicates the principal stresses used to calculate the maximum deviatoric stress at a given point. Figure 10a shows the state of deviatoric stress of the elastic solution. The stress difference increases with depth, as discussed above. At a given depth, the deviatoric stress is higher beneath the initial volcano load increment than outward of the volcano. In Figure $10 \mathrm{~b}$ (at $t=1000 \tau_{\mathrm{M}}$ ) concentrations of high deviatoric stresses have developed in the three characteristic regions of failure from Figure 9. Deviatoric stresses exceed $150 \mathrm{MPa}$ near the volcano summit and in a wide area near the bottom of the plate beneath the volcano. Failure is predicted in both areas. Deviatoric stresses are not quite so high in the nearsurface region immediately surrounding the volcano, but faulting is predicted there because of the low confining pressure. There are two important regions of relatively low deviatoric stress; directly beneath the volcano summit near $z=-4$ to $-14 \mathrm{~km}$, and far from the volcano (at both the top and bottom of the plate). In Figure $10 c$ (at $t=2000 \tau_{\mathrm{M}}$ ) the region of high stress in the edifice 
in magnitude, although the vertical gradient of stress is greater for the thinner plate. Peak deviatoric stresses in the volcanic edifice are significantly higher for the thinner plate.

Results for a model with a thicker elastic lithosphere and crust $\left(T_{e}=t_{c}=60 \mathrm{~km}\right)$ also reveal interesting changes from the first model. After the first loading increment $\left(t=1000 \tau_{\mathrm{M}}\right.$, Fig. 13a), faulting has initiated at the lithosphere base and outside the volcano, but not in the edifice itself. In the outer faulting region we again observe elements where predicted failure evolves from initial normal to later strike-slip. The area of predicted strike-slip faulting is much larger in extent than for the cases with thinner lithospheres. After the final load increment (Figure 13b) the region of predicted near-surface normal faulting expands outward to $590 \mathrm{~km}$ from the center (Table 3), as well as down to a maximum depth of $20 \mathrm{~km}$. The region of failure beneath the volcano is found at a deeper level (30-60 km depth), because of the greater plate thickness. Faulting of any type is absent from the edifice throughout the period modeled.

Maximum deviatoric stresses for this case are shown in Figure 14. Compared to the case with $\mathrm{T}_{\mathrm{e}}=40 \mathrm{~km}$ (Figure 10), there are several differences. At the final time steps shown (Figures 10d and 14b), the region of high stress near the base of the lithosphere (as defined by, say, the 300 MPa contour) is greater in vertical and lateral extent for the case with $T_{e}=60 \mathrm{~km}$, even though the maximum stress deviator is about the same. The deviatoric stress minimum, beneath the volcano, is also larger in extent and centered more deeply (about $-14 \mathrm{~km}$ ) than its counterpart for $T_{e}=40$ $\mathrm{km}$. Deviatoric stresses within the volcanic edifice are significantly lower for this case compared with the other two.

To investigate the effects of different crustal and lithospheric thicknesses, we performed a calculation with a 40-km-thick crust and a 60-km-thick elastic lithosphere. The upper mantle lithosphere has a higher value of Young's modulus and should cause the plate to behave more stiffly than if the plate consisted entirely of crustal material. Figure 15 shows plots of stress orientation and failure for this case; compare with Figure 9 for a case with crust and lithosphere both $40 \mathrm{~km}$ thick and with Figure 13 for a case with crust and lithosphere both $60 \mathrm{~km}$ thick. The evolution of the stress field and zones of predicted failure is qualitatively similar to those discussed 
has intensified, but remains centered at about the same position as before, at the top of the first load increment. The second load increment, emplaced atop the first, shows a much lower level of deviatoric stress than evident below. The deviatoric stress low beneath the volcano has shrunk in size and lowered its mean level to about $z=-10 \mathrm{~km}$. By the time subsidence is nearly complete (Figure 10d), most of the region near the volcano experiences deviatoric stress in excess of 200 MPa. The regions of high deviatoric stress have expanded to maximum size, and the deviatoric stress minimum below the volcano center has again shrunk slightly.

Changing the plate thickness can affect the evolution of regions of failure. For $T_{e}=t_{c}=20$ $\mathrm{km}$, the entire flank is predicted to fail by thrust faulting after $1000 \tau_{\mathrm{M}}$ (Figure 11a).

Circumferential thrust faults on the upper flanks will be surrounded by a small annulus of radially oriented thrusts on the lower flanks. The region of failure outward of the volcano is smaller in radial extent than for the case with $T_{e}=40 \mathrm{~km}$ (Fig. 10b). While strike-slip faulting in the inner portion of this region, initial predicted failure for most of these elements occurs by circumferential normal faulting. In any case, this inner annulus will be covered by volcanic material later in the growth of the volcano. At the final stage (Figure $11 \mathrm{~b}, t=3000 \tau_{\mathrm{M}}$ ), the subsurface region of failure reaches through almost the entire thickness of the plate to the base of the volcano. At the radially distal edge of this region, stresses are rotated such that strike-slip faulting is expected, and the region merges with the failure region outside the volcano to form a continuous zone predicted to be faulting. More elements ( 5 vs. 2 ) in the edifice retain stresses large enough to cause failure than for the case with $T_{e}=40 \mathrm{~km}$.

The evolution of maximum deviatoric stress for this case (Figure 12) follows a course similar to that for $T_{e}=40 \mathrm{~km}$. The regions of high deviatoric stress on the volcano flanks and at the bottom of the plate closely surround a stress minimum whose center lies at about $z=-3 \mathrm{~km}$. After the first load increment is accommodated (Figure 12a), peak stresses in the edifice are nearly twice as large as for the case with $T_{e}=40 \mathrm{~km}$. A comparison of the late-stage stresses for these two cases (Figures 10d and 12b) shows that the deviatoric stresses near the base of the plate are similar 
above. One effect of the stiff upper-mantle lithospheric layer is to concentrate into a narrower depth interval the zone of failure beneath the volcano, seemingly shielding the less rigid crust above from failure. In Figure 13, this zone extends from 30 to $60 \mathrm{~km}$ depth, whereas in Figure 15 only elements in the mantle portion of the lithosphere (40 to $60 \mathrm{~km}$ depth) show stresses that satisfy the failure criterion. We also observe that the size of the zone of near-surface failure outward of the volcano, and the amount of strike-slip faulting within it, are both greater for the plate with a strong upper mantle lithospheric layer (Table 3). Contours of maximum deviatoric stress after the final load increment for this model (Fig 16) are broadly similar to Figure 14, except that the deviatoric stress level is much higher at the base of the lithosphere, revealing a concentration of stress in the strong mantle lithosphere. Also, the deviatoric stress minimum beneath the load occurs at a slightly shallower depth.

\section{Models with Instantaneous Loads}

It is instructive to consider a model with an instantaneously emplaced load, both as a comparison with analytic models and as a reference to study the effects that incremental volcano growth has on the evolution of stresses in volcanoes. Figure 17 shows stress orientations and failure for this case at the conclusion of flexure $\left(t=1000 \tau_{M}\right)$. These are qualitatively similar to those for the case with incremental loading (Figure 9g) except for the volcano flanks, which are predicted to have failed along the entire surface and to $15 \mathrm{~km}$ depth near the summit. Circumferential thrust faults are predicted on the upper flanks, and an annulus of radially oriented thrusts is predicted on the lower flanks. This state is similar to that predicted for the first load increment of a growing volcano (Figures 9d, 11a). The maximum deviatoric stresses for this case (Figure 18) resemble those for the incrementally loaded case (Figure 10d) except for the concentration of stresses at the top of the edifice. In this respect the model behaves like an analytic plate flexure model, in which deviatoric stresses are a maximum at the top and bottom of the plate, with a minimum at mid-plate. The volcano serves effectively to stiffen the plate near $r=0$, thus elevating the mid-plane from $z=-20 \mathrm{~km}$ (for a 40-km-thick plate) to $z=-8$ (for a plate effectively $65 \mathrm{~km}$ thick at $r=0$ ). 


\section{Models with Detached Loads}

The evolution of stress orientations for an incrementally grown volcano detached from the lithosphere is shown in Figure 19. Immediately after loading, stresses in almost the entire edifice are oriented with maximum compression vertical and maximum extension out of the plane (Figure . 19a). This geometry may be compared with that in Figure 9a, where both the maximum and minimum principal stresses are in the $r-z$ plane in the upper flanks of the volcano, and the maximum compressional direction has rotated toward the horizontal. In Figure 19a the onset of faulting is predicted in two areas; at the plate surface just outside the volcano (as observed in most of the other models) and near the base of the volcano near $r=0$. Radial normal faulting is predicted for this second region; the entire lower part of the volcano (near the detachment) exhibits horizontal extensional stress and vertical compressive stress, in contrast to the environment of generally horizontal compression in the models with welded volcanoes. This environment persists as the calculation proceeds (Figure $19 \mathrm{~b}-\mathrm{c}$ ). In Figure 19b, after 1000 Maxwell times, the area of radial normal faulting reaches outward through the edifice, above the detachment, to the surface at the volcano edge. Also note that stresses near the summit of the volcano have rotated to a state of horizontal compression. By the time the flexural response is complete (Figure 19c, 3000 Maxwell times), an annulus (with inner radius $170 \mathrm{~km}$ and outer radius $200 \mathrm{~km}$ ) of radial normal faulting has formed on the lower flanks. Elsewhere, the stress state depicted in Figure $19 \mathrm{c}$ is similar to the final result of the welded case (Figure 9g), except that the area of predicted faulting outside the volcano is deeper, and the faulted area beneath the volcano does not extend as far vertically. These effects may be related to local stiffening of the plate by the welded volcano, which would raise the midplane of the plate.

A plot of maximum deviatoric stress for this case (Figure 20) shows how the distribution of stresses is changed by the detachment. After first load increment, deviatoric stresses in the volcano tend to increase from top to bottom, the reverse of the pattern for the welded volcano (Figure 10b). A region of high deviatoric stress forms beneath the detachment (with approximately the same magnitude as the high stress region at the top of the edifice in Figure 10b). Figure 20b shows 
stresses after completion of loading; stresses in the edifice are greatest at the bottom, directly above the detachment. The upper parts of the edifice have low levels of stress, except for a small area of slightly elevated stresses near the summit. The stress maximum beneath the detachment has grown in magnitude and area.

In order to address the role of the initial stress state of the lithosphere in determining the timedependent evolution of stresses and displacements, we consider a lithosphere with an isotropic prestress equal to the overburden pressure. For a model otherwise similar to that of Figure 9, the first faulting in the region outside the volcano (Figure 21a) is predicted to occur by strike-slip, in contrast to the prediction of circumferential normal faulting for the model of Figure 9. Notice that the onset of faulting in this region occurs at a later time, and the onset of faulting in the region below the volcano is delayed until about $400 \tau_{M}$ (compared with $20 \tau_{M}$ for the model in Figure 9). These delays are to be expected, since deviatoric stresses must build up from zero, as opposed to cases which start with a sizeable deviatoric stress. The extent of faulting at the final time step (Figure 21c) is similar (to $470 \mathrm{~km}$ radius, Table 3), and so is the predicted geometry of faulting in the region beneath the volcano (radial normal). In the early stages of flexure, however, strike-slip faulting is predicted for a greater proportion of the near-surface region than for the model of Figure 9 (Table 3). After the flexure following the final load increment the proportional area of predicted strike-slip to circumferential normal faulting at the surface is still about $10 \%$ greater than that of the model of Figure 9 (Table 3). Thus we conclude that the initial stress state of the lithosphere prior to volcanism can affect the distribution of near-surface faulting surrounding the volcano. Maximum deviatoric stresses (Figure 23) far from $r=0$ are small, as might be expected in a plate which starts out with isotropic prestress. However, the stresses near the base of the plate beneath the volcano and in the volcanic edifice are qualitatively similar to those for cases with Poisson prestress.

\section{DISCUSSION: IMPLICATIONS FOR VOLCANO EVOLUTION}

The time-dependent displacement and stress fields calculated in our models can be used to predict the type and orientation of tectonic features that would result from loading of the lithosphere 
by a volcanic edifice. We may compare these predictions to observed tectonic features on and around the Tharsis volcanoes. The evolution of tectonic deformation is also constrained by the model results, an advantage of the finite element method over analytical flexure and other lithospheric loading models which consider an instantaneously emplaced load. We may then evaluate the validity of each model and the applicability of terrestrial analogues for some tectonic and volcanic features.

Flank Tectonics: Circumferential Graben and Predicted Strike-Slip Faulting

As noted earlier, circumferential graben are observed on the lower flanks and the surrounding plains for all three of the Tharsis Montes (Figures 2-5). Formation of these circumferential graben requires an environment of radial horizontal extension at the top of the crust surrounding the volcano and in the near-surface region of the volcano flank. Almost every model predicts circumferential normal faulting in an annulus around the volcano. Models in which the volcano is welded to the underlying plate give near-surface horizontal compression in the edifice after lithospheric flexure, while models which include a detachment between volcano and plate show horizontal extension in the lower volcano flanks. At the base of the detached volcano, the hoop stress $\sigma_{\theta \theta}$ is extensional, and the radial normal stress $\sigma_{\pi}$ is compressional but small compared with the vertical normal stress $\sigma_{\mathrm{zz}}$. In order for circumferential extensional features to form, $\sigma_{\pi \mathrm{r}}$ should be the least compressive stress. However, since the magnitudes of $\sigma_{\pi}$ and $\sigma_{\theta \theta}$ are small in this region, a small perturbation due to local or regional nonaxisymmetric stresses may determine the orientation of failure features [Nakamura, 1977]. The Tharsis Montes are located slightly below the crest of the Tharsis Rise, on a broad slope to the northwest [U. S. Geological Survey 1989]. This long-wavelength slope of Tharsis, in the presence of a detachment, would be expected to add a northwest-southeast extensional stress; superposition with the axisymmetric model stress field would result in radial extensional features in the northeastern and southwestern quadrants (and, at sufficiently high strains, a NE-SW trending rift), and circumferential graben on the northwestern and southeastern flanks. 
On Arsia Mons, graben are prominent on the half of the volcano centered on the northwestern azimuth (all the way up the flank to the caldera rim, Figures 2,5 ), but are generally absent on the upper southeastern-centered half. Several graben appear at the southeastern edge of the edifice, however. These graben are likely to be related to extensional stresses at the surface of the lithosphere surrounding the volcano, as described above, and thus not related to stresses in the edifice per se. The graben on the northwestern half terminate near the northeast-southwesttrending rift that bisects the volcano. We suggest that a portion of the northwestern half of the volcano was able to slide down the slope of the Tharsis rise, creating a stress state that led to the formation of the numerous graben. In the southeastern half, however, buttressed by the rising slope in that direction and thus unable to move, the stress state remained stable (horizontal compression at the surface, as in Figure 9f). This scenario would account for the dramatic difference in faulting character on the two "halves" of the volcano. Of course, stresses resulting from caldera formation and magma chamber formation may have had a strong effect on the stress field near the summit as well [Zuber and Mouginis-Mark 1992].

We can apply the above arguments to the remaining Tharsis Montes. Graben on the flanks of Pavonis Mons are in general narrower than those on the northwestern flank of Arsia Mons, but more widely distributed in azimuth relative to Arsia Mons [Zimbleman and Edgett, 1991]. The widest graben are on the west and northwest flanks, analogous to the situation on the flanks of Arsia Mons. The graben on the north, northeast, and east flanks of Pavonis Mons, however, indicate that the stress state in the edifice is too complex to be described solely by the above scenario for Arsia Mons. Ascraeus Mons shows the least amount of normal faulting on its flanks; the few concentrations of graben lie on the lower slopes, far from the summit caldera. Thus Ascraeus Mons shows the least evidence of tectonic modification due to the effects of a detachment. Perhaps the detachment is smaller in extent there because of inherent differences in crustal properties, or because it has had less time to develop. The latter scenario is consistent with the conclusion of Crumpler and Aubele [1978] that Ascraeus Mons is at an earlier stage in its development than the other two volcanoes. 
Stresses from both analytic flexure models and our models with instantaneous volcano loads predict strike-slip faulting at the surface of the plate, immediately outside the load Evidence for strike-slip faulting around any of the Tharsis volcanoes, however, is lacking. The absence of such features has been discussed by Golombek [1985] and Schultz and Zuber [1992], in the general context of large axisymmetric loads on planetary lithospheres. Examination of the plots of stress orientation and failure from our models (Figures 11, 13,15) however, reveals that the predicted failure modes for elements in the region surrounding the volcano can change with time. In this region, every element that eventually fails (except the innermost) is predicted to do so first by concentric normal faulting. This can be seen more clearly in a Mohr diagram of the stresses in a typical element in this area (Figure 22). The Mohr circles grow in size as flexure proceeds, until . the failure envelope is exceeded at about $70 \tau_{\mathrm{M}}$ after first loading. The largest circle shows stresses at the conclusion of flexure. This stress state corresponds to that given by analytic plate models (in which flexure occurs instantaneously). Applying a failure criterion simply to the final stress state can be misleading. Consideration of the stress history in our models indicates that at the time of first failure, the shear failure criterion is satisfied in the surface elements immediately outside the volcano, and the principal stress directions predict circumferential normal faulting. These firstformed faults would tend to relieve extensional stresses in their vicinity and would serve as preferred planes of weakness for the relief of stresses accumulated later. Strike-slip features would thus tend to be prevented from forming. We also note that for the lower range of values of lithosphere thickness considered here $(20-40 \mathrm{~km})$, the zone of strike-slip faulting predicted from the late-stage stress models lies at the edge of the volcanic construct, which has the lowest surface elevation (Figure 7). This topographic low could accumulate lava flows and erosional deposits which would tend to cover deformational features (circumferential graben as well as strike-slip features).

\section{Horizontal Compression in the Edifice}

Circumferential terraces high on the flanks of Olympus have been interpreted as concentric thrust faults by Thomas et al. [1990], who applied elastic finite element models to investigate 
edifice stresses and deformation. Our simplest model (a welded, instantaneously emplaced volcano) predicts a similar stress state, with circumferential thrust faulting on the upper flank and radial thrusts on the lower flank (Figure 17). Plate flexure models also predict large horizontal compressive stresses in the area of the load, which increase with height above the mid-plane of the plate, reaching a maximum at the surface, where thrust faulting is predicted. Models with growing loads, however, display a different distribution of stress. The maximum horizontal stress occurs in the lowest (first) load increment and decreases upward with each later load increment (Figures 914). Each successive load increment "feels" tectonic stresses from itself and all later load increments. The last units emplaced are sensitive only to the effects of their own loading and therefore exhibit a low degree of horizontal compression. Thus, thrust faults (predicted by simpler models) associated with such stresses would be expected to occur either early in the evolution of the volcano or not at all and, if formed, would be covered by later units which remain unfaulted because the failure criterion is not satisfied (Figures 9, 11). We note, however, that stresses in these elements are close to failure. Local stress perturbations and/or variations in internal friction $\phi$ could result in some failure visible at the surface. On the other hand, if loading increments are smaller than those adopted here (which is likely), then the degree of horizontal compression from such elements would be smaller than those shown here, and faulting would not be expected.

The presence of graben high on the flanks of the Tharsis Montes is not consistent with the state of horizontal compression in the edifice found in the welded volcano models. Other factors, such as a basal detachment, lithospheric rifting, or caldera stresses must be invoked to explain the presence of these faults on the upper flanks.

\section{Magma Transport}

The volcanic edifice stress fields calculated here have important implications for magma transport and eruption. Magma propagates through the lithosphere along fractures that form perpendicular to the direction of least compressive stress. Immediately following emplacement, the stresses in a given load increment are characterized by $\sigma_{3}$ horizontal (e.g., Figure 9a). Thus show that magma can propagate vertically to the summit region. As a result of flexure, however, the 
principal stress directions in that load increment rotate such that $\sigma_{1}$ is horizontal and $\sigma_{3}$ is vertical. Magma propagation should tend to be horizontal in such a layer, leading outward from the summit to the flanks. Stresses in earlier load increments remain in horizontal compression as volcano growth proceeds. This behavior results in a maximum in horizontal stress near the core of the volcano, with lessening horizontal compression at higher (later) load increments. This stress pattern contrasts with that from analytic flexure calculations, where stresses increase linearly with distance from the plate midplane. Thus an implication of the models treated here is that within an interval of shield building there should be an evolution in favored eruption location from summit to lower flank. Such an evolution is consistent with the first two stages in the sequence of major events for the Tharsis Montes determined by Crumpler and Aubele [1978].

The stress evolution of a growing volcano may affect the location of magma collection zones or chambers. The maximum horizontal compression is achieved within the earliest load increments, near the bottom of the load. Such a region of high compressive stress at lower levels in the edifice could inhibit ascending magma from reaching the summit, and could thus lead to the pooling of magma. Since magma will propagate perpendicular to the direction of least compressive stress, radial propagation of magma in sheet dikes or sills might also occur. On the other hand, high stresses in this region will be relieved by faulting, until the failure criterion is no longer satisfied. This region may thus be the most pervasively faulted and fractured zone, and thus perhaps a favored location for magma to collect.

The issue of compressional versus extensional horizontal stresses in the volcanic edifice is critically important when considering volcano growth. In order for the volcano to grow, there must be a path for magma to reach the surface (or near the surface in the case of growth by intrusion). Large horizontal compressive stresses within the edifice may cut off summit eruptions unless there is sufficient magma overpressure. Thus, the route from a central magma chamber to the summit may be cut off, and flank eruptions would be favored, as noted above. After sufficient flank eruption, however, loading on the flanks might then lead to relief of compressive stresses near the summit, re-opening the path to the summit caldera. When the effects of time-dependent 
loading during volcano growth are included, the magnitude of horizontal stresses in the later stages of evolution are greatly reduced compared with stresses at the equivalert level in instantaneously loaded models. When both time-dependent loading and a basal detachment are included, horizontal compressive stresses in the edifice are reduced further, and a state of extensional hoop stress is reached in the lower part of the edifice, adjacent to the detachment (Figure 19). Summit eruptions are then more easily accommodated. The stress state in the lower edifice resembles that determined seismically for western Hawaii by Gillard et al. [1992], with $\sigma_{1}$ vertical (or nearly so), and both $\sigma_{2}$ and $\sigma_{3}$ horizontal and similar in magnitude. The model stress state also resembles that of a tectonic model for the base of Hawaii proposed in Figure 3 of Wyss and Koyanagi [1992] (based in part on the results of Gillard et al. [1992]). The model of Wyss and Koyanagi [1992] has $\sigma_{3}$ parallel to the direction of slip along the basal detachment, whereas our model has $\sigma_{3}$ perpendicular to the basal slip. However, since $\sigma_{2}$ and $\sigma_{3}$ are similar in magnitude [Gillard et al. 1992], local perturbations and departures from axisymmetry may determine the orientations of these stresses in actual volcanoes.

Flank Tectonics: Aureoles, Lobes and Scarps

Results of our models also help us to understand the flank tectonics of the Tharsis volcanoes, in particular the large downslope motions of material in the form of large slides or slumps. As noted above, the Olympus Mons aureole has been interpreted as a large landslide deposit resulting from slip along large-offset listric normal faults [Francis and Wadge, 1983], the upper reaches of which are postulated to coincide with the basal scarp. Aureole material is most prominent to the north and west; there is an aureole lobe to the southeast, however, suggesting that the Tharsis rise did not fully buttress the southeastern flank of Olympus. Evidence for similar mass movement activity on a smaller scale is seen on the northwestern flanks of Ascraeus and Arsia Montes [Zimbleman and Edgett, 1991].

As discussed above, the interaction between the axisymmetric stress field from the volcano loading and regional stresses due to topography may influence the location, orientation and extent of scarps and of landslides triggered by fault slip on the Tharsis volcanoes. The Olympus Mons 
aureole deposits are of greatest extent to the north and west, but also there is a significant aureole lobe to the southeast. The basal scarp has greatest relief on the northwestern and southeastern flanks. Models with a detachment predict that at the edge of the edifice $\sigma_{3}=\sigma_{\theta \theta}$ and is extensional. This can account for radial normal faulting but not for the scarps and aureole deposits, which in the above scenario require that $\sigma_{3}=\sigma_{\pi}$. The addition of a regional northwestsoutheast extensional stress, induced by the regional gradient in elevation, however, would provided the necessary orientation of stresses in the northwestern and southeastern quadrants of the volcano, where the aureole and scarp are most prominent. The aureole deposits to the north and west of Olympus Mons could then be a result of large landslides analogous to those off the Hawaiian chain but on a larger scale. The basal scarp would then consist of the coalesced head scarps of these landslides. The lobate features to the northwest of Arsia and Pavonis Montes would then be similar in origin but on a smaller scale, without prominent basal scarp formation. This scenario also explains why the deposits are always more prominent on the northwestern side of these volcanoes, since this is the regional downslope direction. Note that the above scenario postulates a consistent stress field (of NW-SE extension) throughout the evolution of the volcano. This contrasts with the view of Francis and Wadge [1983], who suggest that proto-Olympus Mons was elongate to the northwest due to an early NE-SW extensional regime, which allowed preferential effusion along a NW-SE axis.

Large landslides and slumps, triggered by extension on the flanks, may be a second important mode of volcano growth, in that mass movement clears the way for more volcanic material to be emplaced behind it [Lipman et al., 1985]. The model of Lipman and others emphasizes the role of dike intrusion at the rift zones, with the subvolcano detachment passively taking up the resulting strain. Our results suggest that without such a detachment, the rift zones may not be able to form, due to a predicted environment of horizontal compression. As a welded volcano grows, an ever increasing horizontal compressive stress near the base of the edifice would eventually choke off magma supply to the summit. Thus, the Hawaiian rift zones may owe their existence to the presence of the detachment, and volcanoes lacking such a detachment may exhibit important 
structural and evolutionary differences from Hawaiian volcanoes. For example, Nakamura [1980] has suggested that the lack of rift zones in the Galapagos shields is attributable to a paucity of oceanic sediments on the young ocean floor beneath the volcanoes.

\section{Linear Rift Zones}

Linear symmetries observed in all the Tharsis Montes volcanoes may be indirect evidence for failure in the sub-volcano region. The second stage in the Crumpler and Aubele [1978] sequence of volcano evolution involves the development of a linear rift bisecting the volcanoes, with eruptions emanating from this rift. Radially oriented normal faulting under a volcano might be thought at first to tend to divide the volcano into radial sections, much like pie slices. The existence of the linear rifts on the Tharsis Montes, however, suggests that this mode of failure may be concentrated into one large linear feature that bisects the volcano. This feature may owe its orientation to regional stress fields or to pre-existing zones of weakness. Our calculations predict radially oriented normal faulting in a broad zone beneath a volcano. For the case with $T_{e}=20 \mathrm{~km}$ (Figure 11), this zone extends beyond the volcano radius and reaches quite close to the surface. Such a zone, if concentrated into a linear feature and if continued to the surface by sustained faulting, may give rise to the linear rifts and bilateral symmetry observed on the Tharsis Montes. Stresses due to topography of Tharsis might be expected to add a component of northwestsoutheast extension (the direction of greatest slope). This would concentrate the radial faulting into a rift zone striking northeast-southwest, as is observed on the Tharsis Montes. The rift zones would form orthogonal to the regional topographic gradient, as is observed. A problem with this model is that the rifting has to propagate upward somehow to the surface of the lower volcano flanks. The prediction of radially oriented normal faulting on the lower flanks for the model with a sub-volcanic detachment (Figure 20) suggests another mechanism for forming the observed rifts. This explanation has the advantage that rift formation would occur early, almost immediately after volcano creation, a timing more consistent with the chronology of Crumpler and Aubele [1978]. If the detachment model is applicable to Mars, it may help explain the existence of the rifts. 
The evolution of Pacific hotspot volcanoes may provide some insight into the formation and influence of a bisecting rift zone. For instance, Holcomb [1985] has suggested that the island of Molokai in the Hawaiian chain resembles a volcano cut almost exactly in half, with one part transported downslope in one or more massive submarine slides, and the other part remaining to form the present island. Bathymetry of the ocean floor north of Molokai [Moore, 1964] supports this conclusion. We have earlier conjectured that a similar but less extreme mechanism could explain the presence of graben on the upper slopes of Arsia Mons and Pavonis Mons, in that as the volcano halves slide apart from each other, an extensional environment is created near the summit. To investigate this possibility quantitatively, a fully three dimensional model, or an axisymmetric model with non-axisymmetric loading, is required.

\section{Detachment Tectonics}

The flank tectonic characteristics of the Tharsis volcanoes, combined with the observations of and modeling results for terrestrial volcanoes with detachments, strongly suggests that detachments analogous to those of Hawaii-type volcanoes [Lipman et al., 1985] exist on Mars. Such a detachment cannot arise from the presence of a thick oceanic sediment layer as for Hawaii. It has nonetheless been demonstrated that liquid water existed in moderate quantities at the Martian surface earlier in the history of the planet [e.g., Carr , 1987]. While liquid water is now unstable at the surface, large quantities of water are believed to be buried as ground-ice. Tanaka [1985] proposed that gravity sliding and spreading could account for the Olympus Mons aureole (and basal scarp) providing that a basal detachment zone of material with low shear strength was present. He calculated that a layer of material with about $10 \%$ interstitial or interbedded ice could provide the necessary detachment. The pre-volcanic upper crustal layer may have consisted dominantly of an impact breccia regolith produced by repeated impacts. Such a heavily fractured material is likely to be porous and thus may contain interstitial ice. Even in the absence of an excess ice content, the mechanical weakness of such a layer could contribute to the formation of a detachment between a strong lower crust and a volcanic edifice. Tanaka [1985] states that such a structure is unique to Olympus Mons. However, Zimbleman and Edgett [1991] have mapped 
lobate deposits on the northwestern flanks of all three Tharsis Montes that may be smaller-scale analogues to the Olympus Mons aureoles, so some form of detachment beneath all four constructs appears to be indicated.

\section{Plate Thickness and Volcano Size}

The ratio of elastic plate thickness to volcano diameter is observed to have significant effects on the evolution of the subsidence, stress, and regions of predicted failure in our computations. We note several trends as plate thickness increases relative to volcano diameter. Study of the patterns of stress orientations and predicted failure in Figures 9, 11, and 13, shows that the outer region of failure, at a given time, increases in horizontal (and vertical) extent, and a greater proportion of the inner part of this region is predicted to fail at later stages by strike-slip faulting, with increasing plate thickness (Table 3). The deviatoric stress plots of Figures 10, 12, and 14 show that the average depth and volume of the region of low deviatoric stress beneath the volcano also increase with increasing plate thickness. The magnitude of deviatoric stress within the volcanic edifice, and in particular the magnitude of maximum horizontal compressive stress, decreases with increasing plate thickness. As noted above, a zone of large horizontal compressive stress may affect the propagation of magma from its mantle sources to the volcanic edifice. Elastic plate thickness may thus play a role in determining the location of magma storage areas. For the largest plate thickness considered here, stresses in the edifice never exceed the failure limit (Figure 13).

The relative timing of events in our models is generally consistent with the chronology set forth by Crumpler and Aubele [1978] for the Tharsis Montes. After construction of the main shield, rift formation and flank eruptions along this rift occur in the second stage of evolution. Figure $9 \mathrm{~b}$ shows that, after 10 Maxwell times, the principal model result is the beginning of rotation of the stress axes in the edifice (which is expected to favor flank eruptions). After a few tens of Maxwell times the failure zone beneath the volcano (which could favor formation of the rift) has begun to grow. The third stage involves summit subsidence and formation of concentric fractures and graben. After 100 Maxwell times, our computations show increased subsidence as 
well as the growth of the region of normal faulting outward of the volcano (Figure 9c-g). The fourth stage of Crumpler and Aubele [1978] involves further eruption along the rift, flooding the summit and flanks. Late stage flank eruptions are consistent with the stress fields in our calculations. Summit eruptions, however, would not be favored by the computed stress fields. It is likely that the stress field is influenced by the effects of previous stages of the evolution. Flank eruptions result in an added flank load, not modelled here, to which the lithosphere will respond with additional flexure. Subsidence and additional flexure near the flanks of the volcano may at least partially relieve the compressional stresses near the summit, thus enhancing the possibility of additional summit eruptions. By this scenario, the preferred site for eruptions could alternate between summit and flank, on time scales on the order of $100-1000 \tau_{M}$. Also, the effect of sections of the volcano sliding away from the bisecting rift may result in an extensional environment near the summit, once again favoring summit eruptions.

\section{Future Directions}

Because of the limitations of these calculations in accurately modeling the behavior of large volcanoes, we hope to be able to relax some of these limitations in future models. In our models, assume that the crust and mantle are perfectly viscoelastic; within an element, no provision is made for stresses that exceed reasonable failure limits (such as in all the shaded elements in Figures 9, 11 , and 13). The inclusion of localized yielding in a volcano model can be presumed to have important effects on the geometry and magnitudes of the calculated stress and deformation fields. A finite element code that incorporates plastic yielding will allow us to account more realistically for the effects that failure will have on predicted fault locations and styles. Further, the effect of thermal stresses has been ignored. Thermal stresses can play an important role in the evolution of the volcano, both through stresses accumulated by cooling after emplacement of each layer, and through the time-dependent thermal stresses in regions reheated by the later passage or storage of magma. 


\section{CONCLUSIONS}

In this paper we have used finite element calculations to simulate the deformational and stress response of the lithosphere to a volcano load. The results of these calculations are compared with observed tectonic features and inferred eruption characteristics of large Martian volcanoes. Some of the zones of failure and faulting predicted in our models have direct analogues in observed features; others may be indirectly related to observed structures. Three regions of failure with characteristic stress regimes are identified in our calculations. Flexural stresses in the lithosphere immediately surrounding the volcano can result in circumferential graben. Flexurally induced failure in a wide zone beneath the center of a large volcano may play a major role in the development and modification of the edifice. Given that magma ascending through the lithosphere propagates along fractures oriented perpendicular to the direction of least compressive stress, a rotation in the principal stress orientations during lithospheric flexure in the models tends to favor eruption sites shifting from the volcano summit to the flanks as flexure proceeds. We conclude that time-dependent lithospheric flexure is important in determining the location and style of faulting within and surrounding large volcanoes as well as regulating the timing and location of volcanic eruptions.

Horizontal compressive stresses caused by flexure and subsidence may lead to thrust faulting on the flanks of large volcanoes. Incremental volcano growth, however, results in a less extreme environment of horizontal compression on the upper flanks at late stages of development. Late load increments on the flanks are not stressed from earlier flexure, and horizontal stresses are no longer great enough to cause flank thrusting. The most highly stressed area of the edifice is near the top of the earliest load increment. Inclusion of a detachment between volcano and lithosphere results in an environment of horizontal extension in the part of the volcano that overthrusts the lithosphere. Without effects such as these, which reduce the extreme magnitude of horizontal compression in our model volcanoes, it would be very difficult for a volcano to continue growth via summit eruptions. 
A mass movement origin has been suggested for the vast aureole deposits surrounding Olympus Mons [Harris, 1977; Lopes et al., 1980; Francis and Wadge, 1983] as well as smaller lobate deposits to the northwest of each of the Tharsis Montes [Zimbleman and Edgett, 1991]. Analogy with large slumps and slides off of the Hawaiian islands [Moore et al., 1989; Lipman et al., 1985] suggests that a detachment between volcano and lithosphere may play a role in the evolution of volcanoes on Mars as well as Earth. Models that include such a detachment, in contrast with models with welded volcanoes, predict a state of horizontal extension in the edifice (and eventually radial normal faulting on the lower flanks). When the effects of non-axisymmetric stresses due to regional topography are considered, predicted patterns of faulting match well observed structures on the Tharsis Montes. 
34

Acknowledgments. We thank Jay Melos for generously providing us a copy of the TECTON code and for instructing us in its use, Rob Comer for his thick-plate flexure code, and Andrea Borgia, Steve Squyres, and Jim Zimbleman for preprints of their papers prior to publication. Bob Grimm, Buck James, and Ken Tanka offered helpful comments on an earlier draft. This work benefited greatly from discussions with Brad Hagen and Marcia McNutt. P.J.M. would like to thank the convenors of the NASA Field Volcanology Workshop of July 1992 for the opportunity to study an active volcano. This research was supported by the NASA Planetary Geology and Geophysics Program under grants NAGW-1077, NAGW-1937, and NAGW-3276. 


\section{REFERENCES}

Albee, A. L., R. E. Arvidson, and F. D. Palluconi, Mars Observer mission, J. Geophys. Res., 97, 7665-7680, 1992.

Anderson, E. M., The Dynamics of Faulting and Dyke Formation with Applications to Britain, 2nd ed., Oliver and Boyd, Edinburgh, 206 pp., 1951.

Blasius, K. R., and J. A. Cutts, Shield volcanism and lithospheric structure beneath the Tharsis Plateau, Mars, Proc. Lunar Planet. Sci. Conf. 7th, 3561-3573, 1976.

Blasius, K. R., and J. A. Cutts, Topography of Martian central volcanoes, Icarus, 45, 87-112, 1981.

Borgia, A., J. Burr, W. Montero, G. E. Alvarado, L. D. Morales, and G. E. Alvarado, Faultpropagation folds induced by gravitational failure and slumping of the Central Costa Rica volcanic range: Implications for large terrestrial and Martian volcanic edifices, J. Geophys. Res., 95, 14357-14382, 1990.

Chevallier, L., and W. J. Verwoerd, A numerical model for the mechanical behavior of intraplate volcanoes, J. Geophys. Res., 93, 4182-4198, 1988.

Comer, R. P., Thick plate flexure, Geophys. J. R. Astron. Soc., 72, 101-113, 1983.

Comer, R. P., S. C. Solomon, and J. W. Head, Mars: Thickness of the lithosphere from the tectonic response to volcanic loads, Rev. Geophys., 23, 61-92, 1985.

Crumpler, L. S., and J. C. Aubele, Structural evolution of Arsia Mons, Pavonis Mons, and Ascraeus Mons: Tharsis region of Mars, Icarus, 34, 496-511, 1978.

Dieterich J. H., Growth and persistence of Hawaiian volcanic rift zones, J. Geophys. Res., 93, 4258-4270, 1988.

Eliason, E., R. Batson, and A. Manley, Mars Mosiacked Image Model (MDIM) and Digital Terrain Model (DTM), U. S. Geol. Surv., Flagstaff, Az., 1991.

Francis, P. W., and G. Wadge, The Olympus Mons aureole: Formation by gravitational spreading, J. Geophys. Res., 88, 8333-8344, 1983. 
Gillard, D., M. Wyss, and J. S. Nakata, A seismotectonic model for western Hawaii based on stress tensor inversion from fault plane solutions, J. Geophys. Res., 97, 6629-6641, 1992.

Golombek, M. P., Fault type predictions from stress distribution of planetary surfaces: Importance of fault initiation depth, J. Geophys. Res., 90, 3065-3074, 1985.

Greeley, R., and P.D. Spudis, Volcanism on Mars, Rev. Geophys. Space Phys., 19, 13-41, 1981.

Handin, J., Strength and ductility, in Handbook of Physical Constants, edited by S.P. Clark, Jr., Memoir 97, Geol. Soc. Amer., Boulder, Colo., pp. 223-289, 1966.

Harris, S. A., The aureole of Olympus Mons, Mars, J. Geophys. Res., 82, 3099-3107, 1977.

Holcomb, R. T., The caldera of East Molokai volcano, Hawaiian Islands, in National Geographic Society Research Reports (for 1980-1983), 21, 81-87, 1985.

Lipman, P. W., J. P. Lockwood, R. T. Okamura, D. A. Swanson, and K. M. Yamashita, Ground deformation associated with the 1975 magnitude-7.2 earthquake and resulting changes in activity of Kilauea volcano, Hawaii, U. S. Geol. Survey Prof. Paper 1276, 45 pp., 1985.

Lopes, R. M. C., J. E. Guest, and C. J. Wilson, Origin of the Olympus Mons aureole and perimeter scarp, Moon Planets, 22, 221-234, 1980.

McGarr A., On the state of lithospheric stress in the absence of applied tectonic forces, $J$. Geophys. Res., 93, 13,609-13,617, 1988.

McNutt, M. K., Lithospheric flexure and thermal anomalies, J. Geophys. Res., 89, 11,18011,194, 1984.

Melosh, H. J., and A. Rafesky, The dynamical origin of subduction zone topography, Geophys. J. R. Astron. Soc., 60, 333-354, 1980.

Melosh, H. J., and A. Rafesky, Anelastic response of the Earth to a dip slip earthquake, J. Geophys. Res., 88, 515-526, 1983.

Melosh, H. J., and C. A. Williams, Jr., Mechanics of graben formation in crustal rocks: A finite element analysis, J. Geophys. Res., 94, 13,961-13,973, 1989. 
Moore, J. G., Giant submarine landslides on the Hawaiian Ridge, U. S. Geol. Survey Prof. Paper 501-D, pp. D95-D98, 1964.

Moore, J. G., D. A. Clague, R. T. Holcomb, P. W. Lipman, W. R. Normark, and M. E. Torresan, Prodigious submarine landslides on the Hawaiian ridge, J. Geophys. Res., 94 , $17,465-17,484,1989$.

Morris, E. C., The basal scarp of Olympus Mons (abstract), Reports of the Planetary Geology Program-1988, NASA TM 84211, 389-390, 1981.

Nakamura, K., Volcanoes as possible indicators of tectonic stress orientation - principle and proposal, J. Volcanol. Geotherm. Res., 2, 1-16, 1977.

Nakamura, K., Why do long rift zones develop in Hawaiian volcanoes - a possible role of thick oceanic sediments, Bull. Volcanol. Soc. Japan, 25, 255-269, 1980.

Peterson, D. W., and R. B. Moore, Geologic history and evolution of geologic concepts, island of Hawaii, U. S. Geol. Survey Prof. Paper 1350, 149-189, 1987.

Ryan M.P., The mechanics and three-dimensional internal structure of active magmatic systems: Kilauea volcano, Hawaii, J. Geophys. Res., 93, 4213-4248, 1988.

Schultz, R. A., and M. T. Zuber, Why are strike-slip faults that are "predicted" by lithospheric deformation models rarely observed on planetary surfaces?, Lunar Planet. Sci. , 23, 12471248, Lunar and Planetary Institute, Houston, 1992.

Scott, D. H., and K. L. Tanaka, Map showing lava flows in the northeast part of the Phoenicis Lacus quadrangle of Mars, Map I-1277, U. S. Geol. Surv., Reston, Va., 1981.

Scott, D. H., G. G. Schaber, K. C. Horstmann, A. L. Dial Jr., and K. L. Tanaka, Map showing lava flows in the southwest part of the Tharsis quadrangle of Mars, Map I-1268, U.S. Geol. Surv., Reston, Va., 1981 a.

Scott, D. H., G. G. Schaber, and K. L. Tanaka, Map showing lava flows in the southeast part of the Tharsis quadrangle of Mars, Map I-1269, U. S. Geol. Surv., Reston, Va., 1981 b. 
Scott D. H., G. G. Schaber, K. C. Horstmann, A. L. Dial Jr., and K. L. Tanaka, Map showing lava flows in the northwest part of the Phoenicis Lacus quadrangle of Mars, Map I-1272, U. S. Geol. Surv., Reston, Va, 1981c.

Solomon, S. C., and J. W. Head, Heterogeneities in the thickness of the elastic lithosphere of Mars: Constraints on heat flow and internal dynamics, J. Geophys. Res., 95, 11,073-11,083, 1990.

ten Brink, U. S., and T. M. Brocher, Multichannel seismic evidence for a subcrustal intrusive complex under Oahu and a model for Hawaiian volcanism, J. Geophys. Res., 92, 13,68713,707, 1987.

Tanaka, K. L., Ice-lubricated gravity spreading of the Olympus Mons aureole deposits, Icarus, 62, 191-206, 1985.

Tanaka, K. L., The stratigraphy of Mars, Proc. Lunar Planet. Sci. Conf. 17th, J. Geophys. Res., 91, E139-E158, 1986.

Thomas, P. J., S. W. Squyres, and M. H. Carr, Flank tectonics of Martian volcanoes, J. Geophys. Res., 95, 14,345-14,355, 1990.

Thurber, C. H., and A. E. Gripp, Flexure and seismicity beneath the south flank of Kilauea volcano and tectonic implications, J. Geophys. Res., 93, 4271-4278, 1988.

Turcotte, D. L., and G. Schubert, Geodynamics, Wiley, New York. 450 pp, 1982.

U. S. Geological Survey, Topographic maps of the western, eastern equatorial and polar regions of Mars, Map I-2030, U. S. Geol. Surv., Washington, D.C., 1989.

Wu, S. S. C., Mars synthetic topographic mapping, Icarus, 33, 417-440, 1978.

Wu, S. S. C., P. A. Garcia, R. Jordan, F. J. Schafer, and B. A. Skiff, Topography of the shield volcano, Olympus Mons on Mars, Nature, 309, 432-435, 1984.

Wyss, M. and R. Y. Koyanagi, Seismic gaps in Hawaii, Bull. Seismol. Soc. Am., 82, 13731387, 1992.

Zimbleman, J. R., and K. S. Edgett, The Tharsis Montes, Mars: Comparison of volcanic and modified landforms, Proc. Lunar Planet. Sci., 22, 31-44, 1992. 
Zuber, M. T., and P. J. Mouginis-Mark, Caldera subsidence and magma chamber depth of the Olympus Mons volcano, Mars, J. Geophys. Res., 97, 18,295-18,307, 1992.

P.J. McGovern, Building 54-521, Department of Earth, Atmospheric, and Planetary Sciences, Massachusetts Institute of Technology, Cambridge MA 02139.

S. C. Solomon, Department of Terrestrial Magnetism, Carnegie Institution of Washington, 5241 Broad Branch Road, N. W., Washington, DC 20015. 


\section{FIGURE CAPTIONS}

Figure 1. Viking Orbiter view of Olympus Mons. The multiple-pit caldera and basal scarp (at bottom) are the main tectonic features visible. No graben are seen on the flanks of the volcano or on the volcanic plains immediately surrounding the structure. Frame VO641A52; width of image is $440 \mathrm{~km}$.

Figure 2. (a) Viking Orbiter view of western Ascraeus Mons. The complex caldera is seen at the summit, and graben with a predominantly circumferential orientation are seen along the western and southwestern margins. Graben are located on Ascraeus Mons itself and in surrounding flows (unit as, Figure 3); some graben grade into collapse pits or sinuous channels formed by magma withdrawal and downslope flow. Frame VO643A78; width of image is $420 \mathrm{~km}$. (b) Viking Orbiter mosaic of the western flank of Arsia Mons [Eliason et al. 1991]. Note that graben extend all the way up the flank to the edge of the summit caldera. (c) Viking Orbiter mosaic of the eastem flank of Arsia Mons [Eliason et al. 1991]. Note the lack of graben and the radial texture of flows on the upper flank. Graben are evident near the boundary between the edifice and the surrounding plain.

Figure 3. Geologic map of Ascraeus Mons and surroundings, simplified from Scott et al. [1981b] by Comer et al. [1985]. Volcanic units shown include relatively young Ascraeus Mons flows (as), intermediate-age Tharsis Montes flows (tm), and volcanic material undivided by age (vu). Also shown as a distinct unit is slide material (s), interpreted by Scott and coworkers as landslides and debris flows. Dashed lines show approximate elevation contours, in kilometers, relative to a fourth-degree, fourth-order equipotential $[W u, 1978]$. The summit caldera complex is indicated by inward hatched lines. Extensional faults and graben are shown as heavy lines.

Figure 4. Geologic map of Pavonis Mons and surroundings, simplified from Scott et al. [1981a, b, c] and Scott and Tanaka [1981] by Comer et al. [1985]. Units shown, in addition to those described in Figure 3, are relatively young volcanic flows from Pavonis Mons (pm) and Arsia Mons (am). Other information follows the format of Figure 3. Circumferential graben reach 
quite far up the slopes, and an approximate bilateral symmetry can be seen about an axis trending approximately NNE-SSW.

Figure 5. Geologic map of Arsia Mons and surroundings, simplified form Scott et al. [1981c] by Comer et al. [1985]. See Figures 3 and 4 for further explanation of symbols. Circumferential graben extend almost up to the summit caldera complex.

Figure 6. (a) The finite element grid used for the calculations shown in later figures. The volcano is the small triangular area in the upper left-hand comer. (b) Plot of element types for models with incremental volcano loading, implemented by means of time-dependent element properties. Elements marked with a " 3 " are "on" from the start of the calculation; those with a "4" are switched "on" after 1000 Maxwell times, and those with a "5" are switched "on" after 2000 Maxwell times.

Figure 7. Comparisons of the TECTON solution and analytic thick-plate flexure [Comer, 1983] for vertical displacements resulting from an axisymmetric load simulating a conical volcano. For both cases, $T_{e}=t_{c}=40 \mathrm{~km}$. (a) surface elevation relative to that at $r=r_{\max }$ after essentially complete viscoelastic relaxation in the asthenosphere; (b) difference between the two solutions.

Figure 8. Key for stress symbols in models. These symbols denote the principal stress directions under axisymmetry. The hourglass shapes are oriented along the direction of greatest compressive stress, the bars along the direction of least compressive stress. Magma is expected to ascend locally along the plane orthogonal to the least compressive stress, that is, perpendicular to the bar.

Figure 9. Principal stress orientations and predicted failure in the vicinity of an incrementally grown volcano load on a $40-\mathrm{km}$-thick elastic lithosphere. See Figure 8 for the meaning of the stress orientation symbols. Elements in which stresses satisfy the Mohr-Coulomb failure criterion are shaded. Given the orientation of the stress symbol in a shaded element, the style and orientation of faulting can be inferred. (a) The elastic solution. (b-d) 20,100, and 1000 Maxwell times after the first load increment is added; (e-f) 20 and 1000 Maxwell times after the 
second load increment is added; and (g) 1000 Maxwell times after the third load increment is added.

Figure 10. Contours of maximum deviatoric stress in the vicinity of the volcano, for the model of Figure 9. Contour interval is $50 \mathrm{MPa}$. (a) The elastic solution. (b-d) 1000 Maxwell times after the first, second, and third load increments are added, respectively.

Figure 11. Principal stress orientations and predicted failure for an incrementally grown volcano load on a lithosphere with $T_{e}=20 \mathrm{~km}$. (a) 1000 Maxwell times after the first load increment is added; (b) 1000 Maxwell times after the third load increment is added.

Figure 12. Contours of maximum deviatoric stress for the model of Figure 11. (a) 1000 Maxwell times after the first load increment is added; (b) 1000 Maxwell times after the third load increment is added.

Figure 13. Principal stress orientations and predicted failure for an incrementally grown volcano load on a lithosphere with $T_{e}=60 \mathrm{~km}, 1000$ Maxwell times after the third load increment is added.

Figure 14. Contours of maximum deviatoric stress for the model of Figure 13, 1000 Maxwell times after the third load increment is added.

Figure 15. Principal stress orientations and predicted failure for an incrementally grown volcano load on a crust $40 \mathrm{~km}$ thick and on an elastic lithosphere $60 \mathrm{~km}$ thick, 1000 Maxwell times after the third load increment is added.

Figure 16. Contours of maximum deviatoric stress for the model of Figure 15, 1000 Maxwell times after the third load increment is added.

Figure 17. Principal stress orientations and predicted failure for an instantaneous volcano load on a lithosphere with $T_{e}=40 \mathrm{~km}$, after 1000 Maxwell times.

Figure 18. Contours of maximum deviatoric stress for the model of Figure 17, after 1000 Maxwell times.

Figure 19. Principal stress orientations and predicted failure for a model with a growing volcano load, a basal detachment between lithosphere and volcano, and crust and elastic lithosphere 40 
$\mathrm{km}$ thick. (a-b) 10 and 1000 Maxwell times after the first load increment is added; (c) 1000 Maxwell times after the third load increment is added.

Figure 20. Contours of maximum deviatoric stress for the model of Figure 19. (a) 1000 Maxwell times after the first load increment is added; (b) 1000 Maxwell times after the third load increment is added.

Figure 21. Principal stress orientations and predicted failure for a growing volcano load with isotropic prestress in the lithosphere. Crust and elastic lithosphere are $40 \mathrm{~km}$ thick. (a-b) 40 and 1000 Maxwell times after the first load increment is added; (c) 1000 Maxwell times after the third load increment is added.

Figure 22. Mohr diagrams for typical elements in regions of predicted failure. Diagonal line is the Mohr-Coulomb failure envelope for basalt [Handin, 1966] with an angle of internal friction $\phi=$ $49^{\circ}$ and cohesion $c=38 \mathrm{MPa}$. (a) Mohr diagram for an element at the top of the lithosphere (stresses calculated at element center: $r=265 \mathrm{~km}, z=-2.5 \mathrm{~km}$ ). In order of increasing radius, the circles represent the stress state at $t=0$ (elastic solution), 20,100,1000,2000, and 3000 $\tau_{M}$. When the failure envelope is first exceeded $\left(t=70 \tau_{\mathrm{m}}\right), \sigma_{3}=\sigma_{\pi}$ and $\sigma_{1}=\sigma_{z z}$. At the final time shown, $\sigma_{3}=\sigma_{n}$ and $\sigma_{1}=\sigma_{\theta \theta}$. See Figure 9 for the principal stresses used to calculate circles. 
TABLE 1. Dimensions of Tharsis Volcanoes

$$
\text { Diameter, Relief, }
$$

Volcano

$\mathrm{km}$

$\mathrm{km}$

\begin{tabular}{lll} 
Olympus Mons & $600^{\mathrm{a}}$ & $24^{\mathrm{a}}$ \\
Ascraeus Mons & $400^{\mathrm{b}}$ & $18^{\mathrm{b}}$ \\
Pavonis Mons & $320^{\mathrm{b}}$ & $14^{\mathrm{b}}$ \\
\hline Arsia Mons & $420^{\mathrm{b}}$ & $19 \mathrm{c}$ \\
\hline
\end{tabular}

a Wu et al. (1984).

b Blasius and Cutts (1976).

c Blasius and Cutts (1981). 
TABLE 2. Adopted Parameter Values

\begin{tabular}{lcl}
\hline Parameter & Crust & Mantle \\
\hline$E, \mathrm{~Pa}$ & $1 \times 10^{11}$ & $3 \times 10^{11}$ \\
$\rho, \mathrm{kg} / \mathrm{m}^{3}$ & 3000 & 3500 \\
$v$ & 0.25 & 0.25 \\
\hline & & \\
\hline & Lithosphere & Asthenosphere \\
\hline, $\mathrm{Pa} \mathrm{s}$ & $1 \times 10^{27}$ & $1 \times 10^{21}$
\end{tabular}


TABLE 3. Characteristics of Predicted Near-surface Failure for Each Model.

\begin{tabular}{|c|c|c|c|c|}
\hline $\begin{array}{l}\text { Model }^{1} / \\
\text { increment }\end{array}$ & $\begin{array}{l}\text { Inner radius }{ }^{2} \text {, } \\
\text { km }\end{array}$ & $\begin{array}{l}\text { Outer radius }{ }^{2} \text {, } \\
\text { strike-slip } \\
\text { faulting, } \mathbf{k m}\end{array}$ & $\begin{array}{l}\text { Outer radius }{ }^{2} \text {, } \\
\text { normal faulting, } \\
\mathrm{km}\end{array}$ & $\begin{array}{l}\text { First observed } \\
\text { failure (time, } \\
\text { radius, type) }\end{array}$ \\
\hline $\begin{array}{ll}\text { GW40 } & 1 \\
& 2 \\
& 3 \\
\end{array}$ & $\begin{array}{c}140 \\
150^{3} \\
170^{3} \\
\end{array}$ & $\begin{array}{l}230 \\
270 \\
300 \\
\end{array}$ & $\begin{array}{l}380 \\
440 \\
490 \\
\end{array}$ & $\begin{array}{l}20 \tau_{\mathrm{M}} \\
130-170 \mathrm{~km} \\
\text { mixed } \\
\end{array}$ \\
\hline $\begin{array}{ll}\text { GW20 } & 1 \\
& 2 \\
& 3 \\
\end{array}$ & $\begin{array}{c}120 \\
120^{3} \\
140^{3} \\
\end{array}$ & $\begin{array}{l}170 \\
190 \\
220 \\
\end{array}$ & $\begin{array}{l}280 \\
320 \\
360 \\
\end{array}$ & $\begin{array}{l}30 \mathrm{\tau M}_{\mathrm{M}} \\
120-140 \mathrm{~km} \\
\text { radial normal } \\
\end{array}$ \\
\hline $\begin{array}{ll}\text { GW60 } & 1 \\
& 2 \\
& 3 \\
\end{array}$ & $\begin{array}{r}180 \\
180 \\
190^{3} \\
\end{array}$ & $\begin{array}{l}270 \\
330 \\
360 \\
\end{array}$ & $\begin{array}{l}410 \\
520 \\
590 \\
\end{array}$ & $\begin{array}{l}40 \tau_{M} \\
170-220 \mathrm{~km} \\
\text { mixed } \\
\end{array}$ \\
\hline $\begin{array}{ll}G W 40 / 60 & 1 \\
& 2 \\
3 \\
3\end{array}$ & $\begin{array}{l}200 \\
200 \\
210 \\
\end{array}$ & $\begin{array}{l}300 \\
350 \\
390 \\
\end{array}$ & $\begin{array}{l}430 \\
550 \\
630 \\
\end{array}$ & $\begin{array}{l}40 \tau_{M} \\
200-220 \mathrm{~km} \\
\text { radial normal }\end{array}$ \\
\hline IW 401 & $190^{3}$ & 290 & 490 & $\begin{array}{l}10 \tau_{M} \\
200-250 \mathrm{~km} \\
\text { radial normal }\end{array}$ \\
\hline $\begin{array}{rr}\text { GD40 } & 1 \\
2 \\
3 \\
\end{array}$ & $\begin{array}{c}120 \\
130^{3} \\
150^{3} \\
\end{array}$ & $\begin{array}{l}240 \\
280 \\
310 \\
\end{array}$ & $\begin{array}{l}380 \\
440 \\
500 \\
\end{array}$ & $\begin{array}{l}20 \tau_{\mathrm{M}} \\
120-150 \mathrm{~km} \\
\text { mixed }\end{array}$ \\
\hline $\begin{array}{ll}\text { GWPS40 } & 1 \\
& 2 \\
& 3 \\
\end{array}$ & $\begin{array}{c}150 \\
160 \\
170^{3} \\
\end{array}$ & $\begin{array}{l}290 \\
310 \\
320 \\
\end{array}$ & $\begin{array}{l}340 \\
410 \\
470 \\
\end{array}$ & $\begin{array}{l}40 \tau_{M} \\
140-190 \mathrm{~km} \\
\text { mixed } \\
\end{array}$ \\
\hline
\end{tabular}

1 Model key:

$\mathbf{G}=$ growing volcano,

$\mathrm{W}=$ welded volcano,

$I=$ instantaneously emplaced volcano,

$\mathrm{D}=$ detached volcano,

PS = isotropic pre-stress applied to lithosphere, integer = elastic lithosphere

thickness.

2 Radius values given at $t=1000 \tau_{M}$ after application of given load increment.

3 Value less than the maximum radius of the volcano at a given load increment 


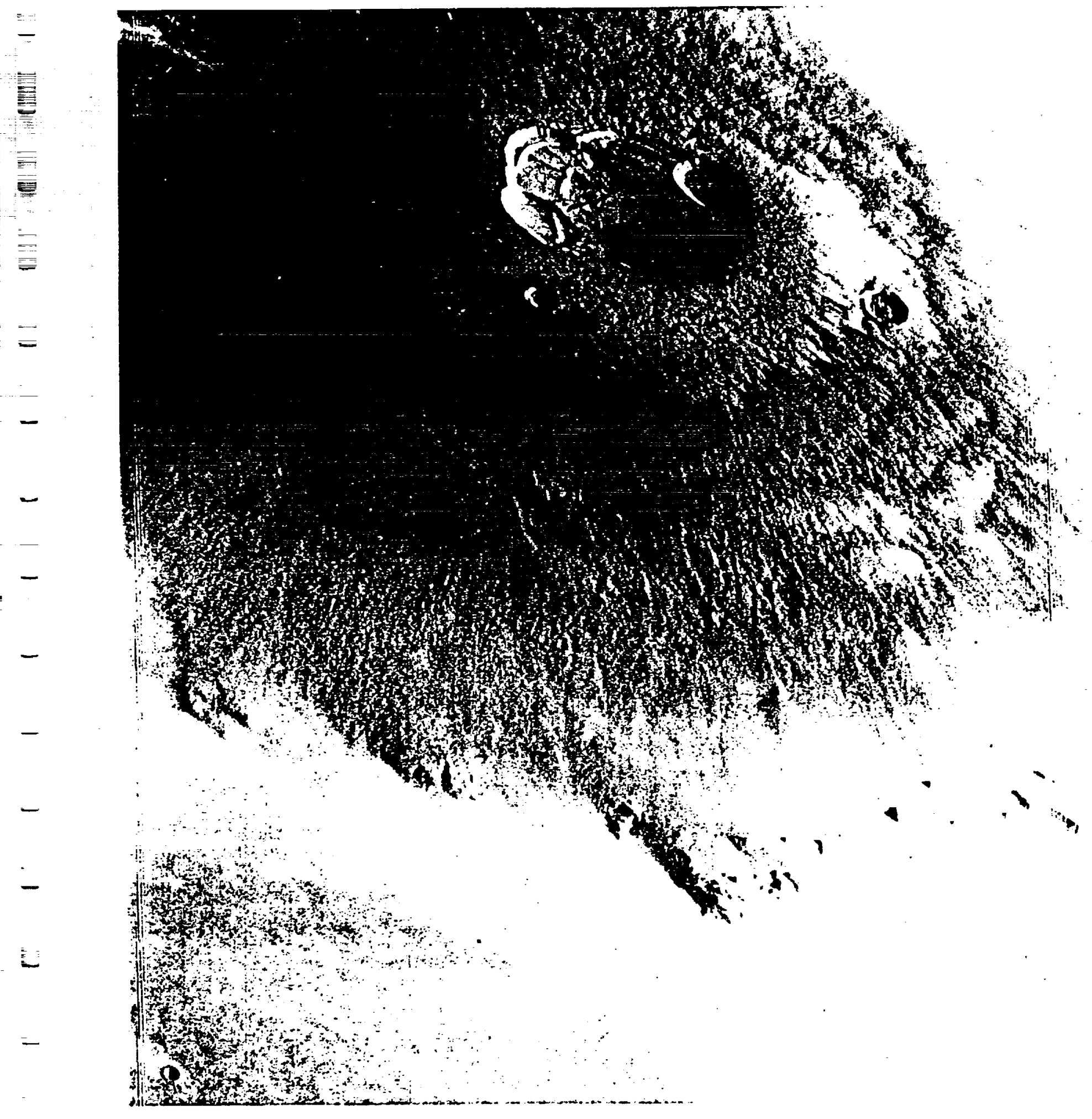

Figure 1 


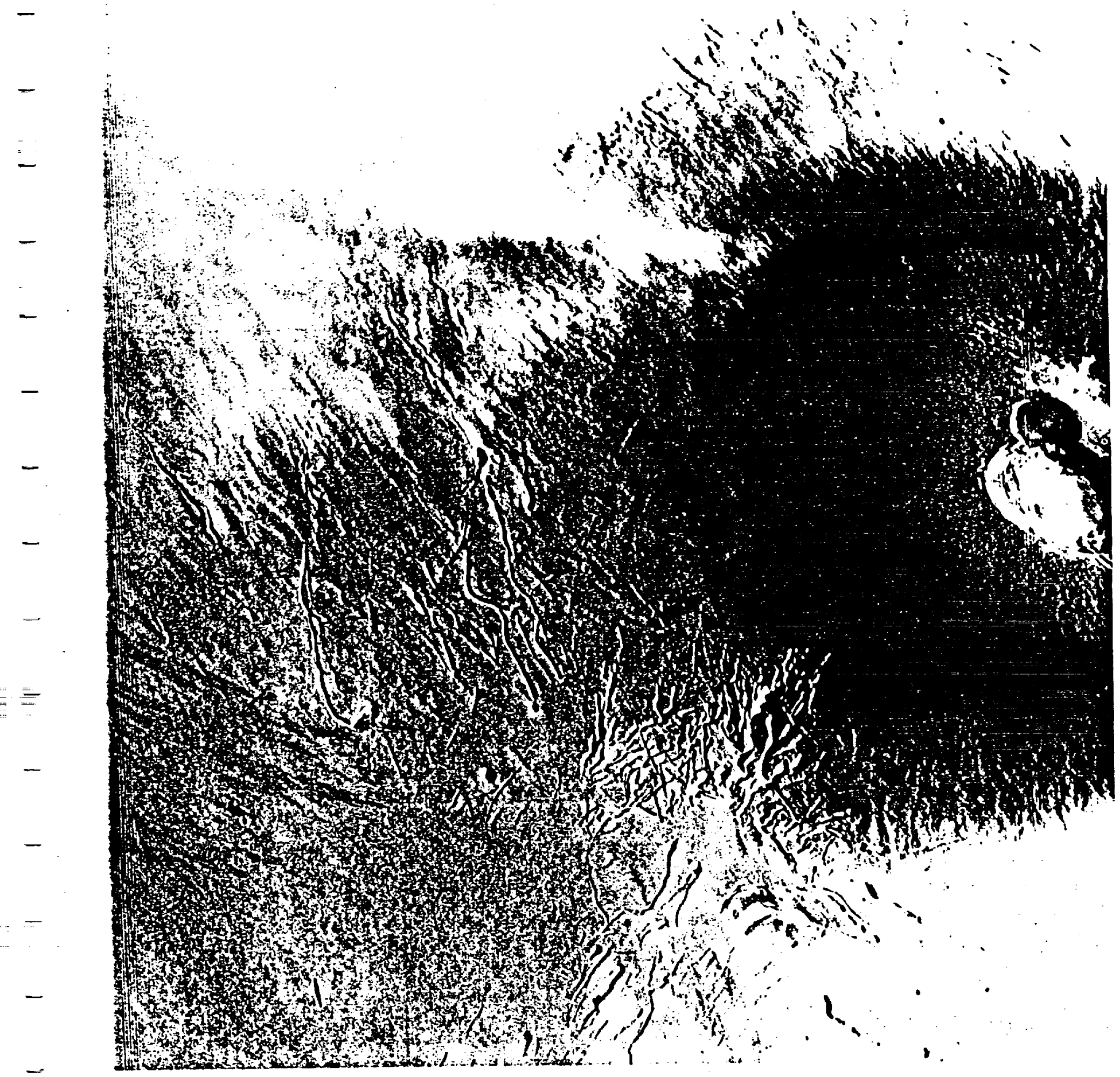



三

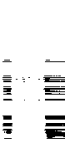
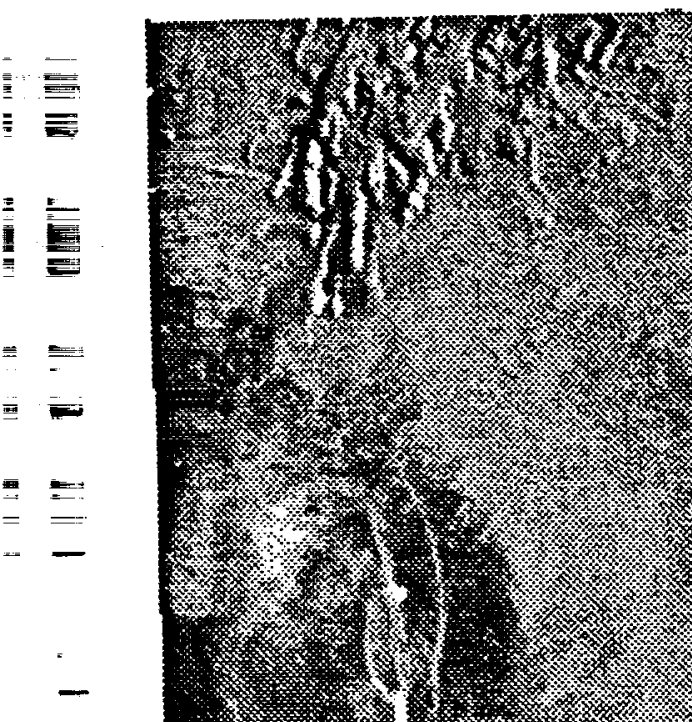

$\equiv$

$=$

-

$=$

.

17.

(.).

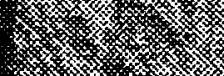

$f^{2}$

-3.

1.

.

-
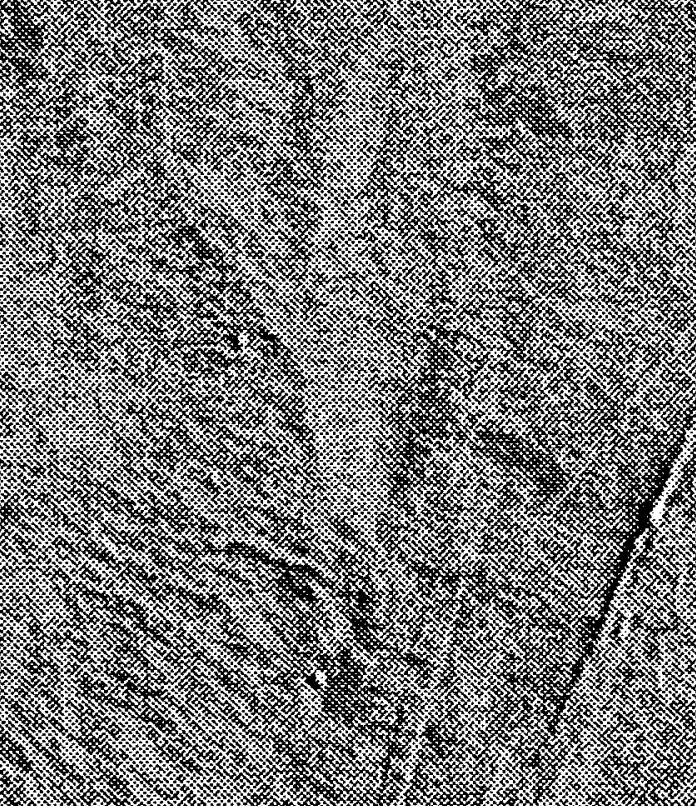


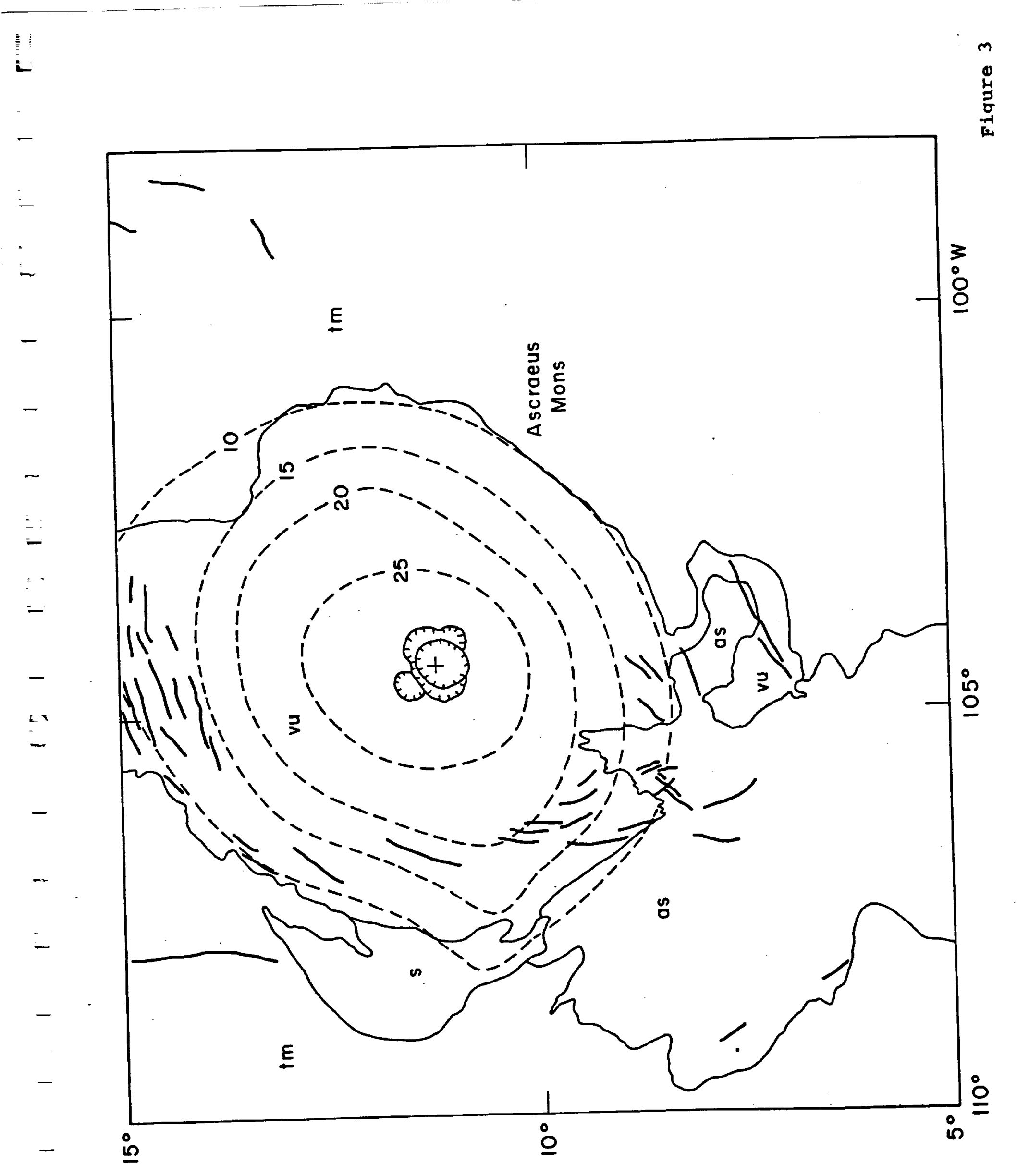




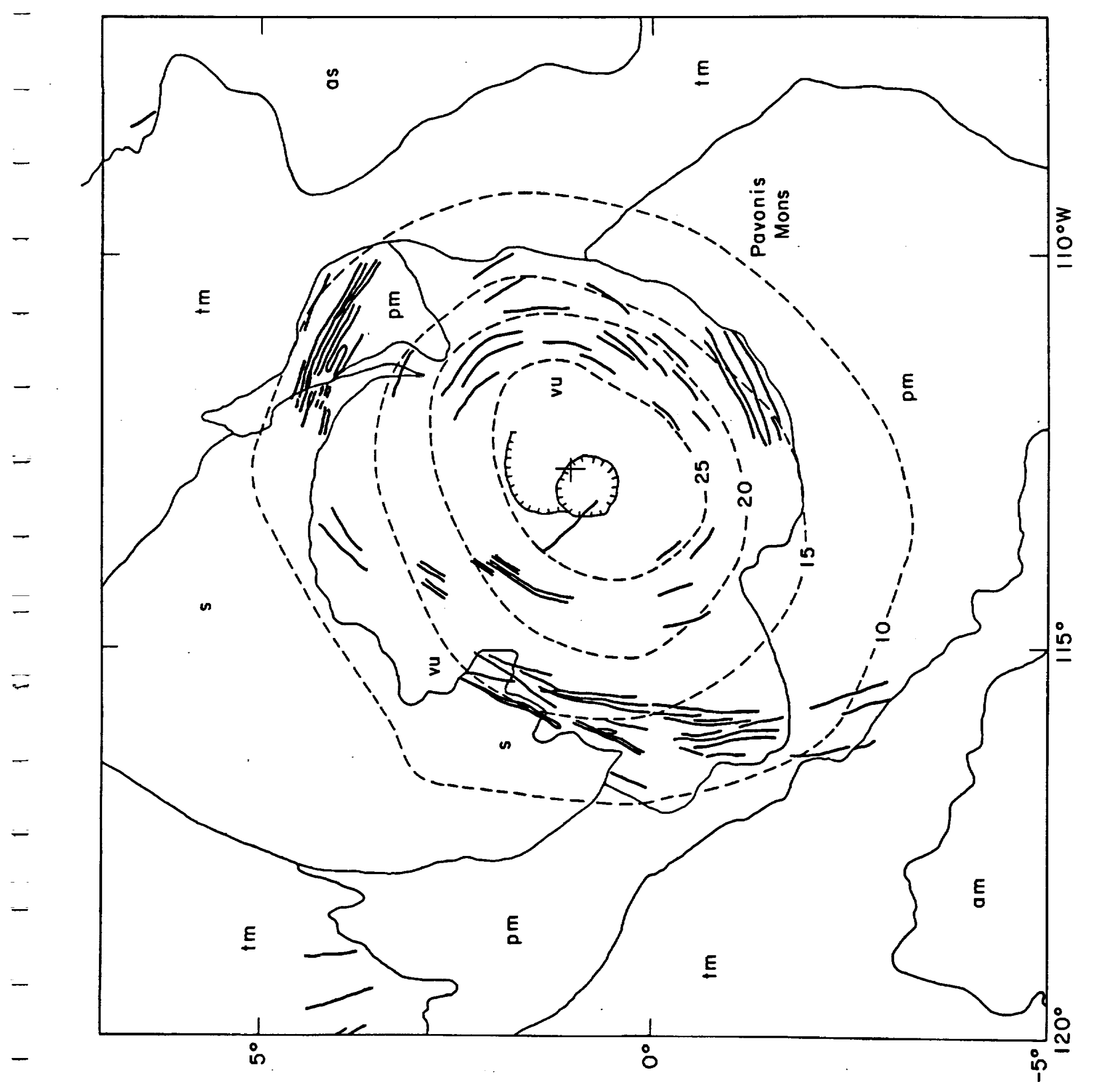




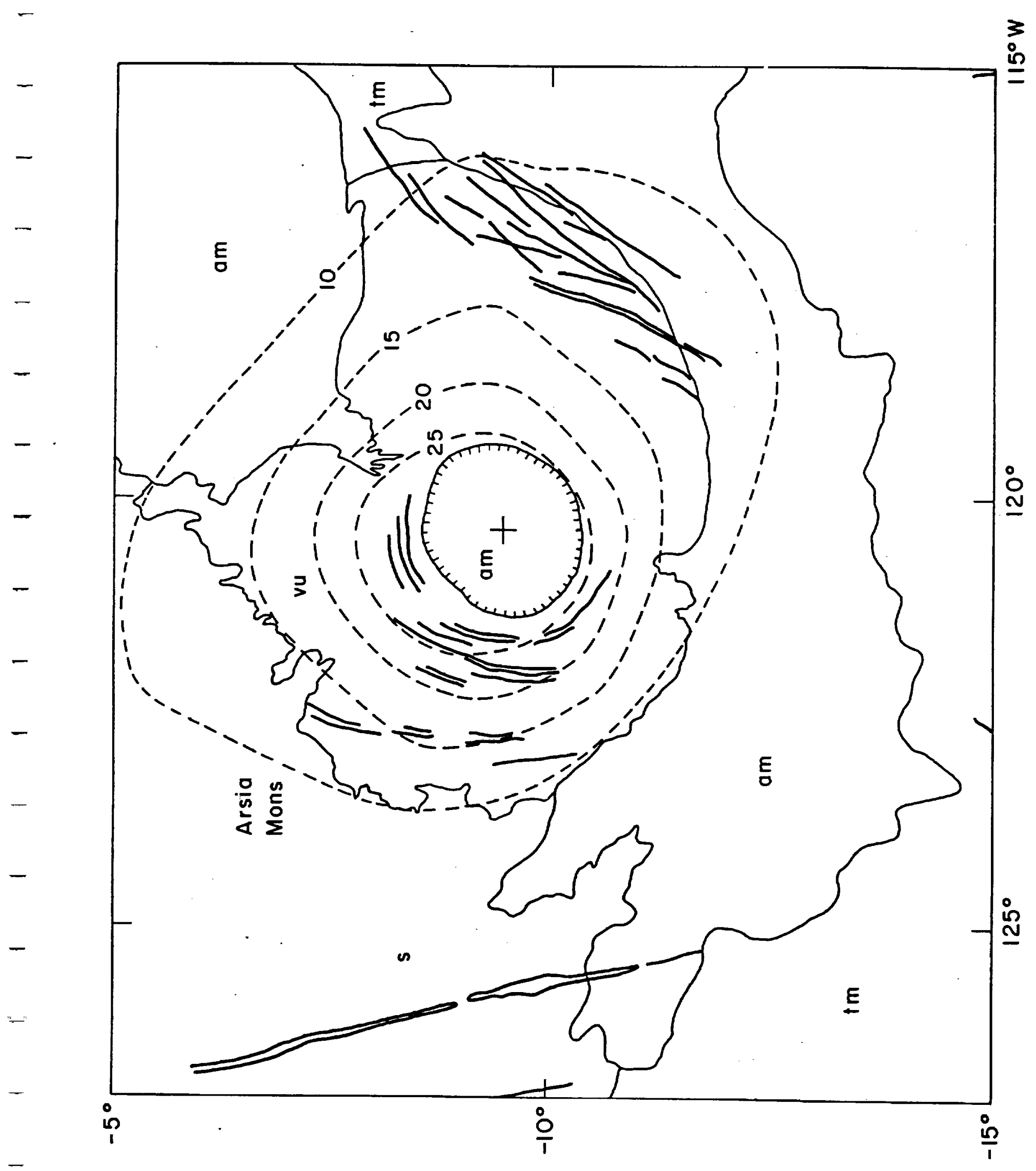




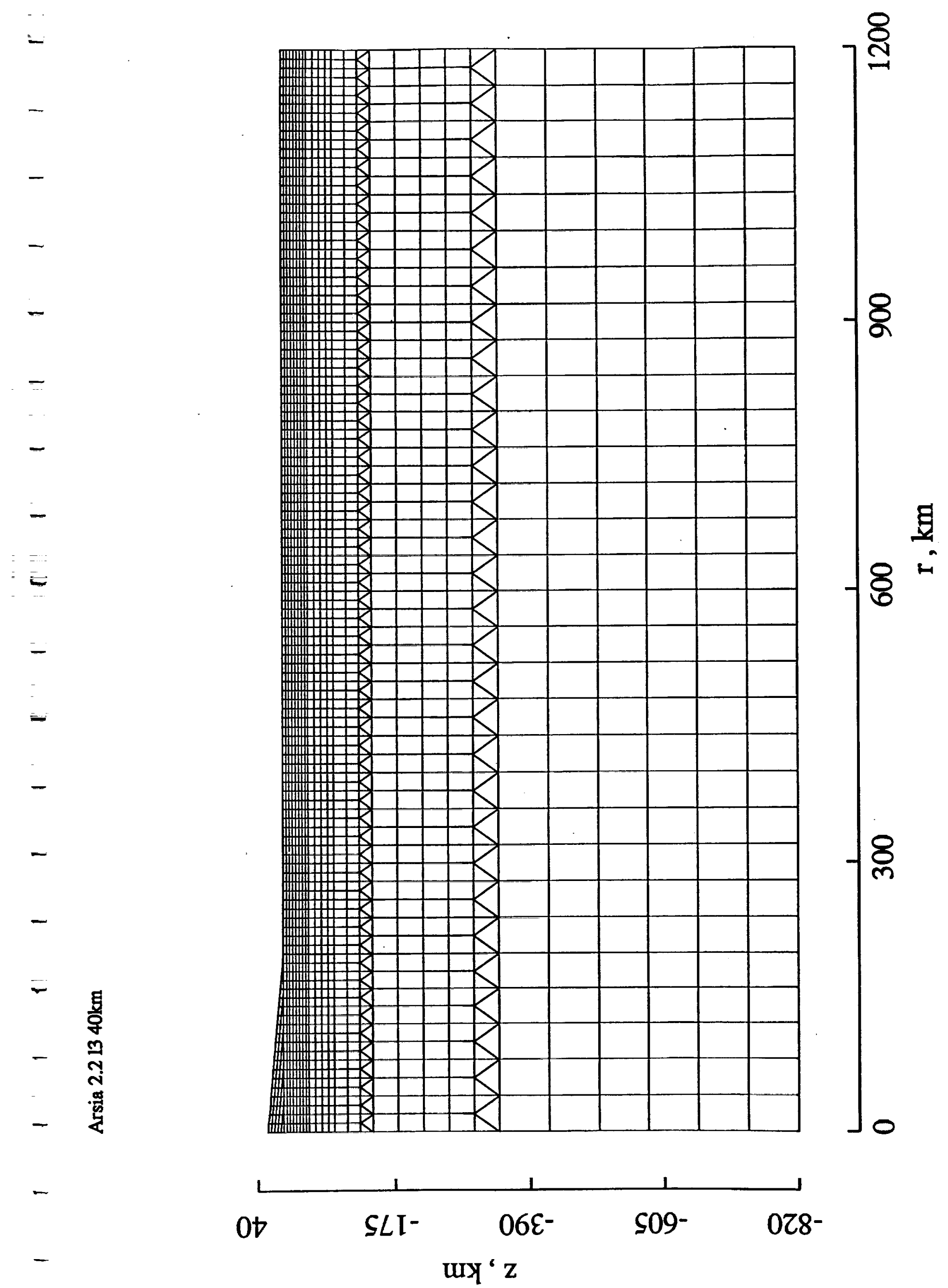





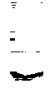

$=$

:

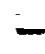

$-$

-

-

$-$

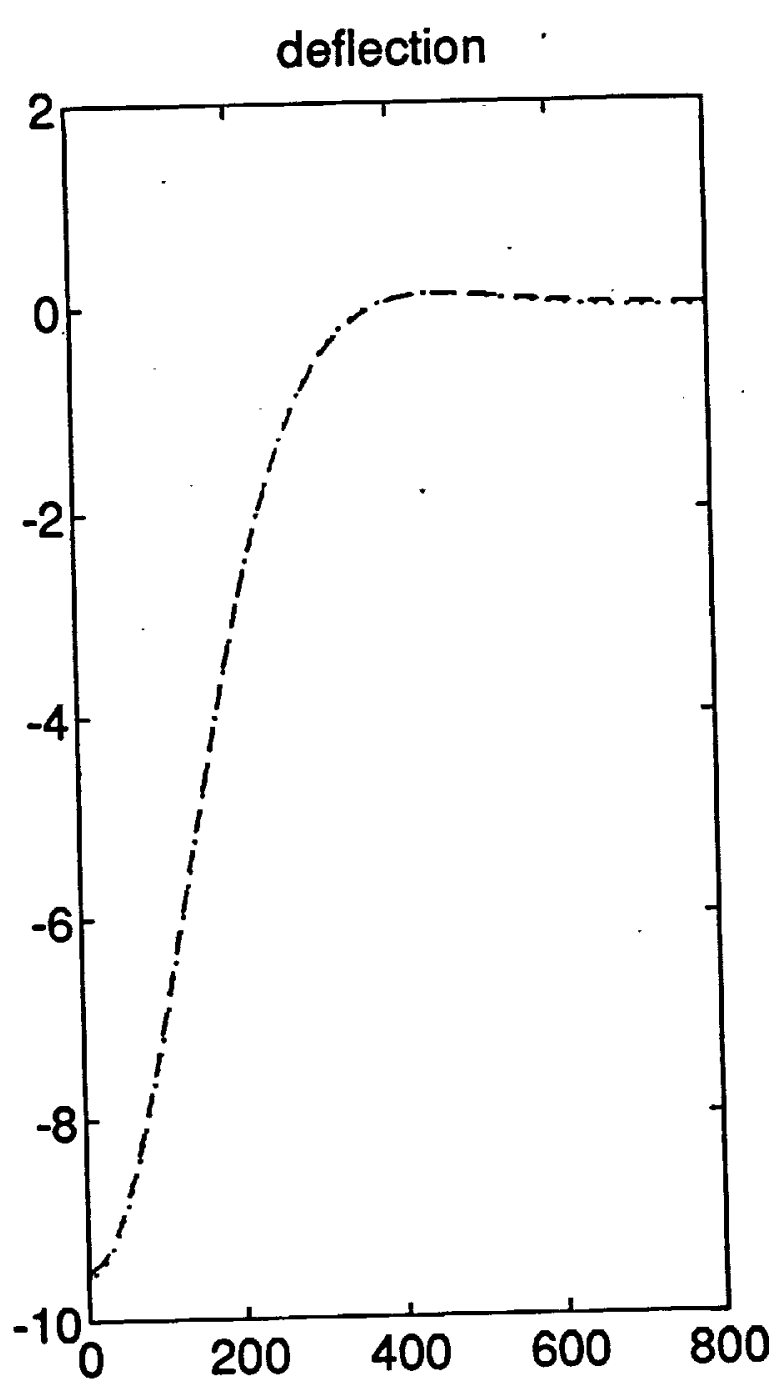

analytic deflection - tecton deflection

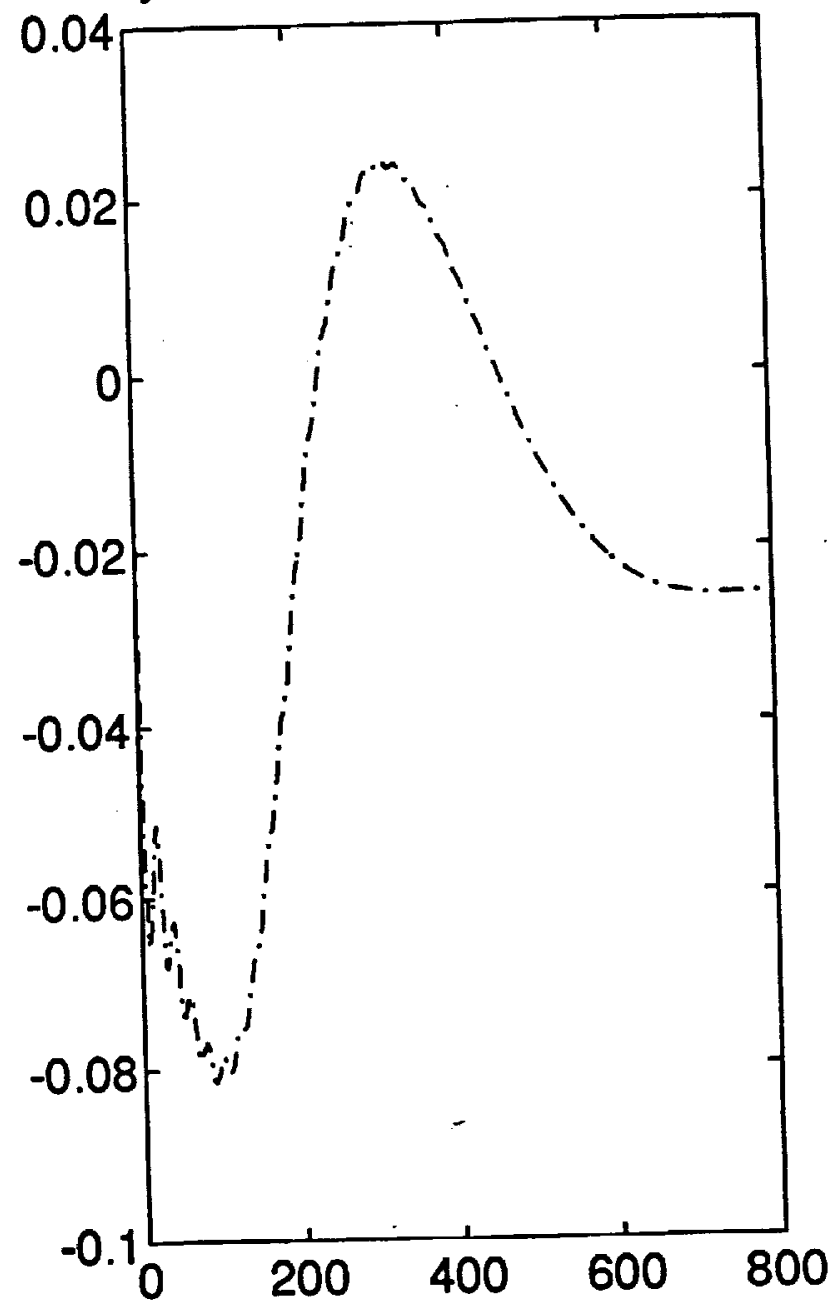

Figure 7 


\section{Maximum Stress:}
Symbol
Compressive
Extensional
"Predicted" Fault Type
vertical
horizontal
circumferential normal

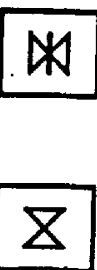
horizonal
vertical
circumferential thrust
$\nabla \quad$ vertical
out of plane
radial normal
$\bowtie$ horizontal
out of plane
strike-slip
$\theta$
out of plane
horizontal
strike-slip
(1)
out of plane
vertical
radial thrust

Figure 8 


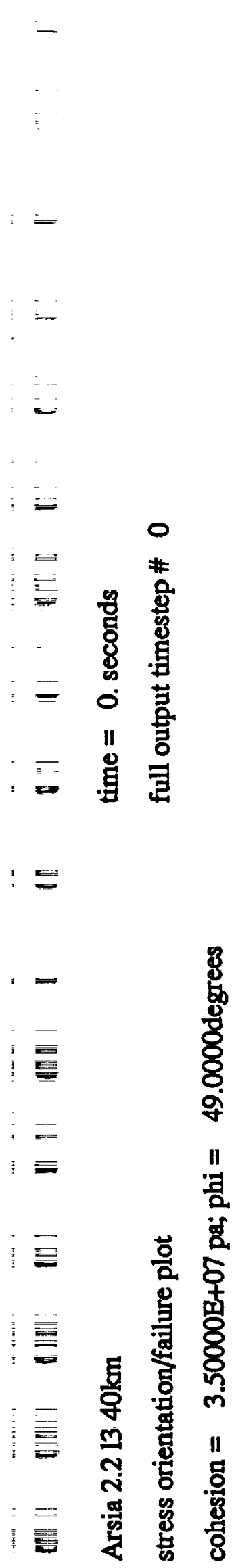

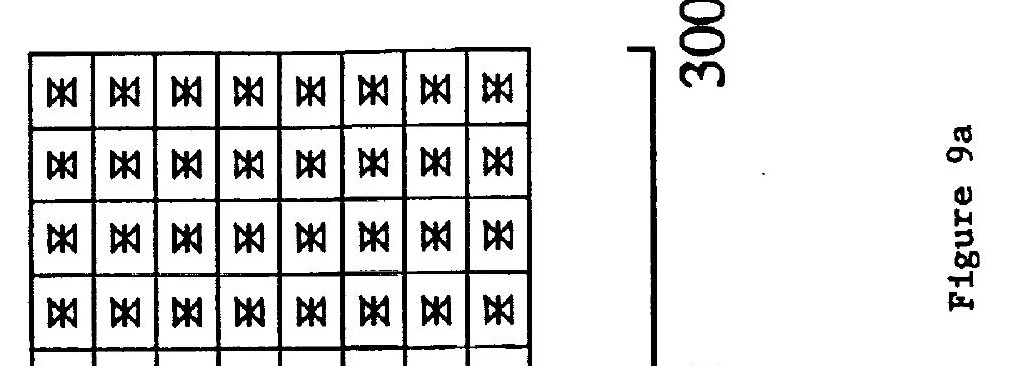

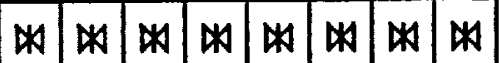

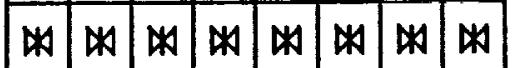

勿

勿

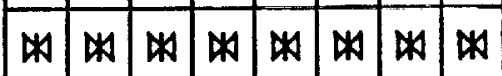

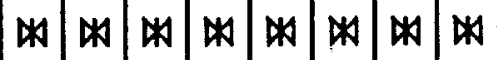

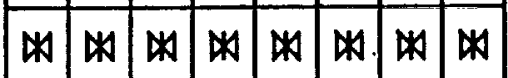

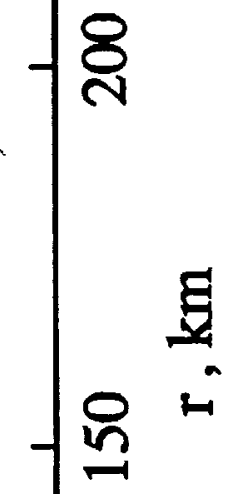

经

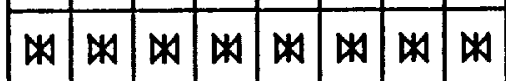

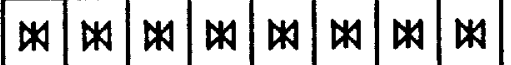

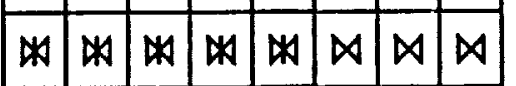
为

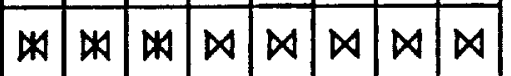
州 多

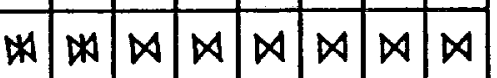

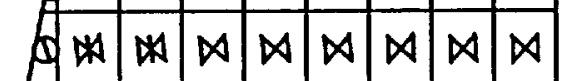

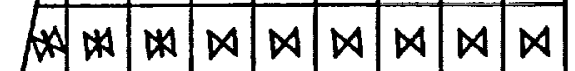

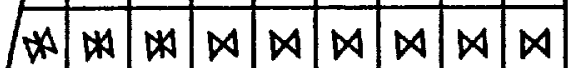

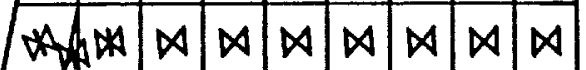

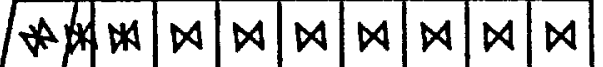

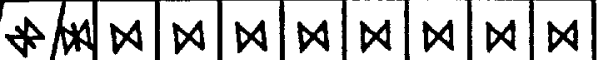
in

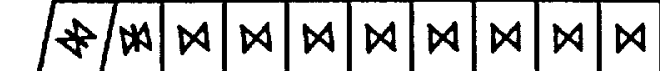

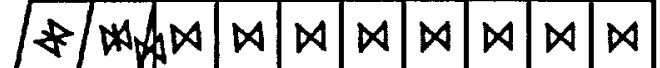

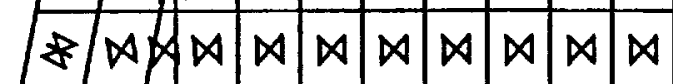

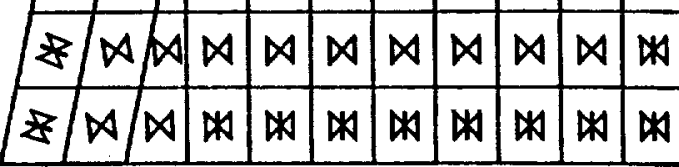




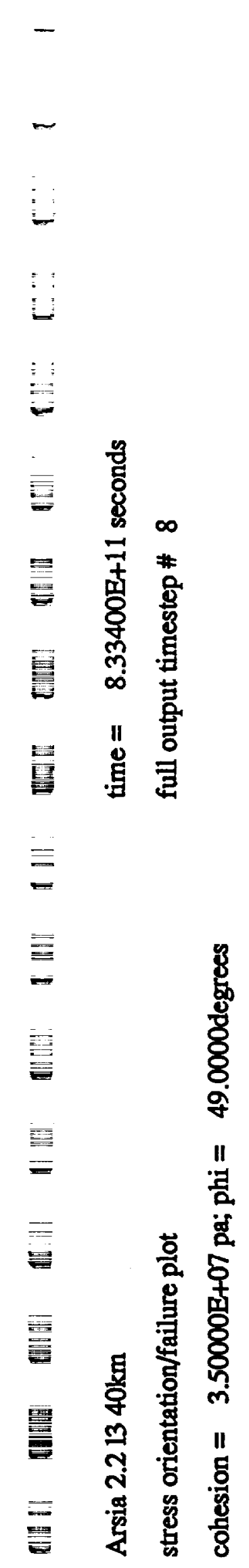

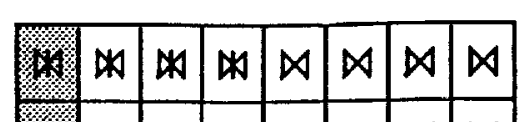

$7 \stackrel{8}{m}$

$-1$

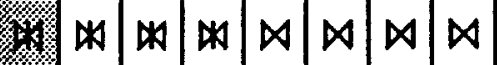

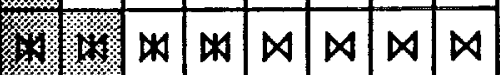

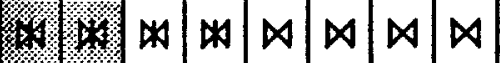

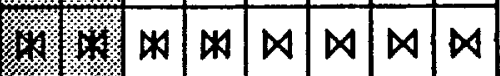

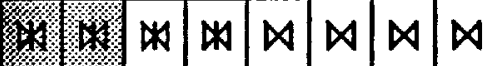

(10.0.

\%

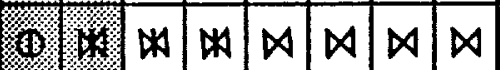

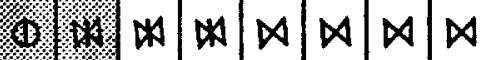

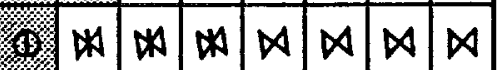

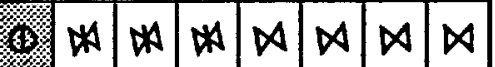

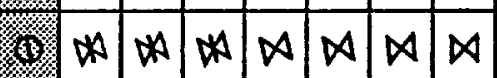

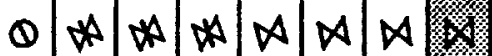

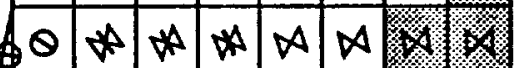

$\theta \theta+\infty A N A D W$

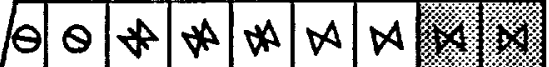

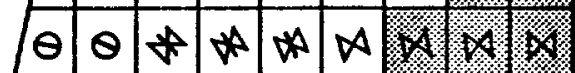

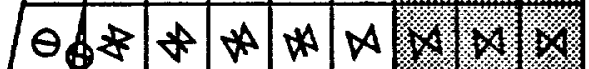

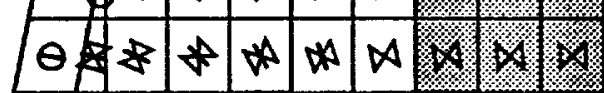

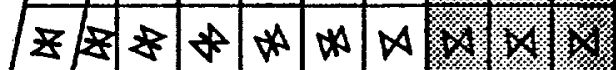

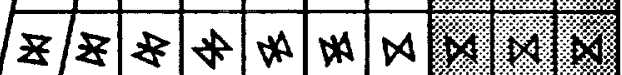

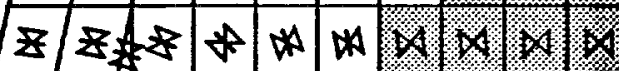

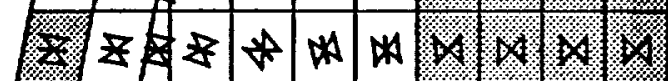

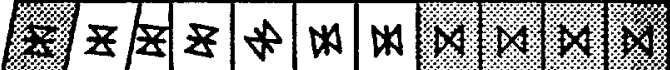

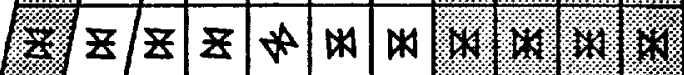

$-8$

$-8$

- n

$=$

를 


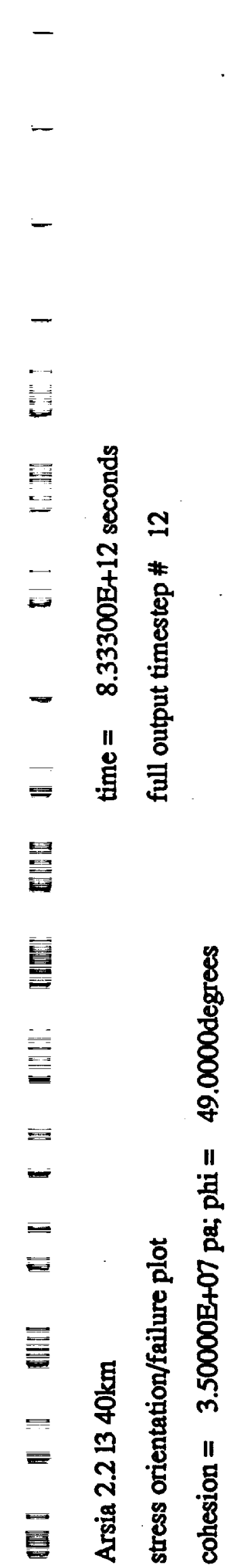

\begin{tabular}{|c|c|c|c|c|c|c|c|}
\hline 40 & 4 & $w$ & W & $\Delta$ & 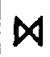 & 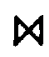 & $\bowtie$ \\
\hline 4 & 9 & W & W & $\bowtie$ & $\Phi$ & $\bowtie$ & $\bowtie$ \\
\hline 4 & 18 & $W$ & $\omega$ & $M$ & $\bowtie$ & $\Delta$ & $\bowtie$ \\
\hline 19. & 4 & W & 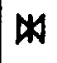 & $\Delta$ & 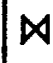 & $\Delta$ & $\bowtie$ \\
\hline$x$ & 林 & $w$ & W & $\Delta$ & 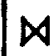 & $\Delta$ & 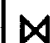 \\
\hline
\end{tabular}

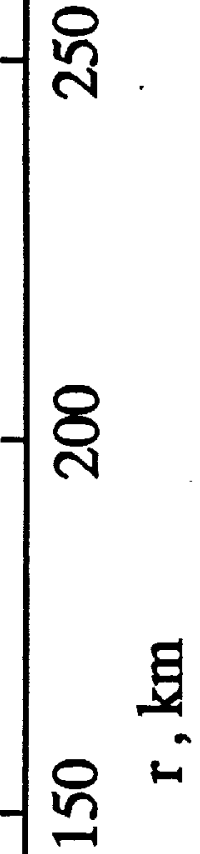

$\because 0$ \%

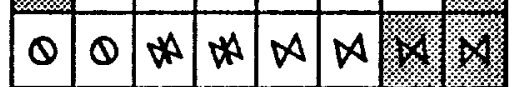

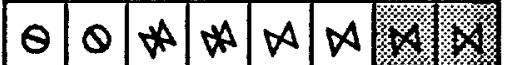

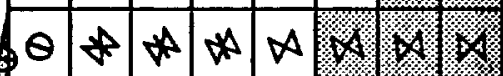

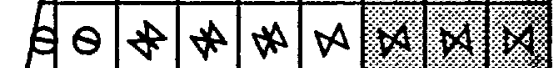

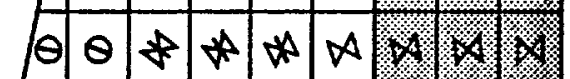

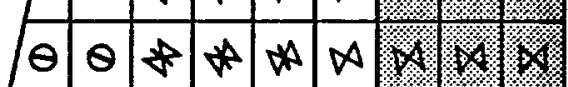

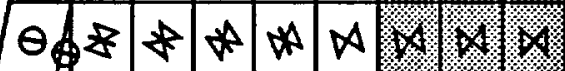

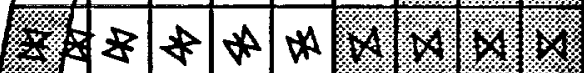

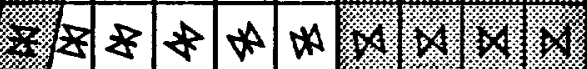

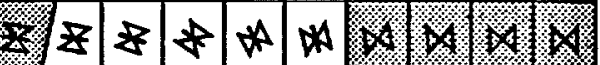

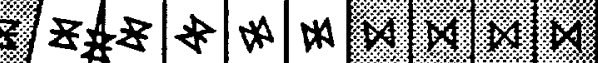

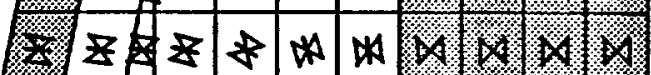

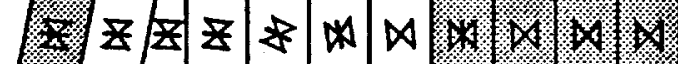

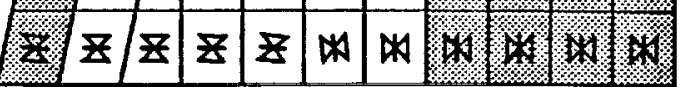
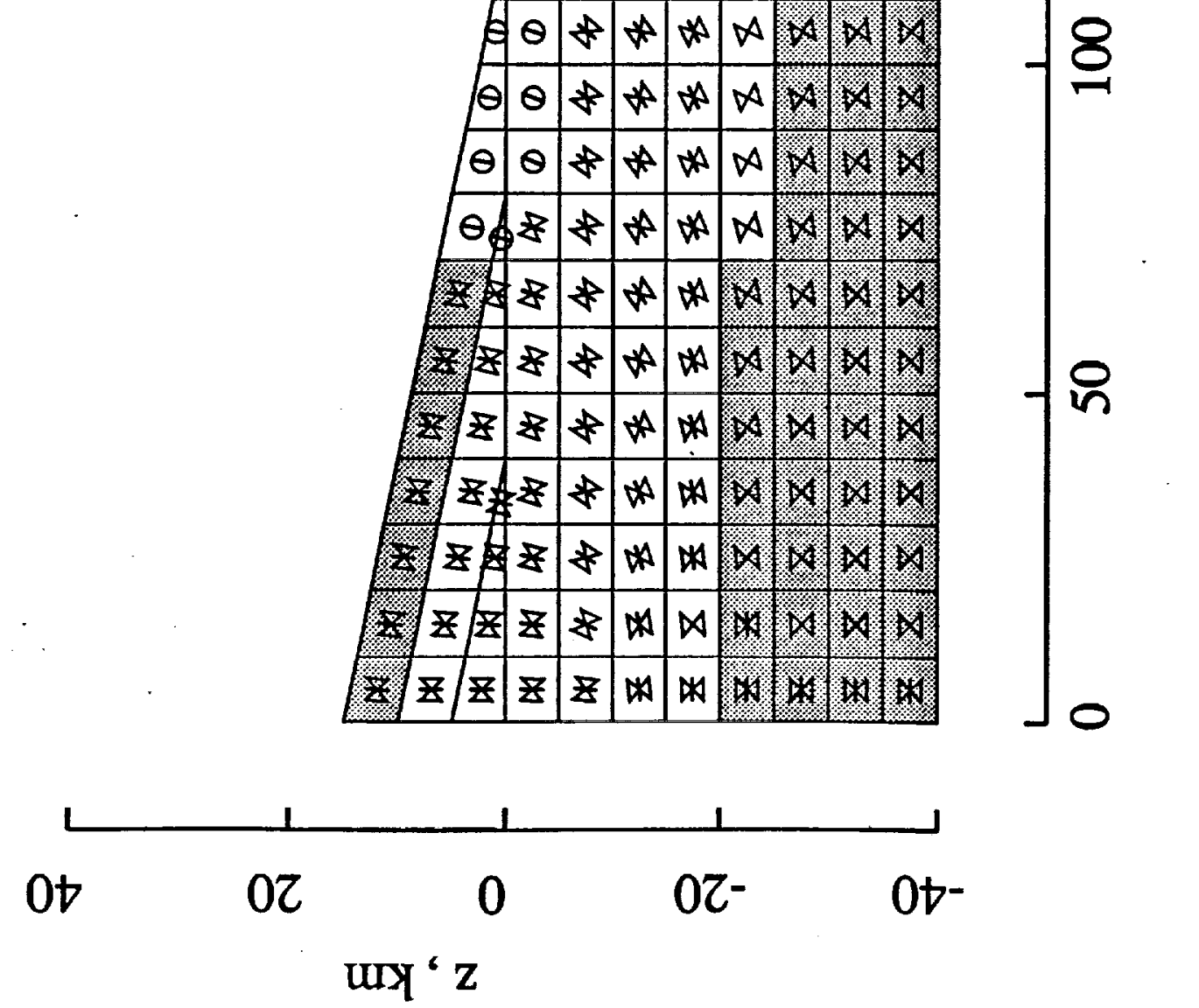

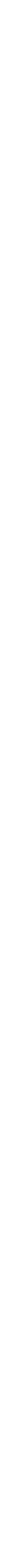

(3)

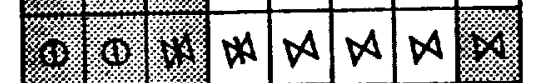

$-18$

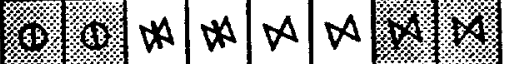

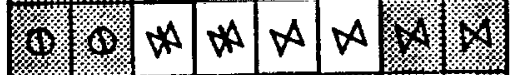

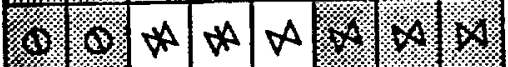

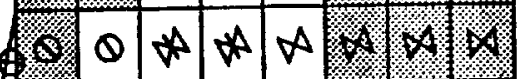

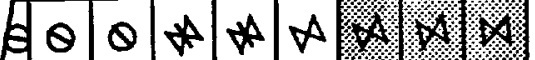

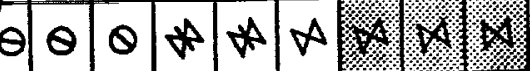

$\theta \quad \theta \quad \theta \quad *$ *

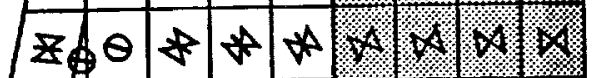

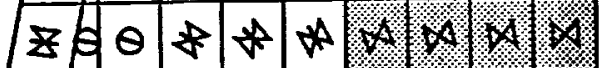

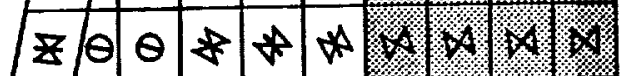

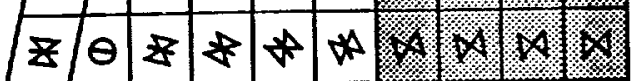

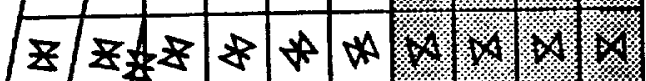

z $z$ \& $\&$ \& + a

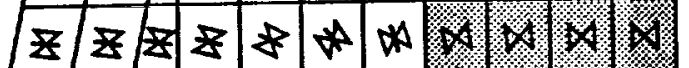

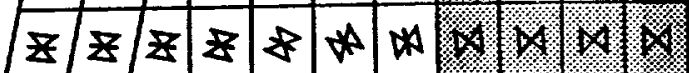

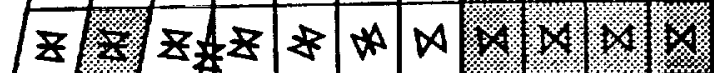

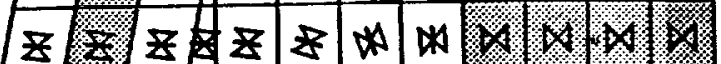

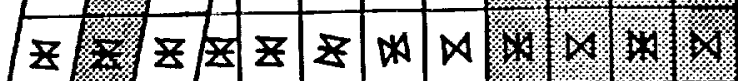

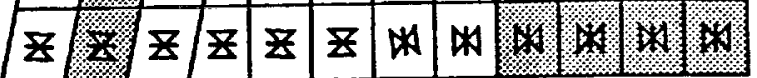
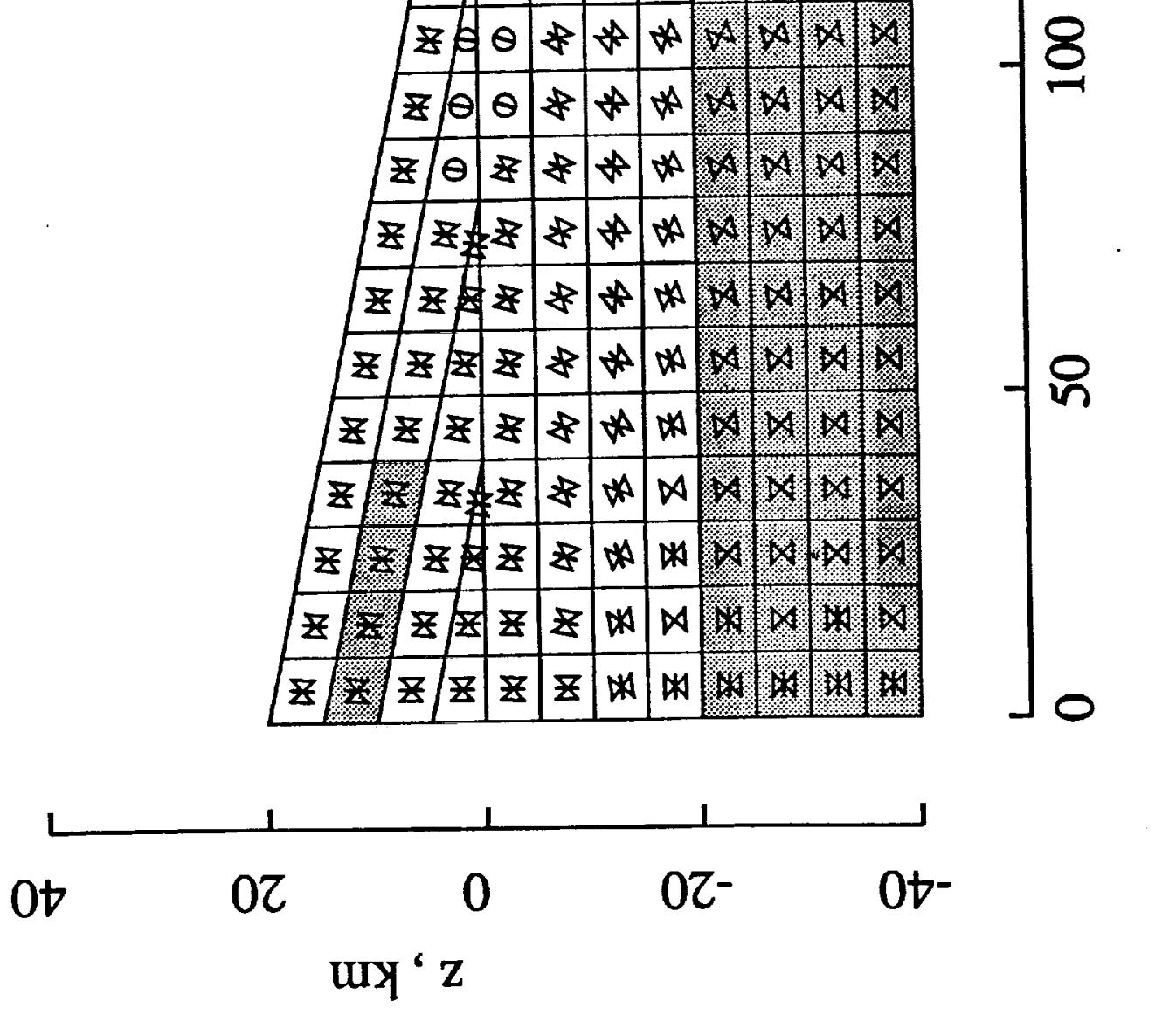


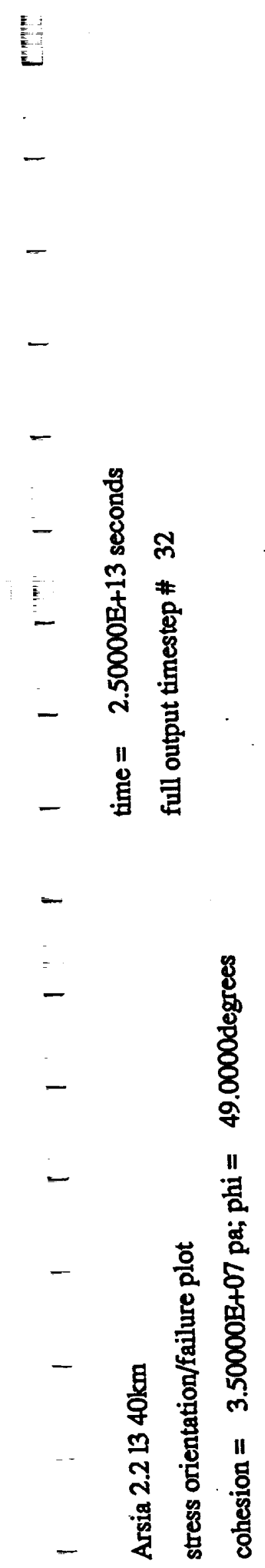

\begin{tabular}{|c|c|c|c|c|c|c|c|}
\hline 6 & 111 & $x$ & 4 & $\bowtie$ & $\bowtie$ & $\bowtie$ & $\infty$ \\
\hline 48 & 4 & 14 & $W$ & $\bowtie$ & $\bowtie$ & $\bowtie$ & 8 \\
\hline 99 & 111 & 4 & 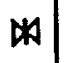 & $\bowtie$ & $\bowtie$ & 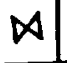 & $\mathbf{z}$ \\
\hline 80 & 4 & \% & W & $\infty$ & $\infty$ & $\infty$ & $\mathbf{z}$ \\
\hline 准 & 4 & 4 & $W$ & $\infty$ & 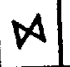 & $\infty$ & $\nabla$ \\
\hline 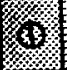 & 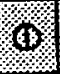 & 細 & W & 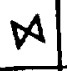 & $\infty$ & $\infty$ & 8 \\
\hline 格 & $8 \%$ & 楼 & 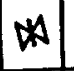 & $\infty$ & $\infty$ & $\Delta$ & 4 \\
\hline 6 & 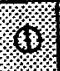 & 端 & $\mathbb{A}$ & $\Delta$ & $\Delta$ & $\%$ & 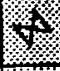 \\
\hline 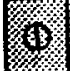 & 0 & tx & $\infty$ & $\infty$ & $\infty$ & $1 \%$ & 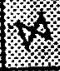 \\
\hline w & 10 & 6 & $\$$ & $\infty$ & 4 & $\%$ & $(x)$ \\
\hline 689 & 30 & (x) & $\forall$ & $\Delta$ & $1 \%$ & $y$ & $y$ \\
\hline
\end{tabular}

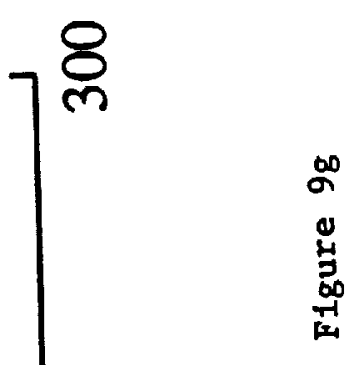

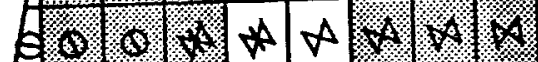

$\theta \% 0 \%$ on $A$ atw.

$\theta \theta 010$ A

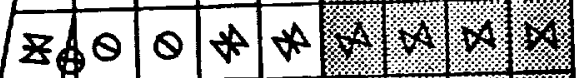

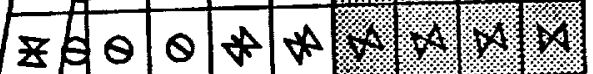

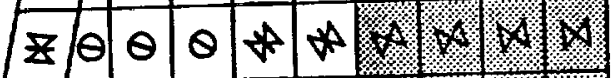

$-1$

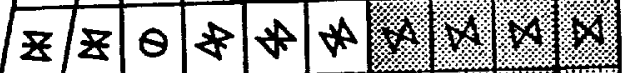

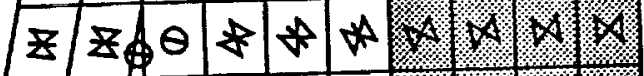

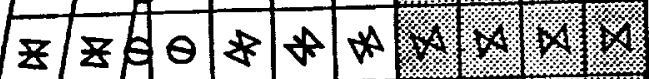

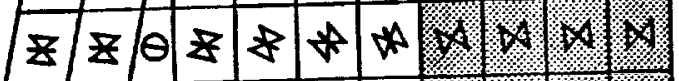

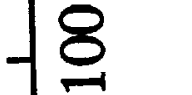

z $z$ z $z$ \&

z

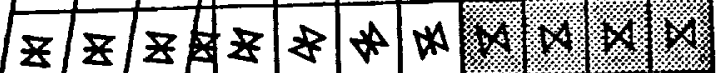

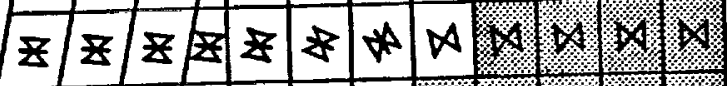

$-8$

ह

z $z$ z $z$ z $z$ z

Z

Z

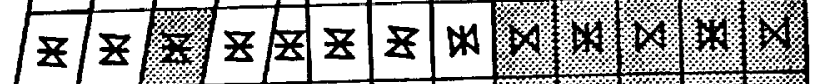
z z
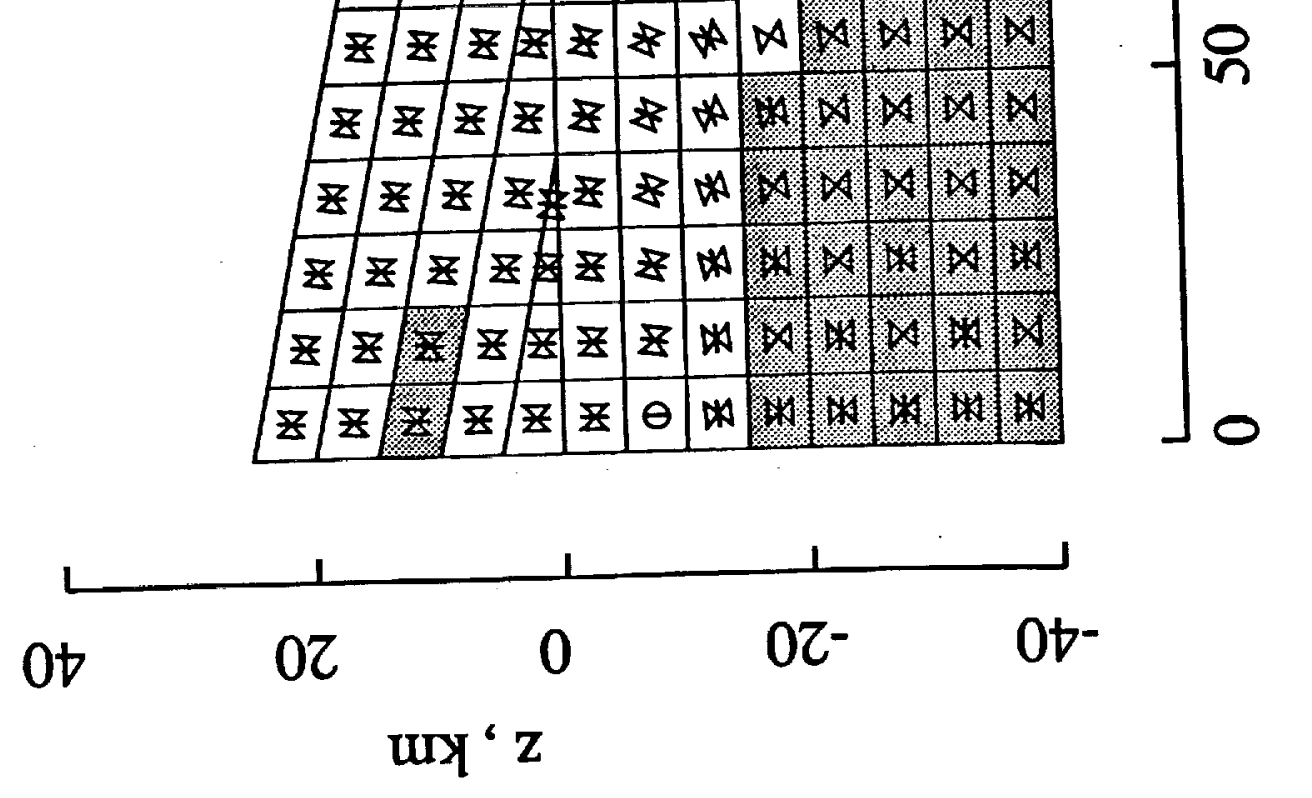


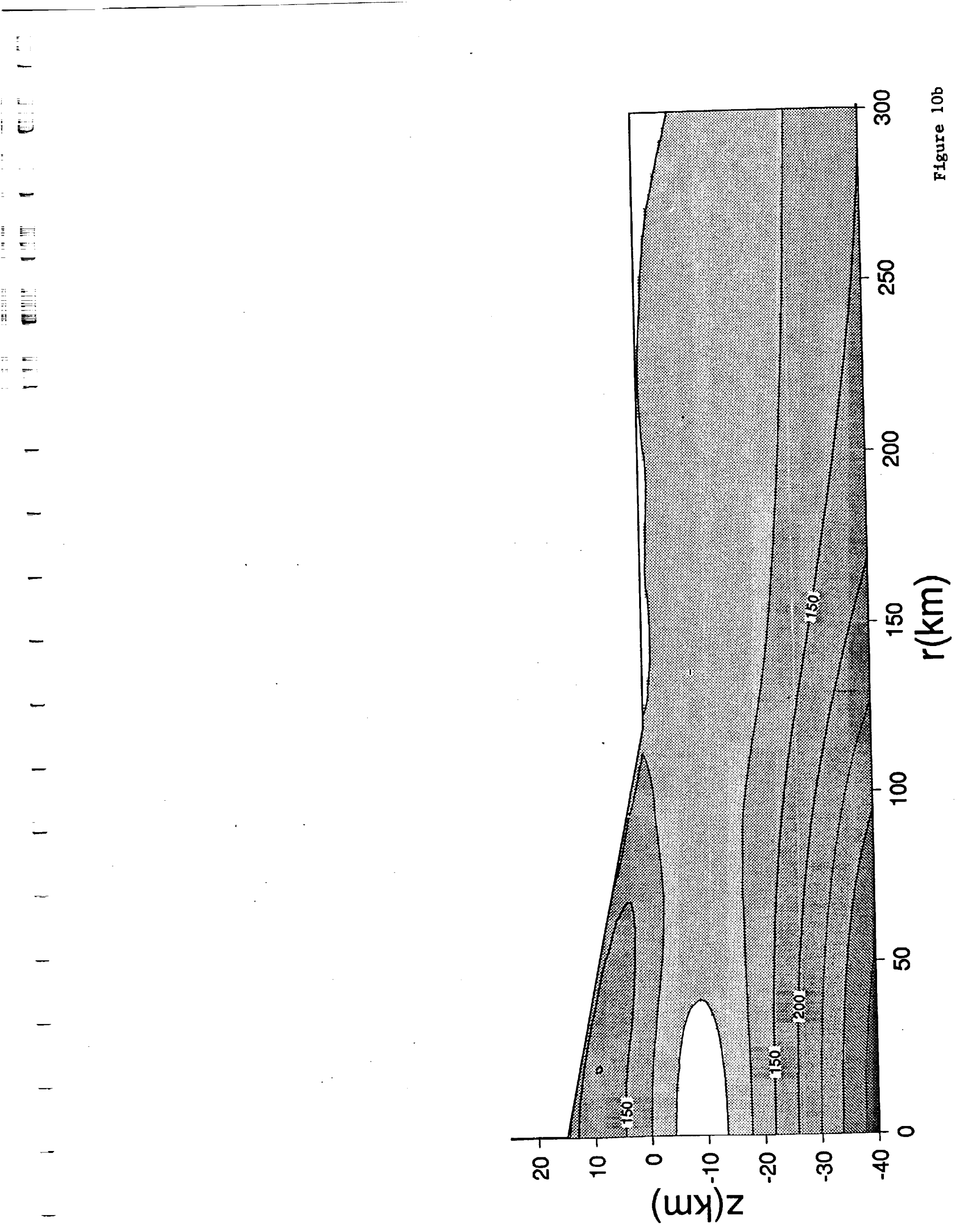




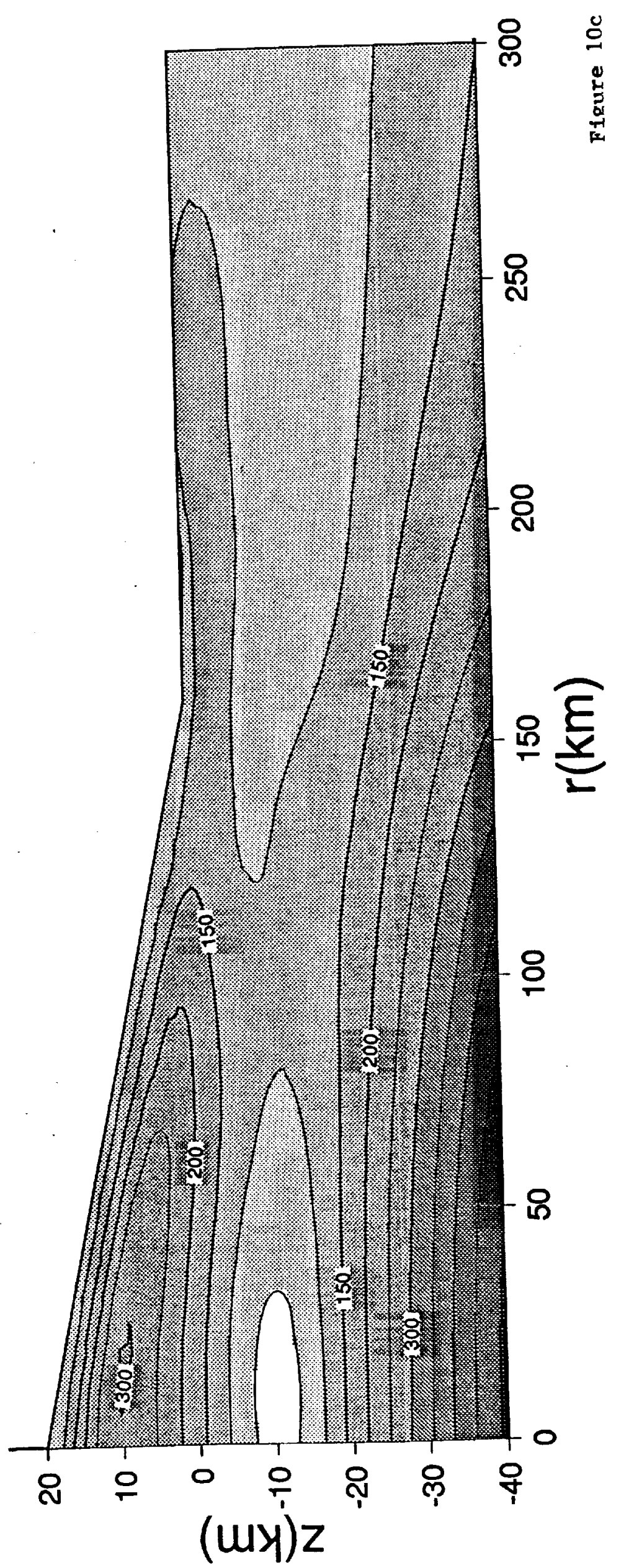




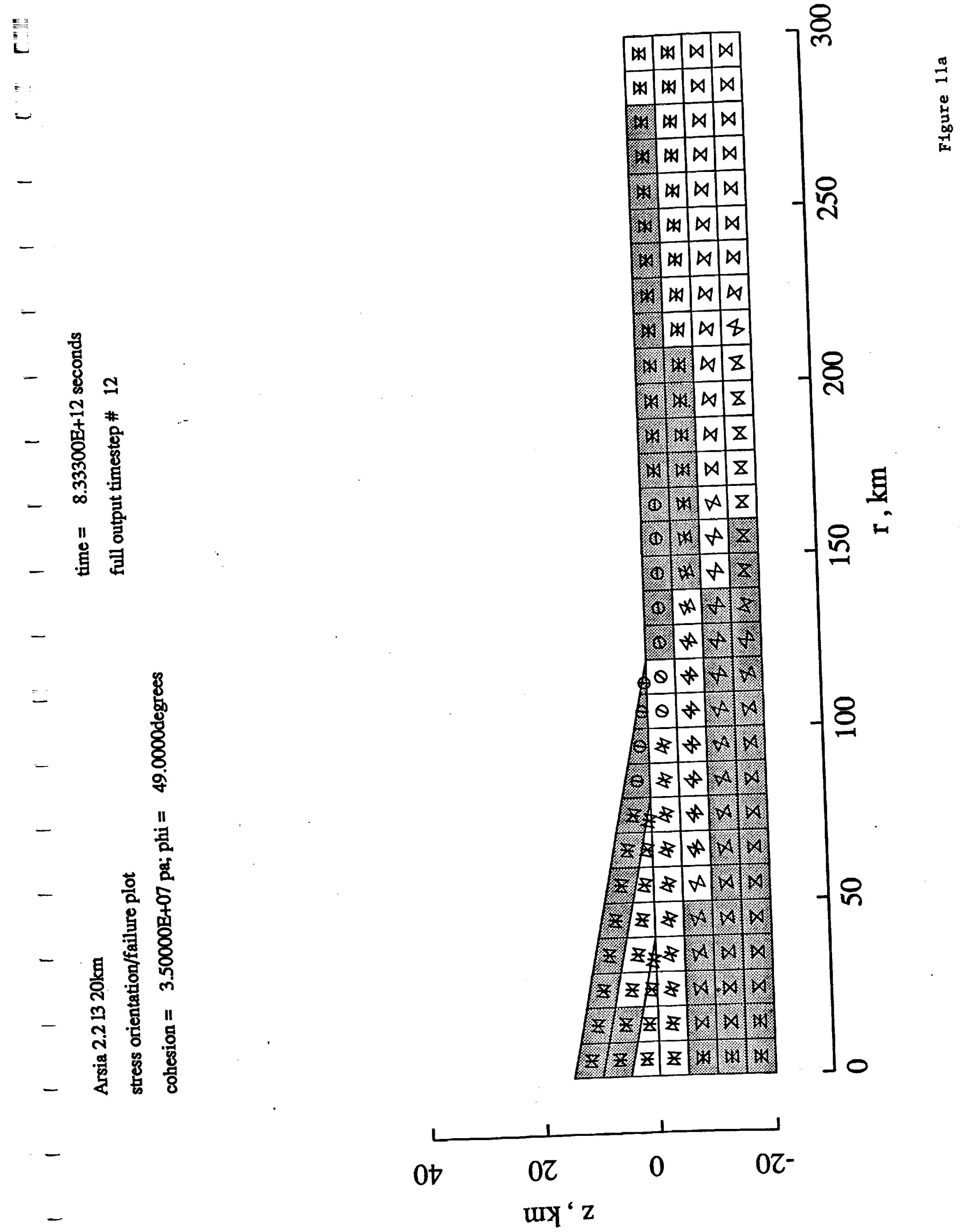




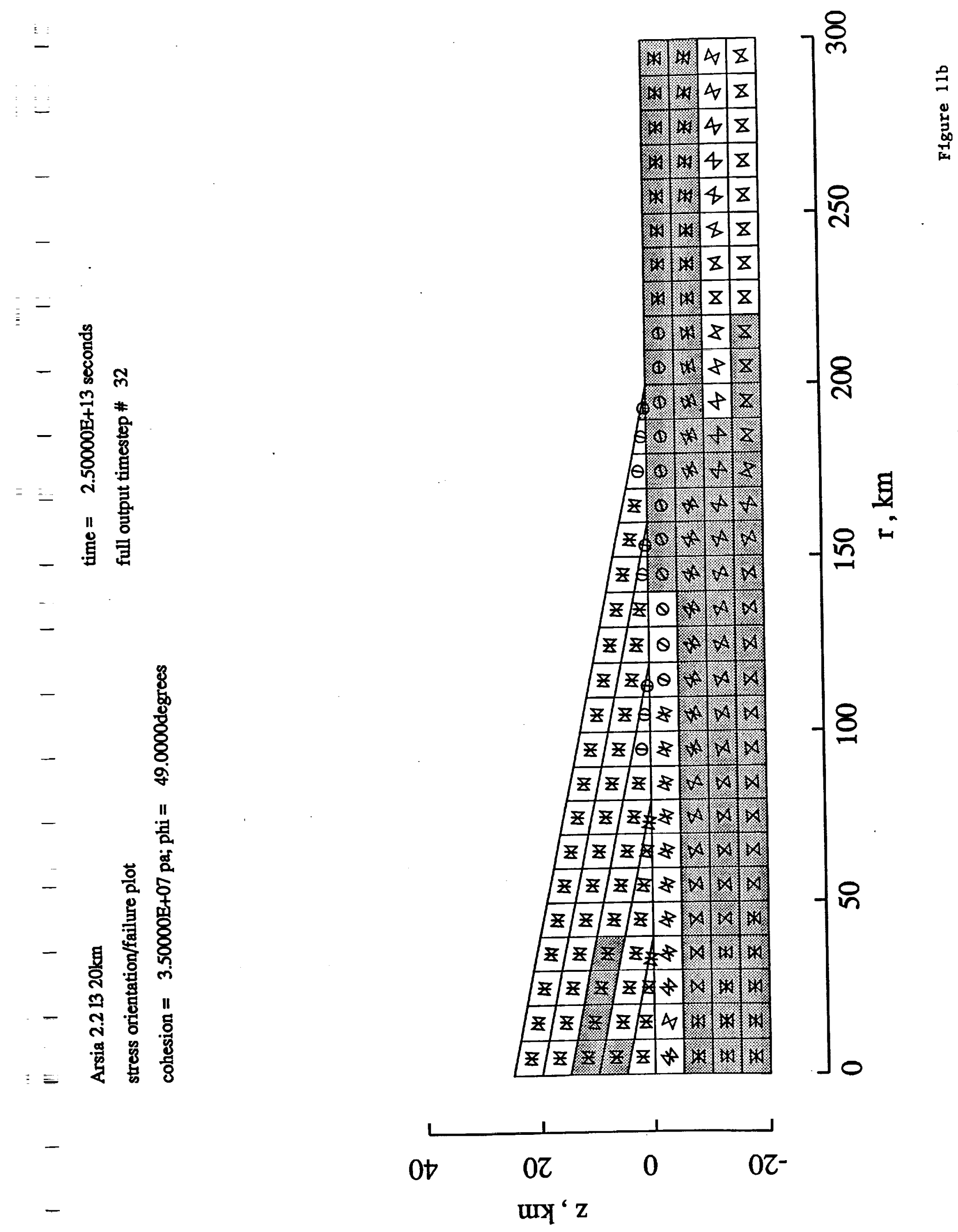




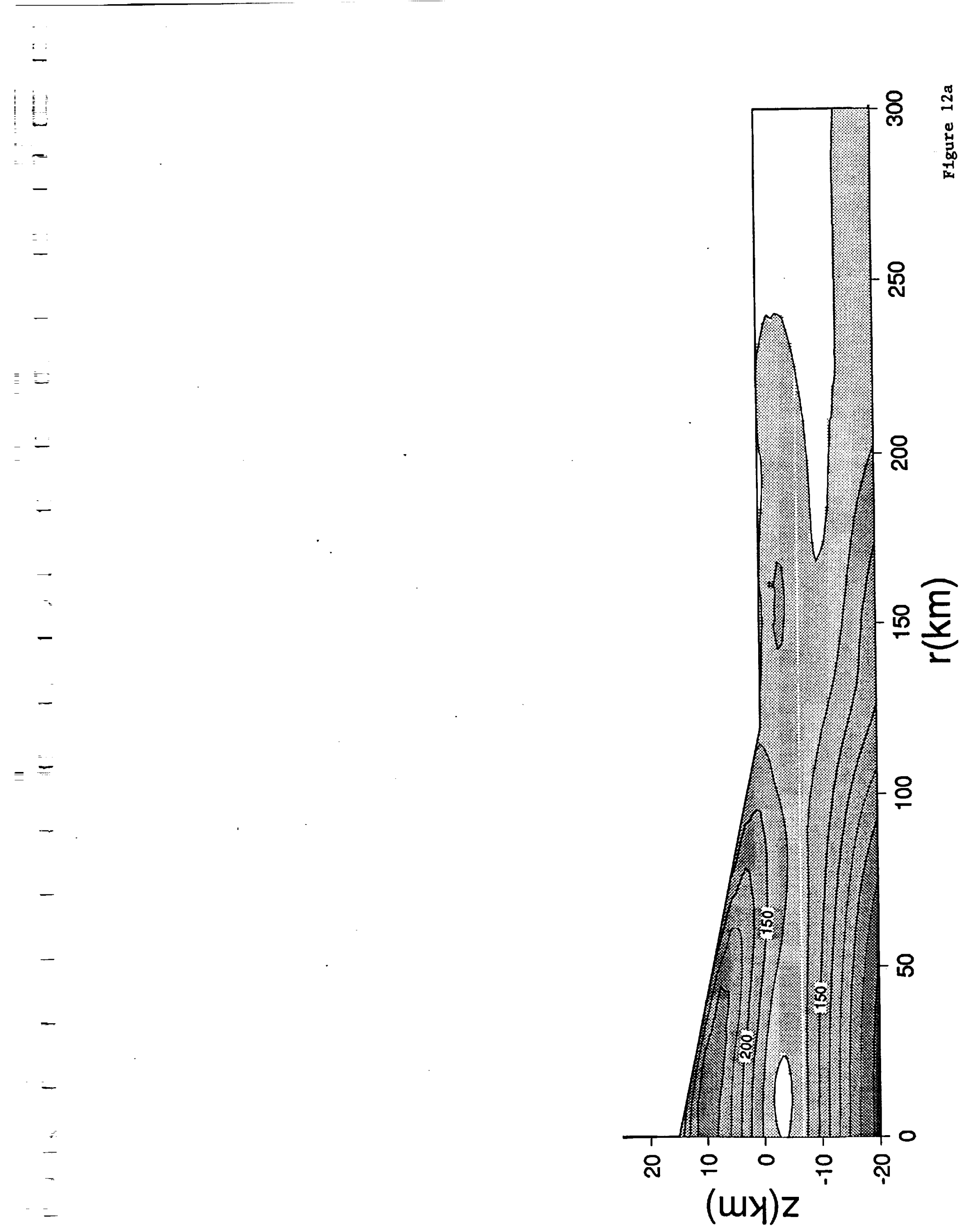




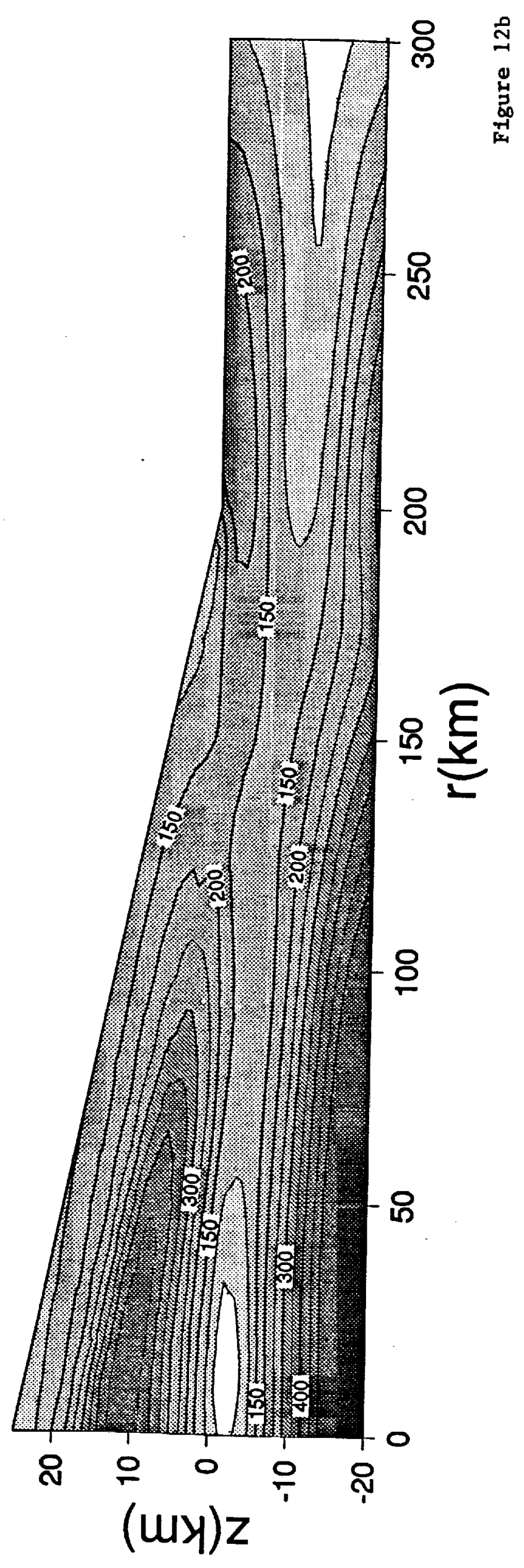




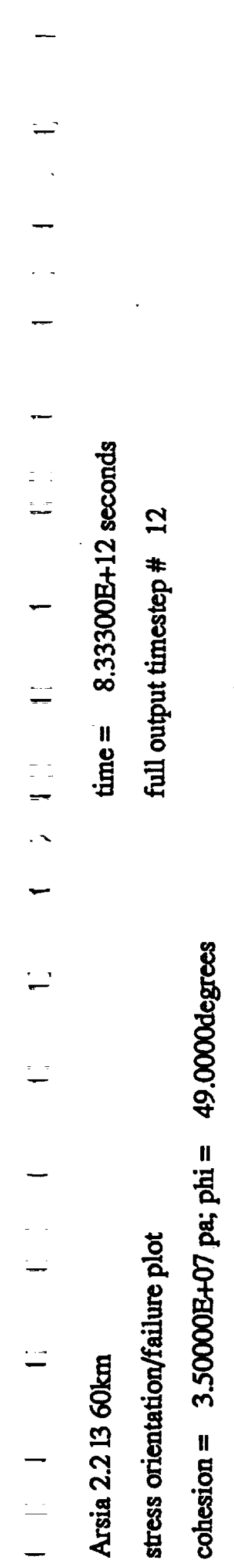

\begin{tabular}{|c|c|c|c|c|c|c|c|c|c|}
\hline 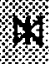 & 16 & W & $W$ & $W$ & $W$ & 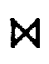 & $\bowtie$ & $\bowtie$ & $\bowtie$ \\
\hline 8 & 4 & W & $N$ & W & $W$ & 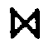 & $\bowtie$ & $\bowtie$ & $凶$ \\
\hline 滀 & 4 & $W$ & $W$ & $W$ & $W$ & $\Delta$ & $\bowtie$ & $\bowtie$ & $\bowtie$ \\
\hline 绽 & 6 & $W$ & 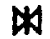 & $w$ & 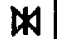 & $\Delta$ & $\bowtie$ & $\triangle$ & 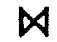 \\
\hline
\end{tabular}

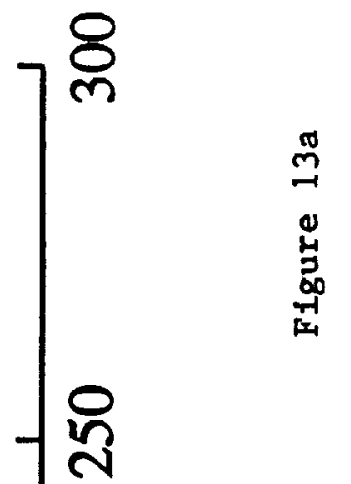

\begin{tabular}{|c|c|c|c|c|c|c|c|c|c|}
\hline 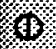 & 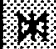 & $w$ & $M$ & $w$ & $w$ & $\bowtie$ & $\Delta$ & $\bowtie$ & $\Delta$ \\
\hline (1) & $W$ & $W$ & $\dot{D}$ & $W$ & $W$ & $\Delta$ & $\Delta$ & $\bowtie$ & $\Delta$ \\
\hline
\end{tabular}

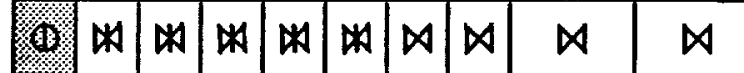

\begin{tabular}{|c|c|c|c|c|c|c|c|c|}
\hline 6 & $W$ & W & $w$ & W & $W$ & $\bowtie$ & $D$ & \\
\hline
\end{tabular}

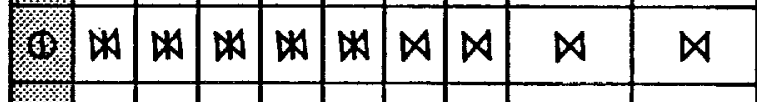

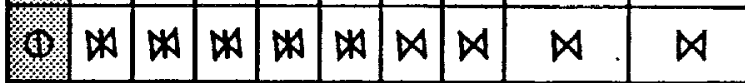

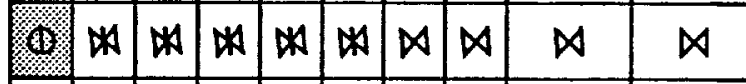

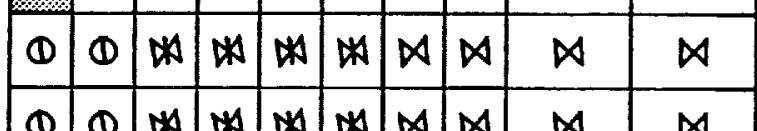

\begin{tabular}{|c|c|c|c|c|c|c|c|c|c|}
\hline & (1) & $\mathbb{N}$ & $W$ & $W$ & $N$ & $\bowtie$ & $\bowtie$ & $\bowtie$ & $\bowtie$ \\
\hline & 0 & $W$ & $W$ & $W$ & $W$ & 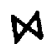 & $\bowtie$ & $\bowtie$ & $D$ \\
\hline
\end{tabular}

\begin{tabular}{|c|c|c|c|c|c|c|c|c|c|}
\hline & 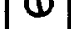 & W & 1 & $\mathbb{N}$ & W & W & 8 & $凶$ & \ \\
\hline$\theta$ & 0 & 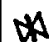 & 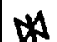 & $1 *$ & $N$ & $\Delta$ & 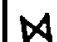 & 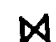 & $凶$ \\
\hline
\end{tabular}

\begin{tabular}{|c|c|c|c|c|c|c|c|c|c|}
\hline$\theta$ & 10 & $M$ & $\$$ & $W$ & W & 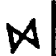 & $\bowtie$ & $\bowtie$ & $\bowtie$ \\
\hline$A$ & $\theta$ & 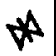 & $M$ & $M$ & $W$ & $M$ & 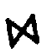 & $\Delta$ & 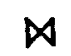 \\
\hline
\end{tabular}

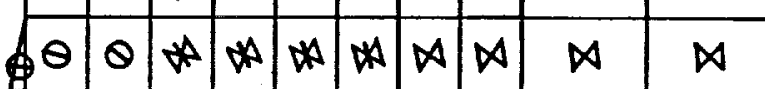

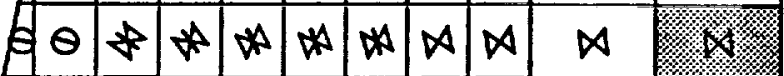

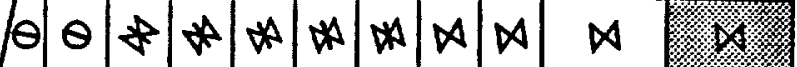

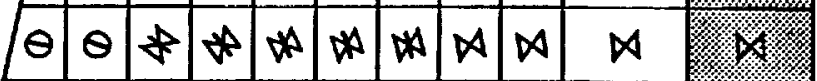

\begin{tabular}{llllllllll}
\hline$\theta_{\phi} \&$ & $*$ & $A$ & $M$ & $M$ & $M$ & $M$ & $A$ & $M$ & $M$
\end{tabular}

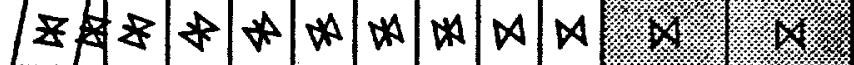

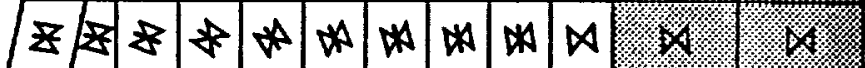

Z古古

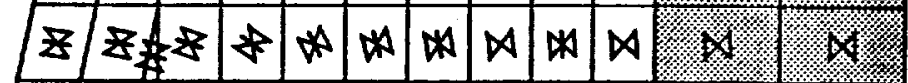

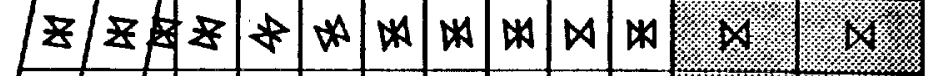

\begin{tabular}{l}
\hline \\
\hline
\end{tabular}

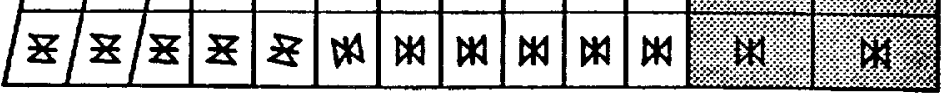

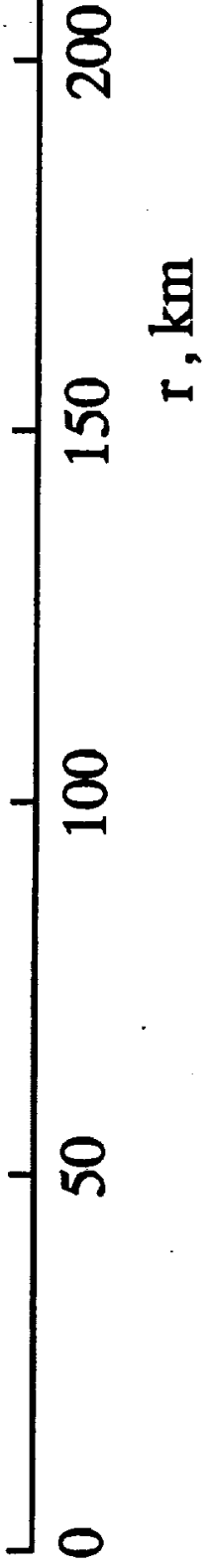




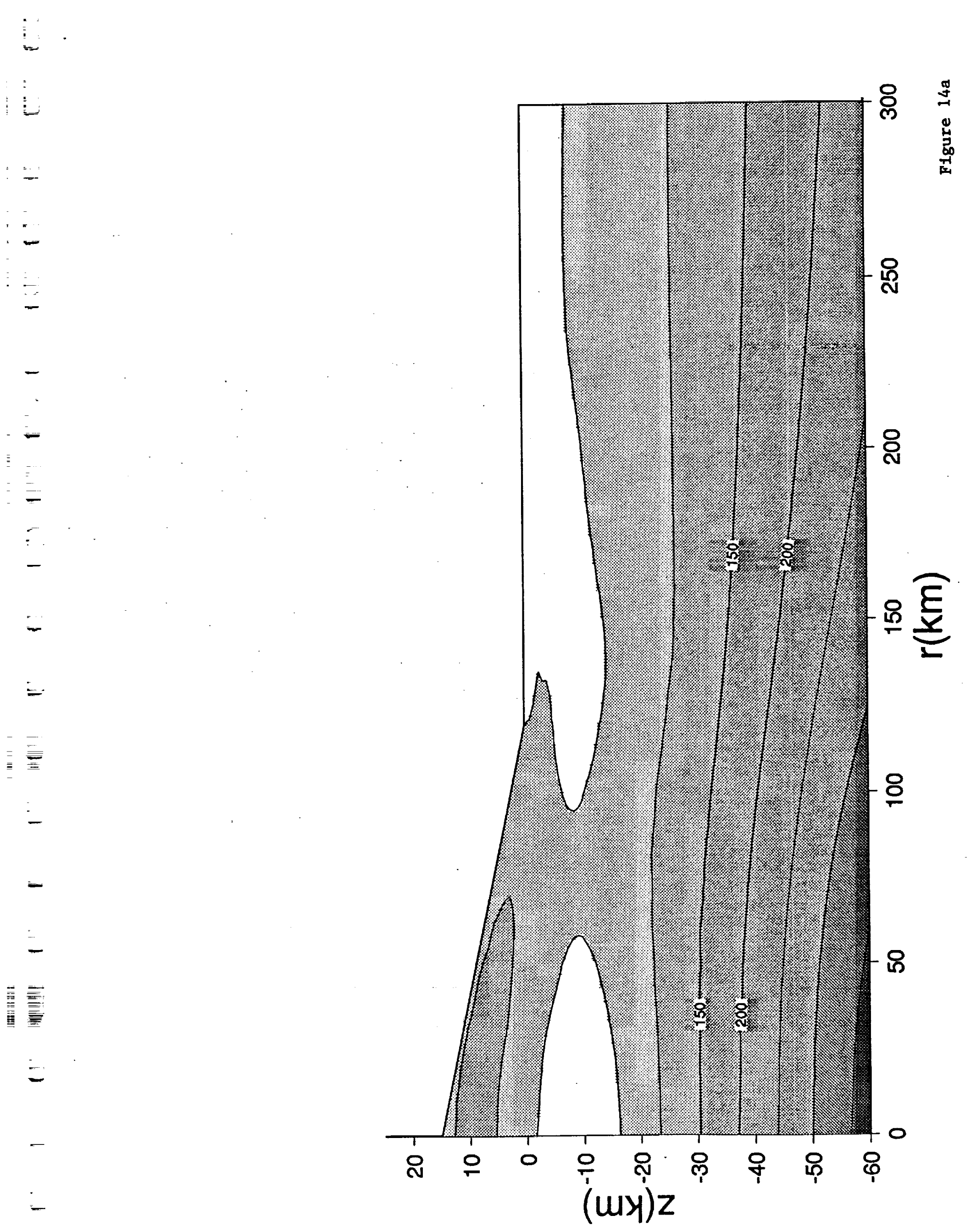




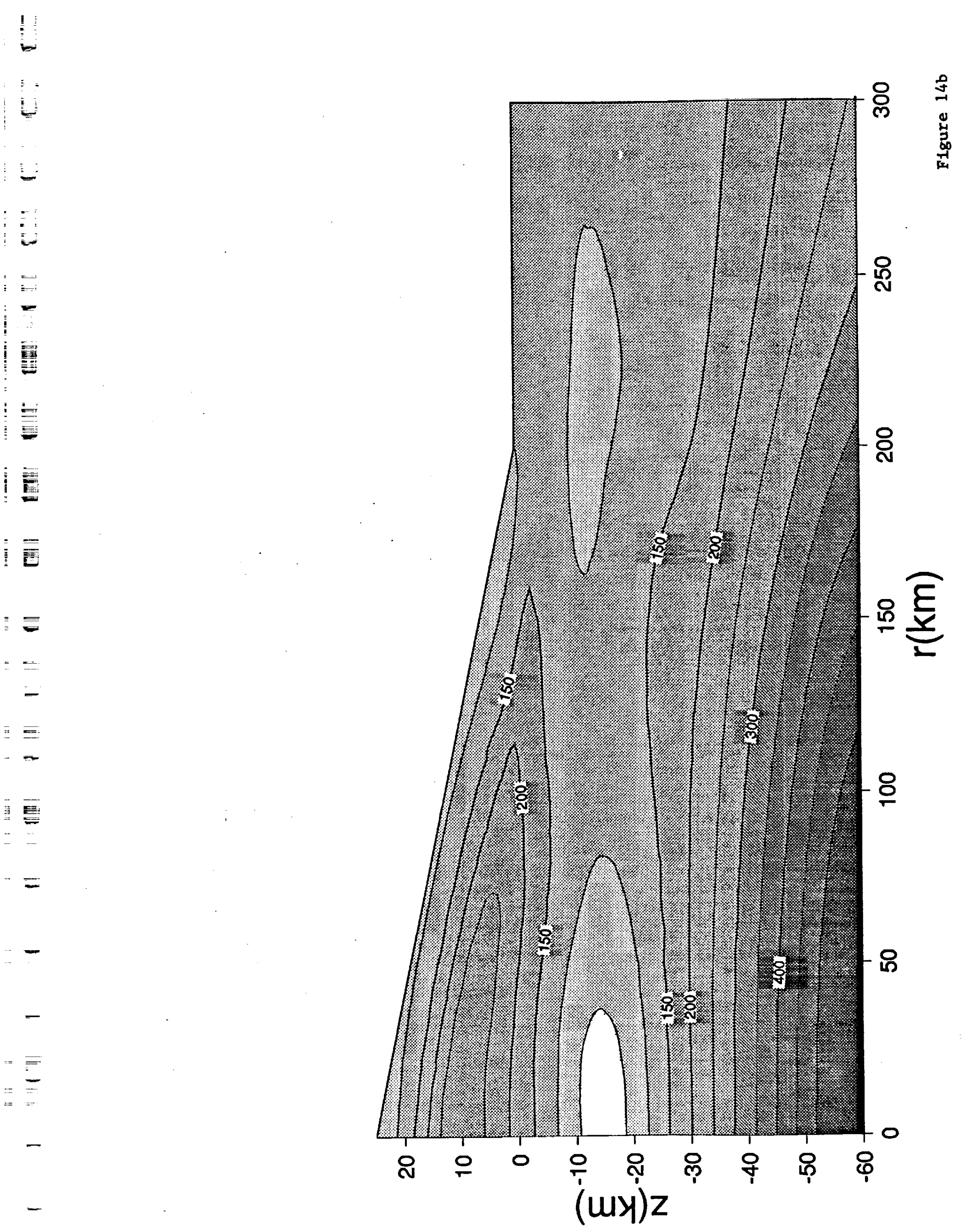




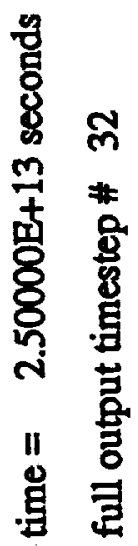

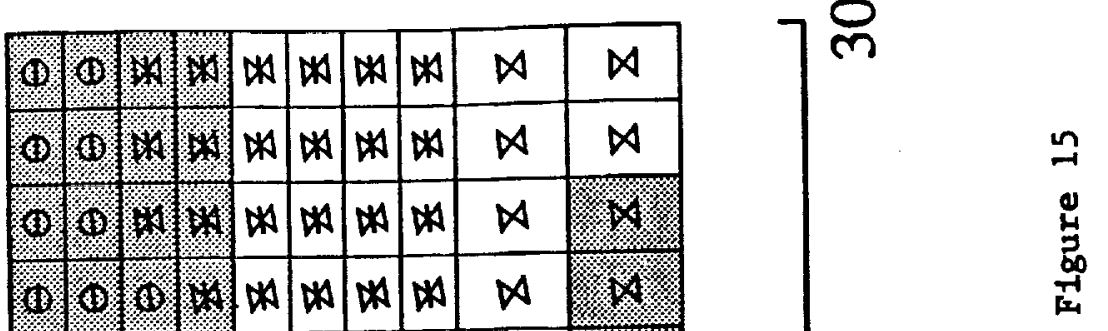

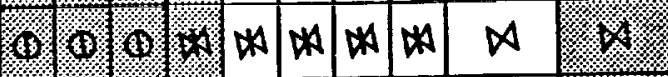

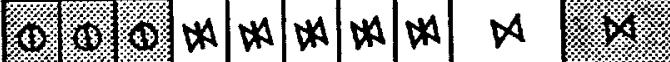

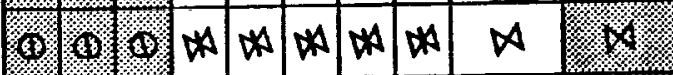

$00001 \%$ N

$-1$

$00000 \%$ O

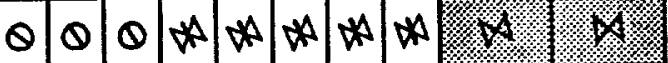

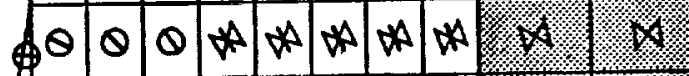

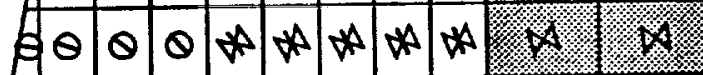

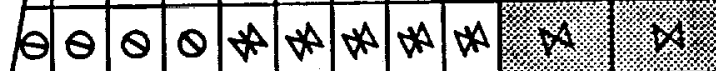

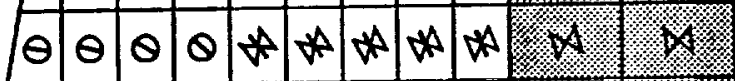

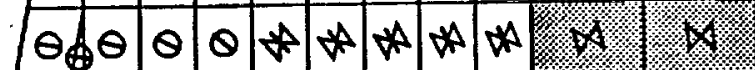

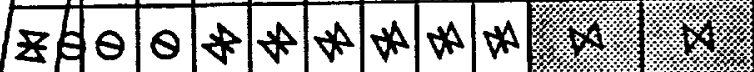

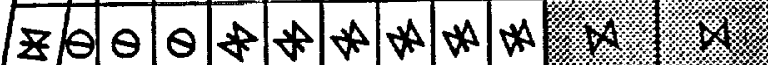

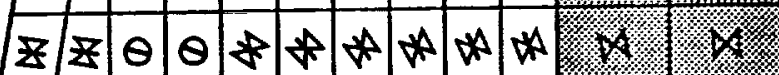

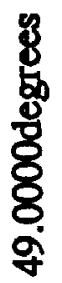

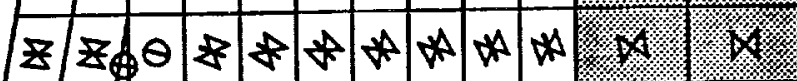

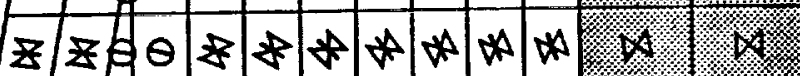

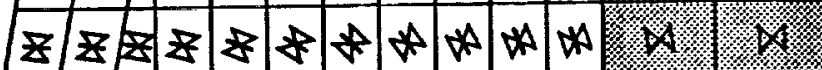

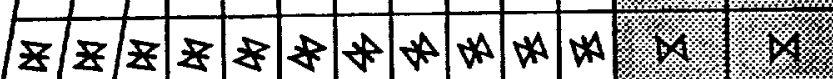

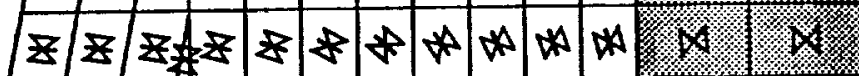

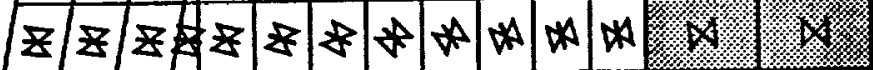

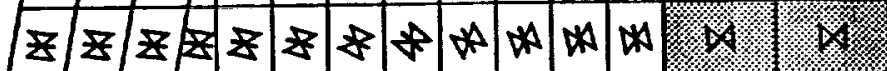

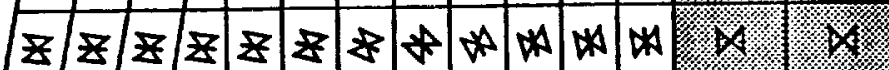

Z

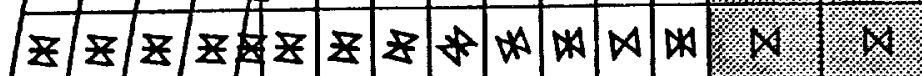

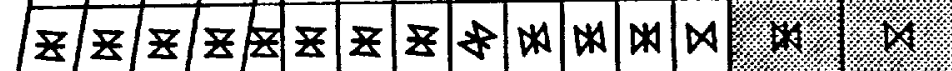

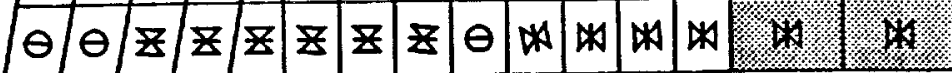




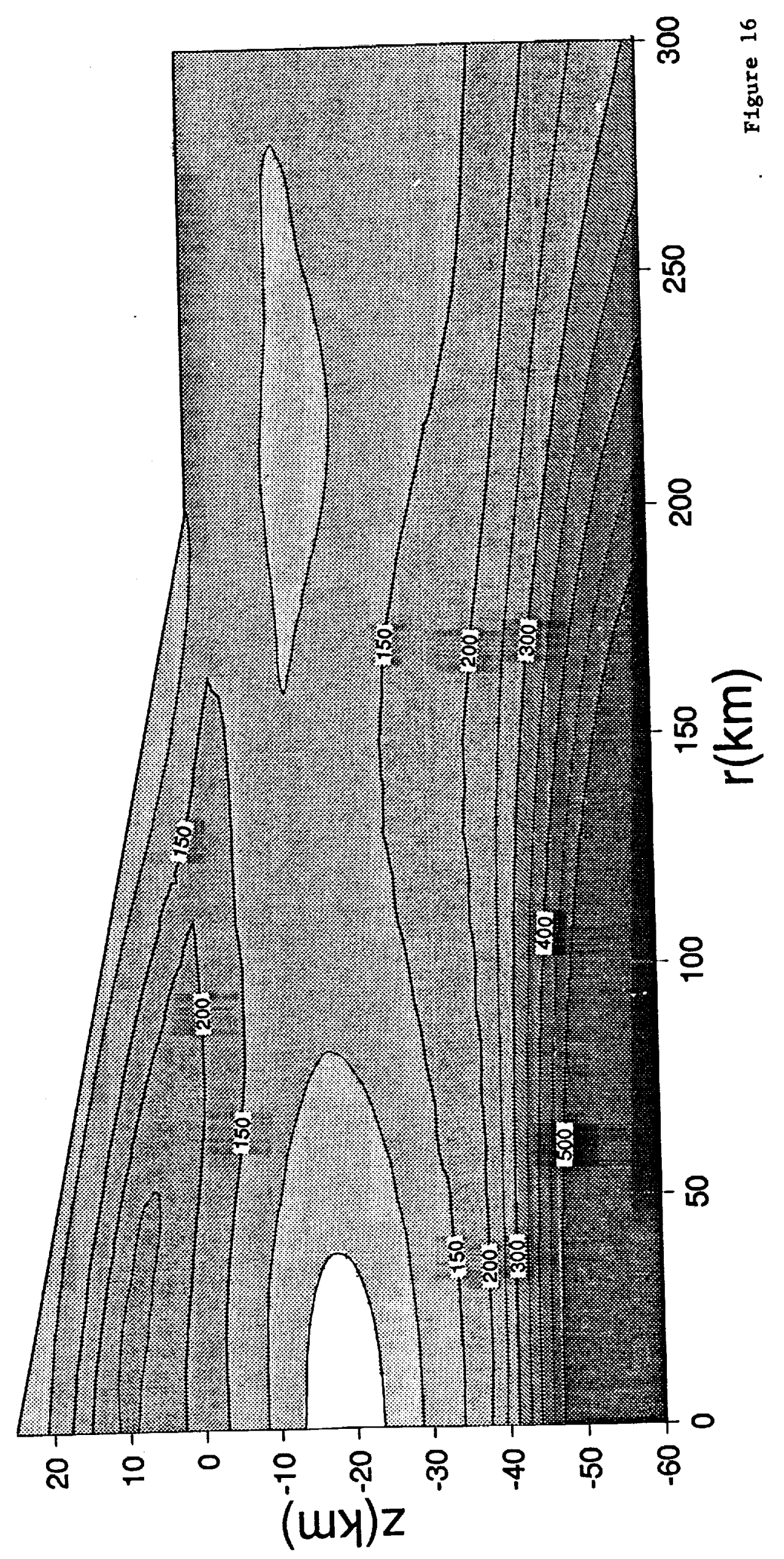




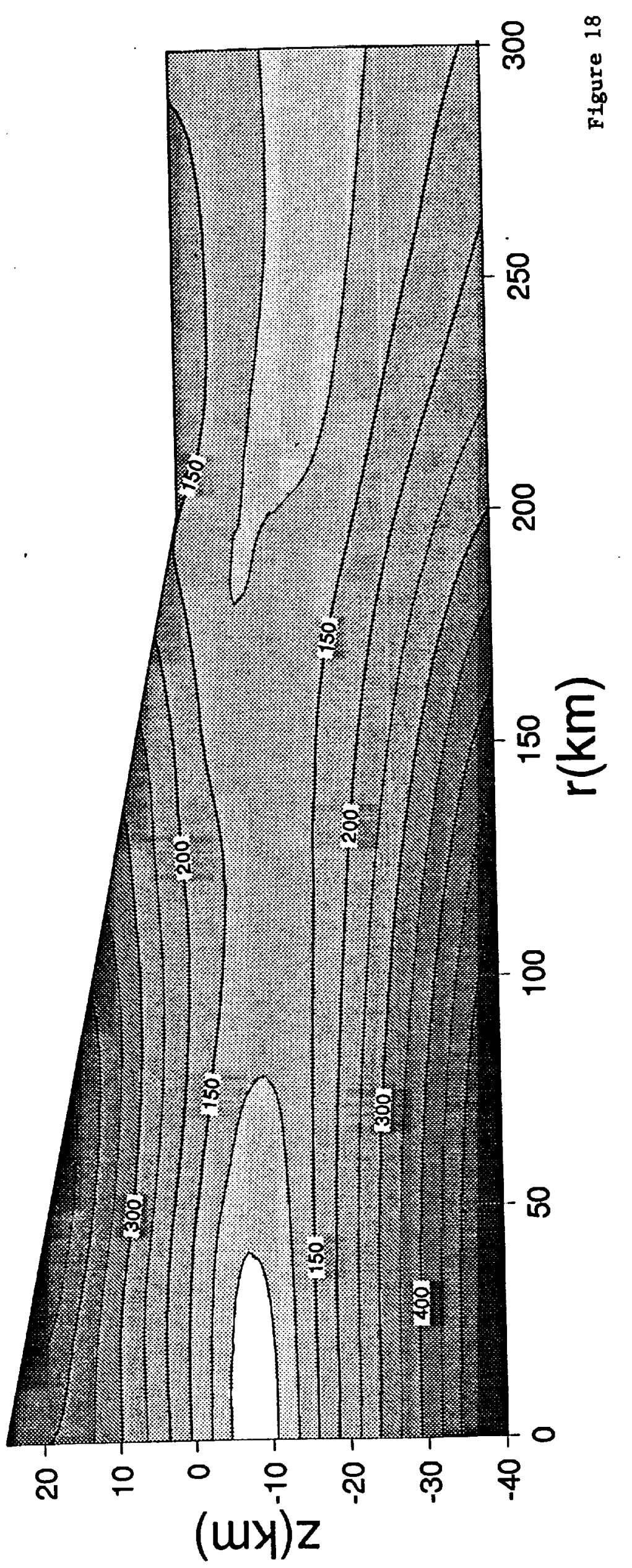




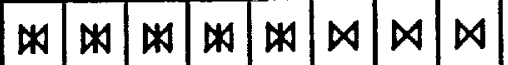

$M$ 州

州

为

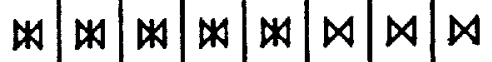

次

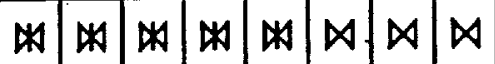

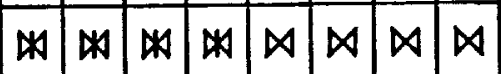

W $\bowtie \bowtie \bowtie$

州

州

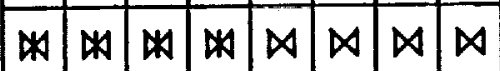

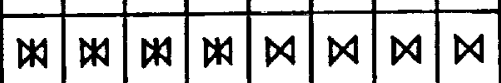
W $\backsim \bowtie \bowtie \bowtie$

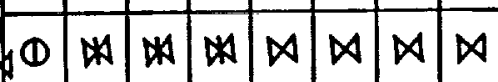

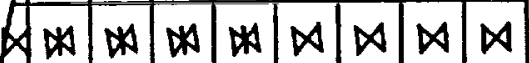

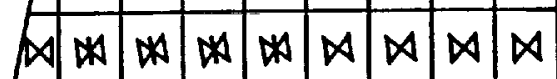

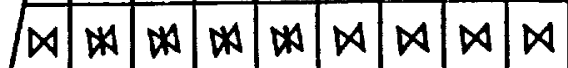

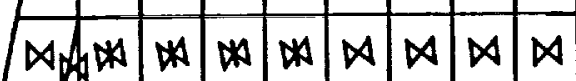

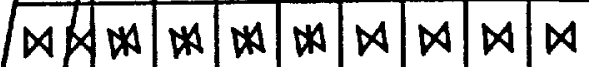

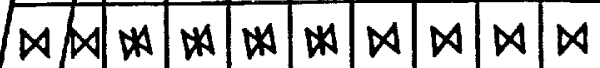

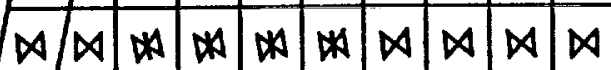

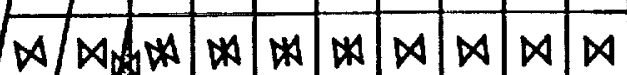

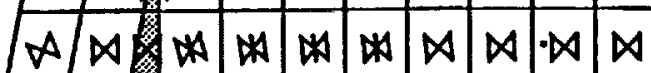

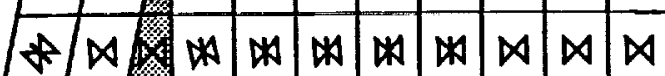

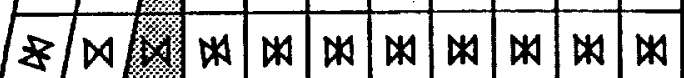
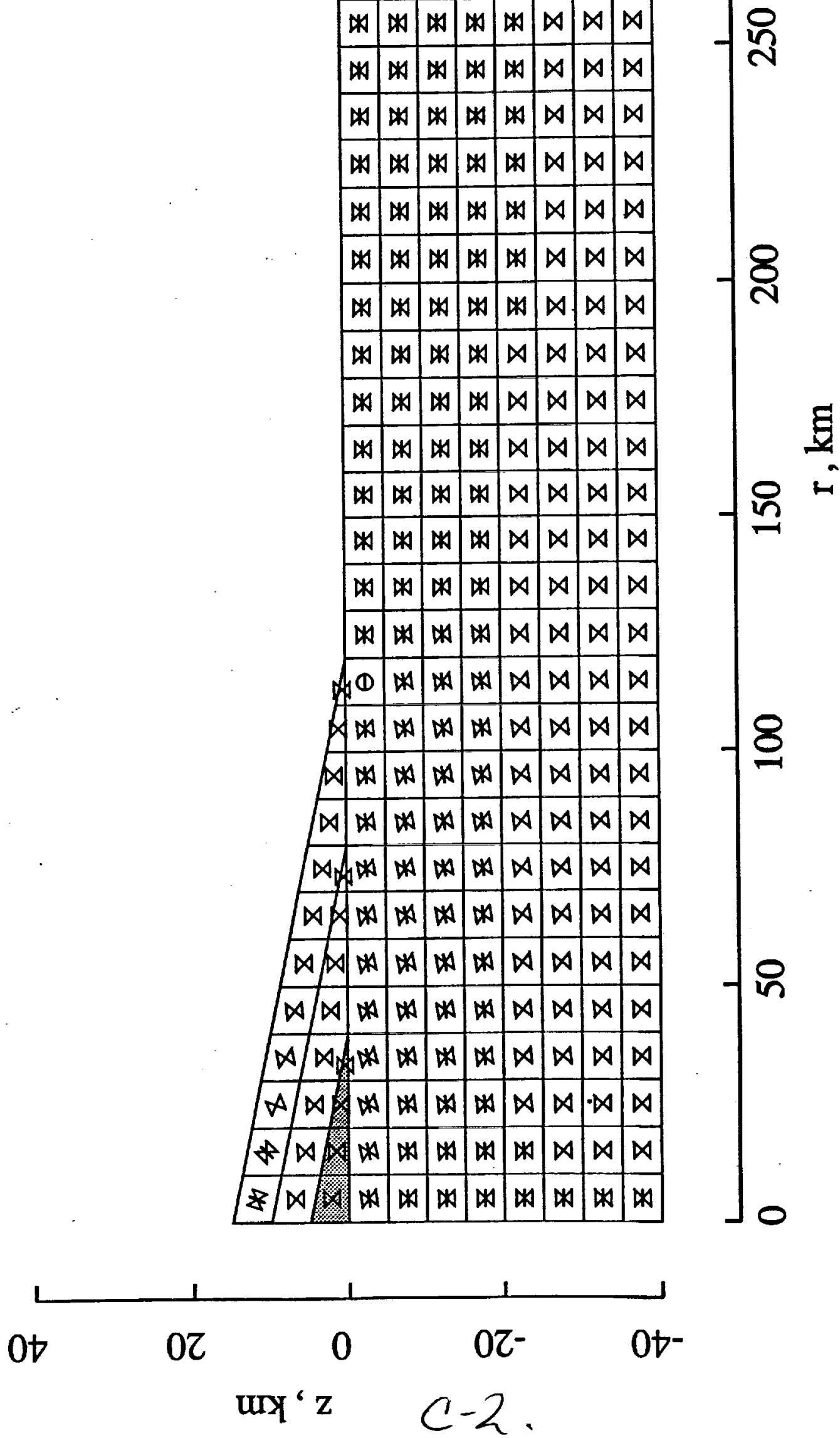


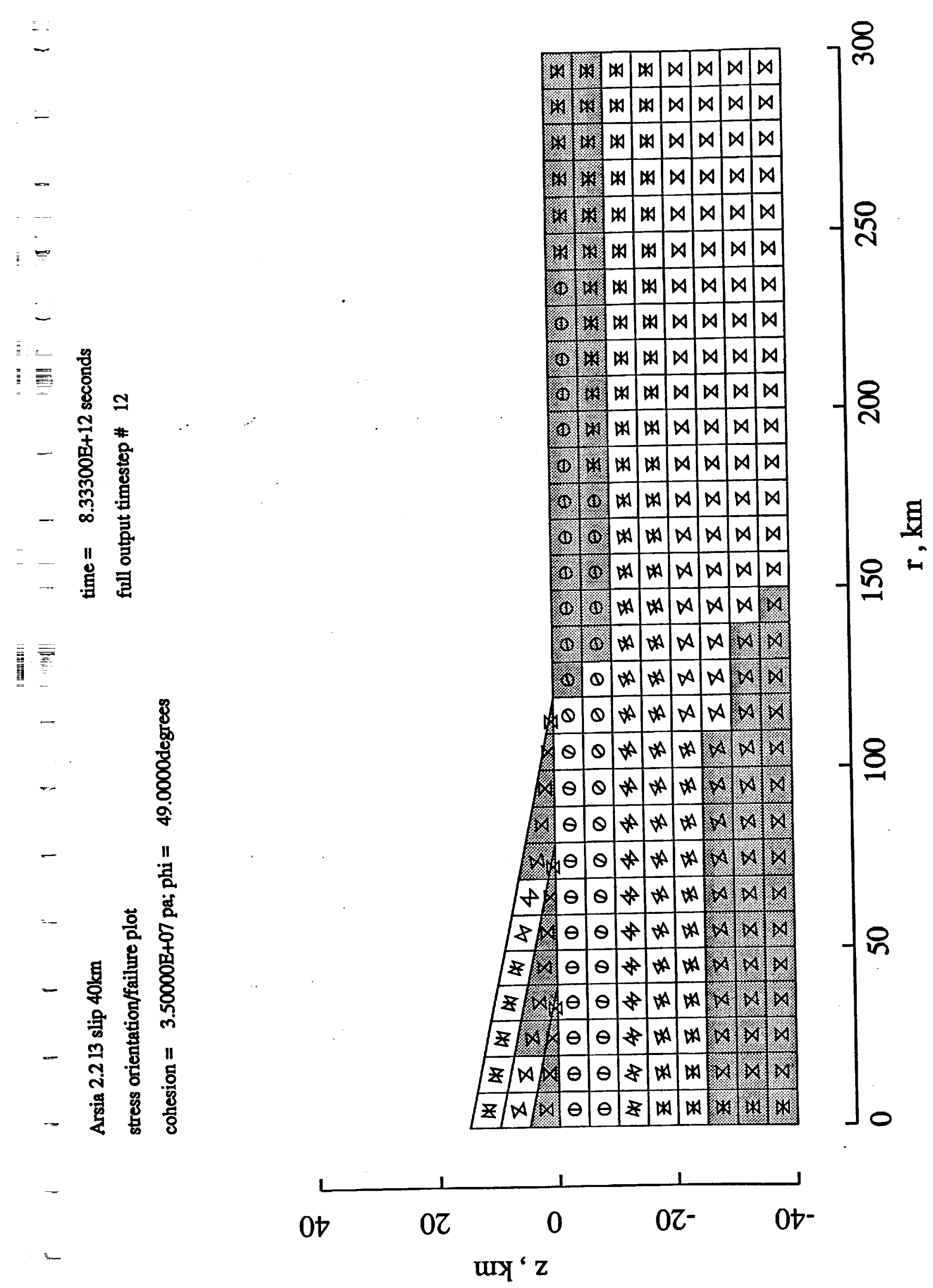





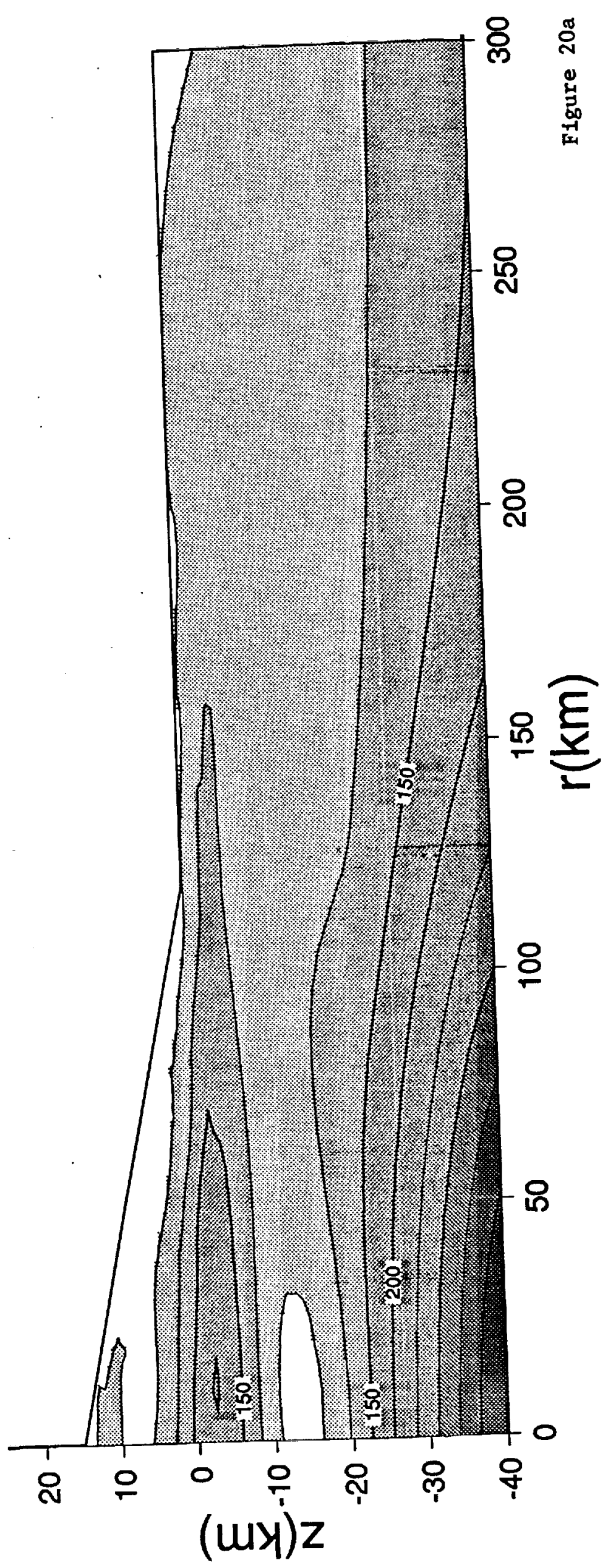




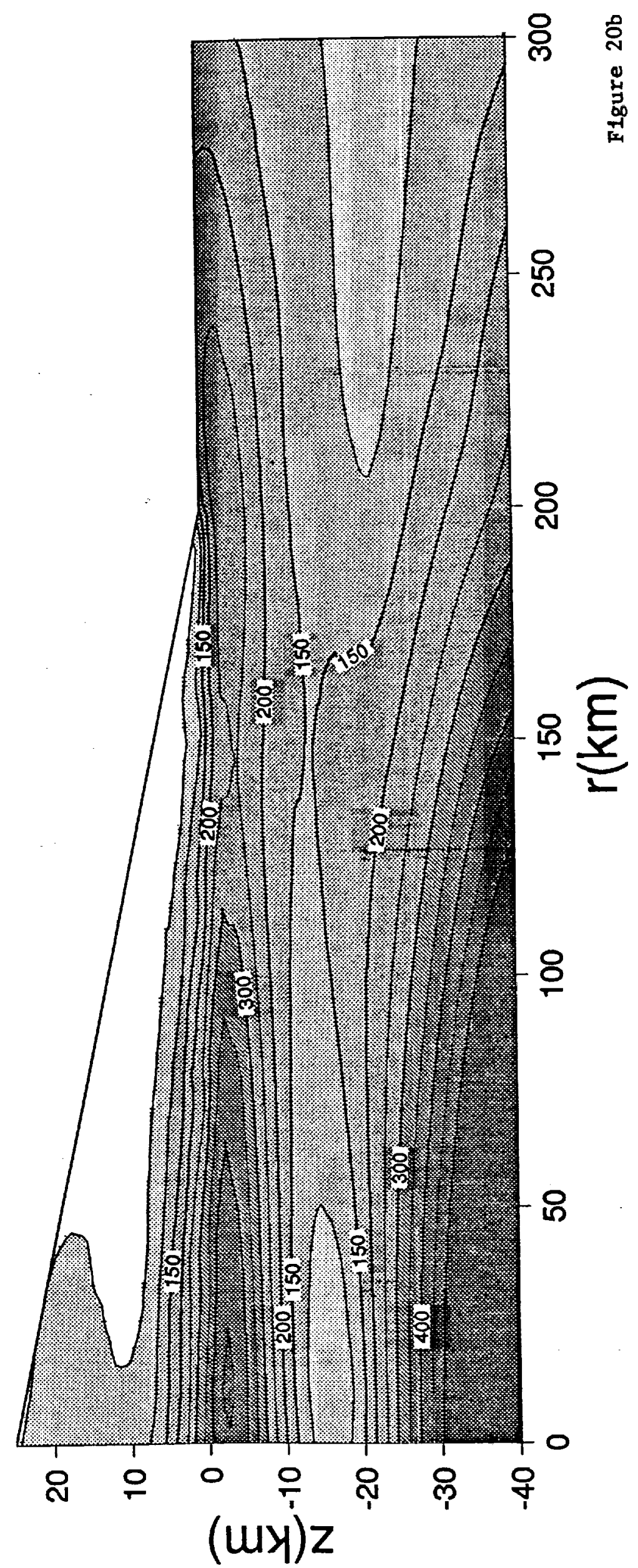




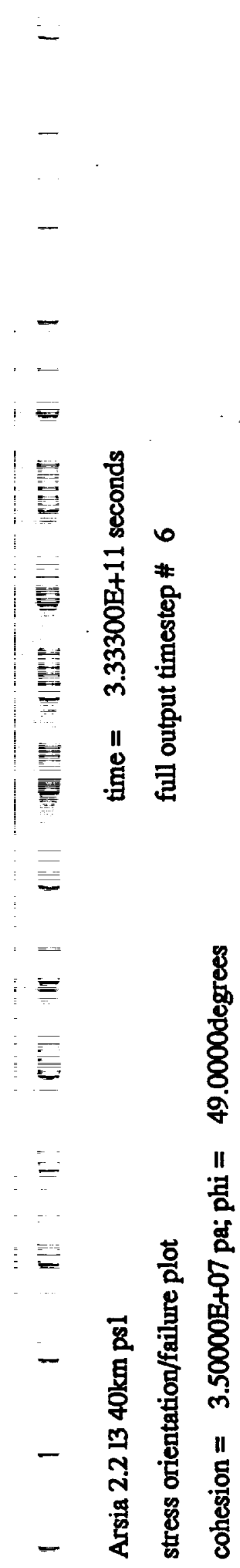

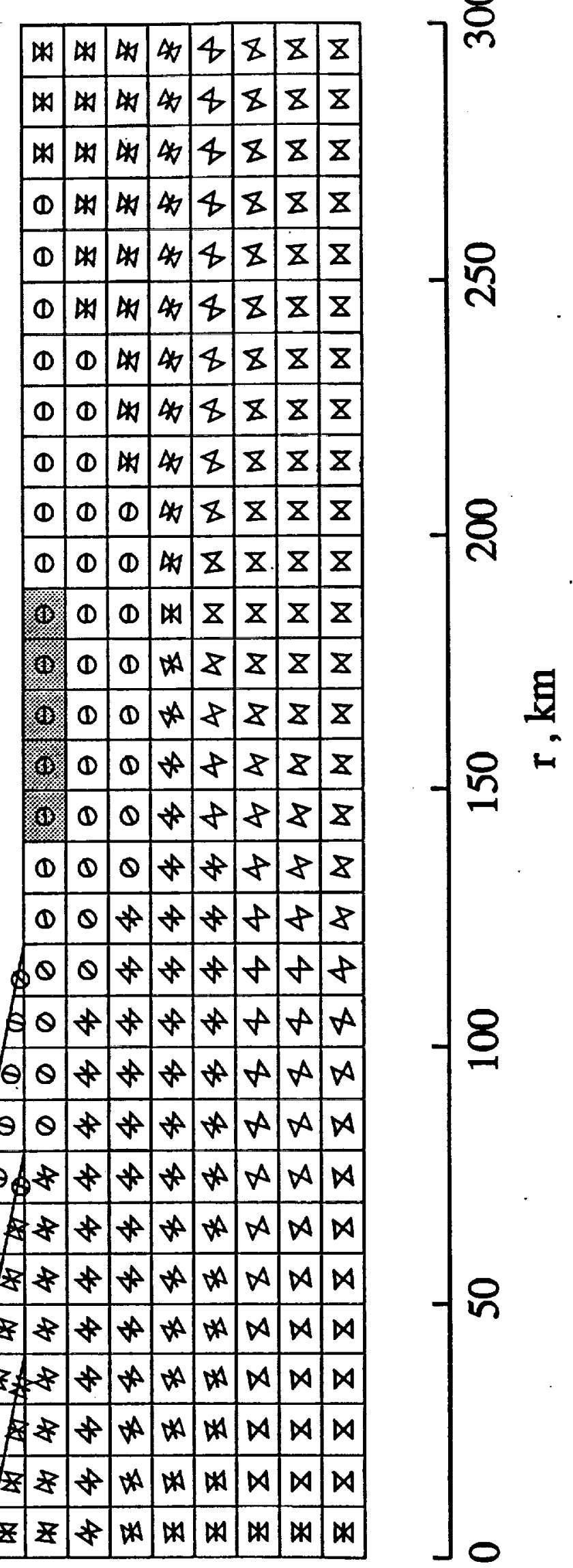

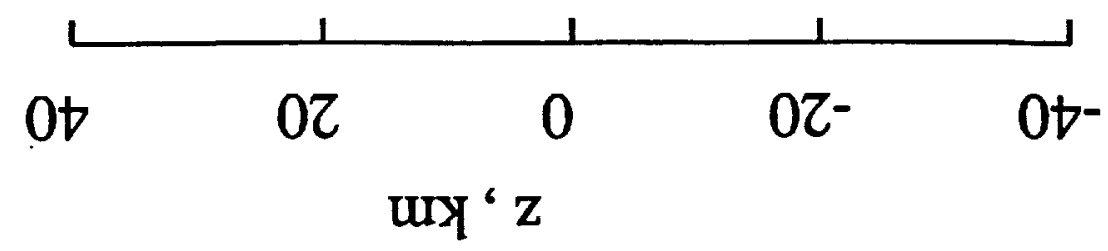




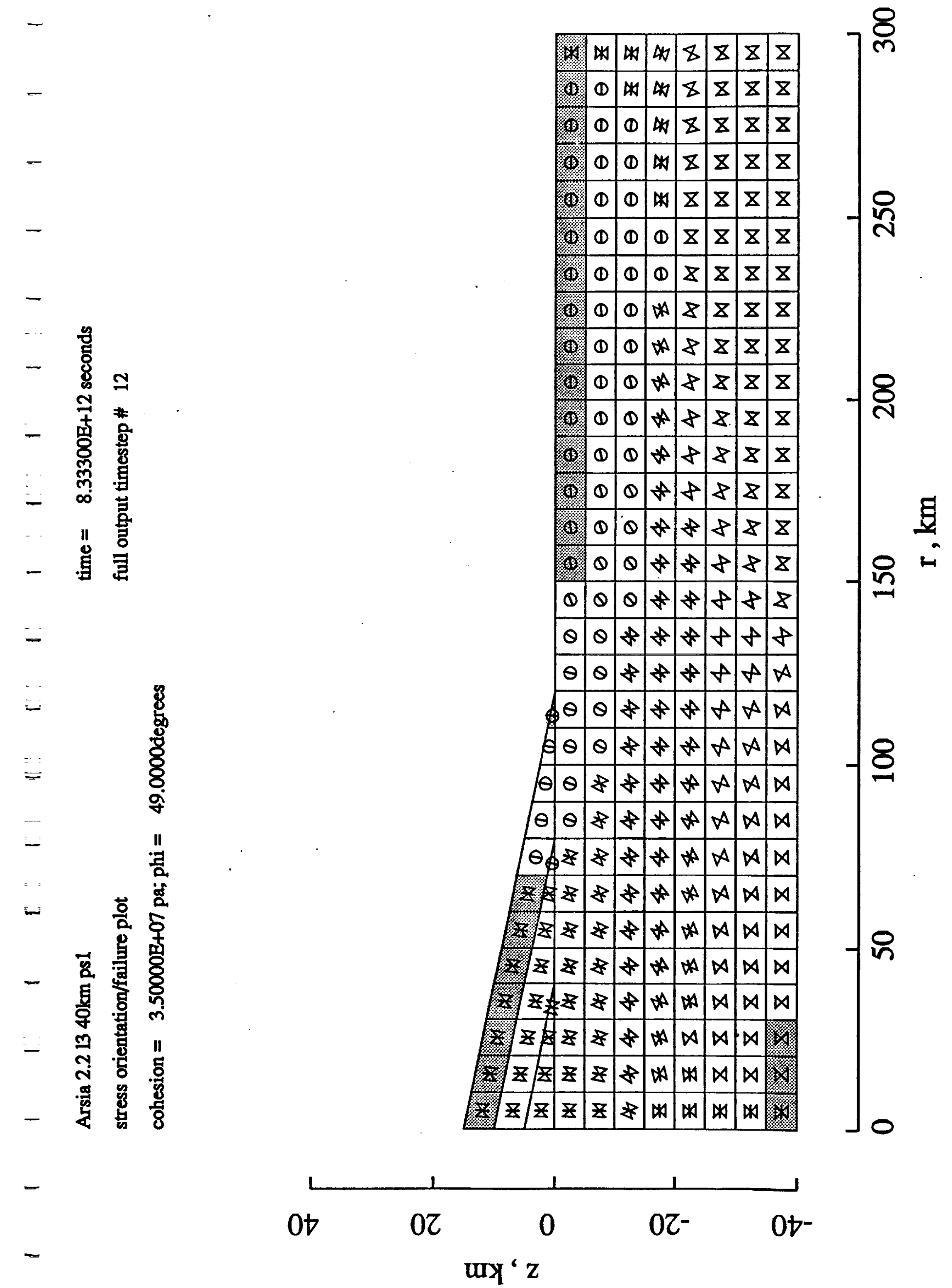




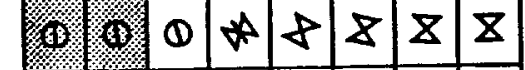




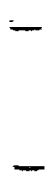

$-$

-

二

$-$

-

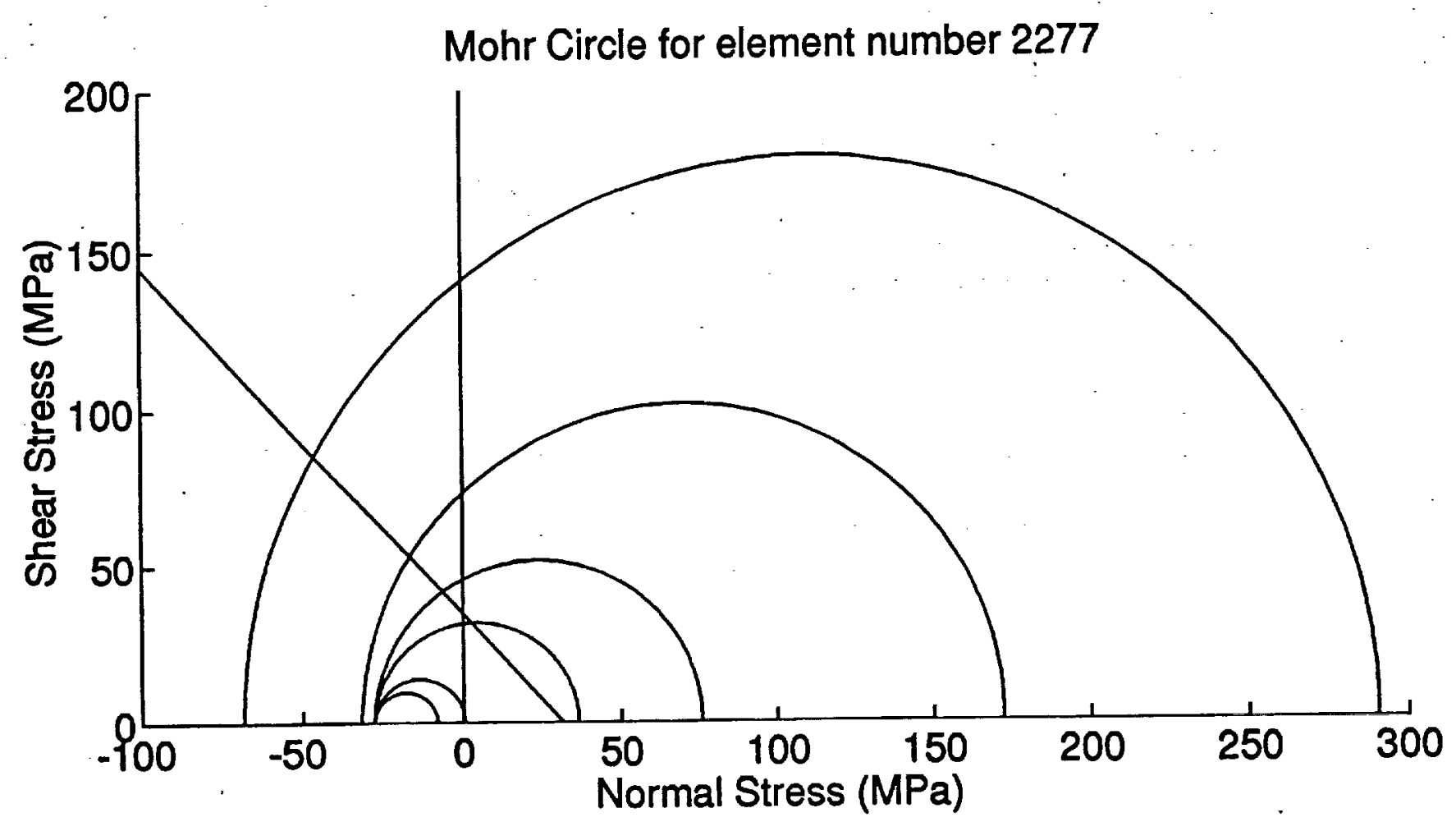




\section{Features on Venus Generated by Plate Boundary Processes}

Dan McKenzie (Bullard Laboratories, Madingley Road, Cambridge, CB3 0EZ, U.K.; ph. 44-223-337177; fax. 44-223-60779; e-mail dpm1@phx.cam.ac.uk); Peter G. Ford (Center for Space Research, MIT, Cambridge, MA 02139); Catherine Johnson and David Sandwell (Scripps Institution of Oceanography, La Jolla, CA 92093); Barry Parsons (Department of Earth Sciences, Oxford University, Oxford OXI 3PR, U.K.); Stephen Saunders (Jet Propulsion Laboratory, 4800 Oak Grove Drive, Pasadena, CA 91109); Sean C. Solomon (Dept. of Earth, Atmospheric and Planetary Sciences, MIT, Cambridge, MA 02139)

SAR images of Venus, taken with a radar whose wavelength is 12.6 $\mathrm{cm}$, are compared with GLORIA images of active plate boundaries, obtained with a sound source whose wavelength is $23 \mathrm{~cm}$. Features similar to transform faults and to abyssal hills on slow and fast spreading ridges can be recognized within the Artemis region of Venus, but are not clearly visible elsewhere. The composition of the basalts measured by the Venera 13 and 14 and the Vega 2 spacecraft corresponds to that expected from adiabatic decompression, like that which occurs beneath spreading ridges on the Earth. Structures that resemble trenches are widespread on Venus, and show the same curvature and asymmetry as they do on Earth. These observations suggest that the same simple geophysical models that have been so successfully used to understand the tectonics of the Earth can also be applied to Venus. 
THE GABBRO - ECLOGITE pHASE tRANSITION AND THE ELEVATION OF MOUNTAIN BELTS ON VENUS; Noriyuki Namiki and Sean C. Solomon, Department of Earth, Atmospheric, and Planetary Sciences, Massachusetts Institute of Technology, Cambridge, MA 02139.

Introduction. The linear mountain belts of Ishtar Terra on Venus are notable for their topographic relief and slope and for the intensity of surface deformation $[1,2]$. The mountains surround the highland plain Lakshmi Planum. Volcanism is rare to absent in Maxwell, Freyja, and Akna Montes, but a number of magmatic features are evident in Danu Montes [2,3], the mountain range least elevated above Lakshmi Planum. Whether western Ishtar Terra is a site of mantle upwelling and consequent hot spot volcanism [4-6] or of mantle downwelling and consequent convergence of lithospheric blocks $[7,8]$ is currently a matter of debate. However, the mountains are generally regarded as products of large-scale compression of the crust and lithosphere [2,9].

Among the four mountain belts surrounding Lakshmi Planum, Maxwell Montes is the highest and stands up to $11 \mathrm{~km}$ above the mean planetary radius and $7 \mathrm{~km}$ above Lakshmi Planum. The bulk composition and radioactive heat production of the crust on Venus, where measured, are similar to those of terrestrial tholeiitic basalt [10]. Because the thickness of the low-density crust may be limited by the gabbro-gamet granulite - eclogite phase transitions (Fig. 1), the $7-11 \mathrm{~km}$ maximum elevation of Maxwell Montes is difficult to understand except in the unlikely situation that the crust contains a large volume of magma [11]. A possible explanation is that the base of the crust is not in phase equilibrium. It has been suggested that under completely dry conditions, the gabbro - eclogite phase transition takes place by solid state diffusion and may require a geologically significant time to run to completion [12]. Solid state diffusion is a strongly temperature-dependent process. In this paper we solve the thermal evolution of the mountain belt to attempt to constrain the depth of the gabbro - eclogite transition and thus to assess this hypothesis quantitatively.

Thermal Model. The one-dimensional heat equation is solved numerically by a finite difference approximation. The deformation of the horizontally shortening crustal and mantle portions of the thermal boundary layer is assumed to occur by pure shear, and therefore the vertical velocity is given by the product of the horizontal strain rate $\gamma$ and depth $z$. The thermal diffusivity is assumed to be $1.0 \times 10^{-6} \mathrm{~m}^{2} \mathrm{~s}^{-1}$ in both crust and mantle. Crustal heat production is assumed to equal $1.4 \times 10^{-}$ ${ }_{13} \mathrm{~K} \mathrm{~s}^{-1}$. The initial temperature profile is determined by the assumption of steady-state conditions with zero velocity. Temperature at the surface and the bottom of the thermal boundary layer are fixed at $750 \mathrm{~K}$ and at a value $T_{b l}$ taken as free parameter.

The phase diagram is assumed to be that of tholeiitic basalt [13], and the densities of gabbro and eclogite are taken to be 2900 and $3500 \mathrm{~kg} \mathrm{~m}^{-3}$. The density of garnet-granulite is assumed to increase linearly from that of gabbro to that of eclogite as pressure increases at a given temperature. The density of the mantle is assumed to be $3400 \mathrm{~kg} \mathrm{~m}^{-3}$. The micromechanism of the gabbro eclogite transition is not well understood. In this study we assume that the volume diffusion of cations is the most likely rate-limiting process of the transformation, which involves chemical as well as phase changes. The volume fraction of reacted component, $\psi$, is given by,

$$
\dot{\psi} \psi=\mathrm{D} / \mathrm{r}^{2}
$$

where $r$ is the grain radius and $D$ is the diffusion coefficient [12]. Since the slowest-moving cation limits the reaction rate and $\mathrm{Al}^{3+}$ is likely to be this cation, we adopt as a minimum value for $\mathrm{D}$ the lower end of the range of estimates of the diffusion rate of $A 1^{3+}$ in orthopyroxene [14]:

$$
D=D_{A 1}, O_{p x}=1.1 \times 10^{-5} \exp (-400 \mathrm{~kJ} / \mathrm{RT})
$$

where $R$ is the gas constant and $T$ is the absolute temperature. The diffusion rate, however, is experimentally uncertain because $\mathrm{Al}^{3+}$ diffusion is extremely sluggish, particularly at low temperature. In order to bound $\mathrm{D}$ from above, we use the diffusion rate of $\mathrm{Fe}$ in gamet $\left(\mathrm{D}_{\mathrm{Fe}}, \mathrm{Gl}=\right.$ $\left.6.4 \times 10^{-8} \exp \left[-\left(270 \mathrm{~kJ}+5.7 \times 10^{-5} \mathrm{P}\right) / \mathrm{RT}\right]\right)$, where $\mathrm{P}$ is in $\mathrm{Pa}$. For each parcel of shortening lithosphere, $\psi$ is obtained by integration over time. The density at a given depth is determined from the volume fractions of unreacted and reacted components.

Numerical Results. Temperatures in the thickening crust and mantle are calculated for rates of 
horizontal convergence of $10^{-15}$ (Fig. 1a) and $10^{-16} \mathrm{~s}^{-1}$ (Fig. 1b). For all models discussed here (Table 1), thicknesses of crust and thermal boundary layer are assumed to be initially 20 and 50 $\mathrm{km}$, respectively, and to increase to 100 and $250 \mathrm{~km}$, respectively. Temperature profiles for the strain rate of $10^{-15} \mathrm{~s}^{-1}$ are vertically stretched as the crust and lithospheric mantle are thickened (Fig. 1a). Temperatures do not increase significantly from initial values because heat is mainly transferred by advection and the contribution of crustal heat production is minor. Hence gabbro remains metastable for $50 \mathrm{My}$ or more, and the elevation of shortened lithosphere can increase as much as $12 \mathrm{~km}$ above the surrounding plains in that time interval (Fig. 2a). The phase transition proceeds, i.e., elevation is limited, only if grains are small and diffusion is fast (Model 3).

For $\ddot{y}=10^{-16} \mathrm{~s}^{-1}$, crustal heat production dominates advective heat transfer after the crust becomes as thick as $60-80 \mathrm{~km}$ (Fig. 1b). The resulting increase in temperature hastens the phase transition. The slower strain rate also lengthens the formation time of the mountains relative to the characteristic reaction time, which depends on $r, D$, and temperature at the base of the crust. For larger grains $(r=10 \mathrm{~mm})$, the elevation reaches $11 \mathrm{~km}$ or more if the initial temperature at the base of the crust, $T_{c}$, is $1150 \mathrm{~K}$ (Model 6 in Fig. 2b). For the same value of $T_{c}$ the elevation is at most 6 $\mathrm{km}$ for grains of $1 \mathrm{~mm}$ radius (Model 7). This result constitutes an upper bound on $T_{c}$ for small grain size. If $\mathrm{D}=\mathrm{D}_{\mathrm{Fe}, \mathrm{Gt}}$ is assumed, that upper bound is lowered to $1050 \mathrm{~K}$ (Model 8).

Discussion. Because at long wavelengths the topography of western Ishtar Terra is correlated with the gravity field, dynamical support of the broad 4-km elevation of the region is likely [e.g., 15]. Therefore the 7-km elevation of Maxwell Montes above the adjacent plateau is a more meaningful constraint on maximum relief than the $11-\mathrm{km}$ elevation above mean planetary radius. The results are insensitive to the assumed initial thickness of crust but are sensitive to the density difference between crust and mantle. If densities of 3000 and $3300 \mathrm{~kg} \mathrm{~m}^{-3}$ for crust and mantle are assumed, elevations are $\sim 40 \%$ lower than the values presented here. Such changes constrain the models of thermal structure and phase transition depth more severely at low strain rate than the density values adopted above.

Two diffusion rates have been assumed in this study so as to represent a wide range of diffusion data. We should note, however, that under wet conditions, i.e., in the presence of either water [16] or melt [17], grain-boundary diffusion becomes much more efficient than volume diffusion. This is potentially noteworthy for understanding the contrast between Maxwell and Danu Montes. Despite the fact that Danu Montes display compressional deformation as extensive as the other mountain belts, the maximum elevation is as little as $0 \mathrm{~km}$ above the bounding plateau. Such comparatively modest elevation may be related to the presence of magmatic features within Danu Montes, if elevation is limited by an enhanced diffusion rate because of the melt at grain boundaries. Assessing the cause of higher temperatures beneath Danu Montes requires more detailed thermal models than the simple one-dimensional model considered here.

Conclusions. Taking into account the temperature-dependent reaction rate of the gabbro eclogite phase transition, horizontal strain rates of $10^{-15}$ and $10^{-16}$ result in significant differences in the of maximum elevation of mountains, not only because of the difference in the formation time for relief, but also because of the difference in the thermal regime from advection-dominanted to crustal-heat-production dominated. For $\gamma=10^{-15} \mathrm{~s}^{-1}$, the observed maximum elevation of mountain belts can be explained as a consequence of disequilibrium phase boundary depth for a wide range of physical parameters, although a comparatively young age for Maxwell Montes ( $50 \mathrm{My})$ is implied. For the lesser horizontal strain rate of $10^{-16} \mathrm{~s}^{-1}$, only limited parameter values for thermal models are allowed.

References. [1] V.L. Barsukov et al., JGR, 91, D378, 1986; [2] S.C. Solomon et al., Science, 252, 297, 1991; [3] J.W. Head et al., Science, 252, 276, 1991; [4] A. A. Pronin, Geotectonics, 20,271, 1986; [5] A. T. Basilevsky, Geotectonics, 20, 282, 1986; [6] R. E. Grimm and R. J. Phillips, GRL, I7, 1349, 1990; [7] K.M. Roberts and J.W. Head, GRL, 17, 1341, 1990; [8] D.L. Bindschadler and E.M. Parmentier, JGR, 95, 21329, 1990; [9] L.S. Crumpler et al., Geology, 14,1031, 1986; [10] Yu.A. Surkov et al., JGR, 92, E537, 1987; [11] R.W. Vorder Bruegge and J.W. Head, Geology, 19, 885, 1991; [12] T.J. Ahrens and G. 


\section{ELEVATION OF MOUNTAIN BELTS ON VENUS: Namiki N. and Solomon S.C.}

Schubert, Rev. Geophys. Space Phys., 13, 383, 1975; [13] K. Ito and G.C. Kennedy, in Geophys. Mon.,14, AGU, 303, 1971; [14] D. Smith and B.R. Barron, Am. Mineral., 76, 1950, 1991; [15] R.E. Grimm and R.J. Phillips, JGR, 96, 8305, 1991; [16] R. Jo. Condit et al., in Atomic Ordering and Mass Transport
Geophys. Mon., 31, AGU, 97, 1985.

Table 1. Model parameters.

\begin{tabular}{|c|c|c|c|c|c|}
\hline Models & $\mathrm{r}, \mathrm{mm}$ & $\mathrm{y}, \mathrm{s}^{-1}$ & $\mathrm{D}$ & $\mathrm{T}_{\mathrm{c}, \mathrm{K}}$ & $\mathrm{T}_{\mathrm{bl}, \mathrm{K}}$ \\
\hline 1 & 1 & $10^{-15}$ & $\mathrm{D}_{\mathrm{AL}, \mathrm{Opx}}$ & 1050 & 1321 \\
2 & 10 & $10^{-15}$ & $\mathrm{D}_{\mathrm{AL}, \mathrm{ppx}}$ & 1050 & 1321 \\
3 & 1 & $10^{-15}$ & $\mathrm{D}_{\mathrm{Fe}, \mathrm{Gt}}$ & 1050 & 1321 \\
4 & 1 & $10^{-16}$ & $\mathrm{D}_{\mathrm{Al}, \mathrm{Opx}}$ & 1050 & 1321 \\
5 & 10 & $10^{-16}$ & $\mathrm{D}_{\mathrm{Al}, \mathrm{Opx}}$ & 1050 & 1321 \\
6 & 10 & $10^{-16}$ & $\mathrm{D}_{\mathrm{Al}, \mathrm{Opx}}$ & 1350 & 1521 \\
7 & 1 & $10^{-16}$ & $\mathrm{D}_{\mathrm{AL}, \mathrm{Opx}}$ & 1150 & 1521 \\
8 & 10 & $10^{-16}$ & $\mathrm{D}_{\mathrm{Fe}, \mathrm{Gl}}$ & 1050 & 1321 \\
\hline
\end{tabular}
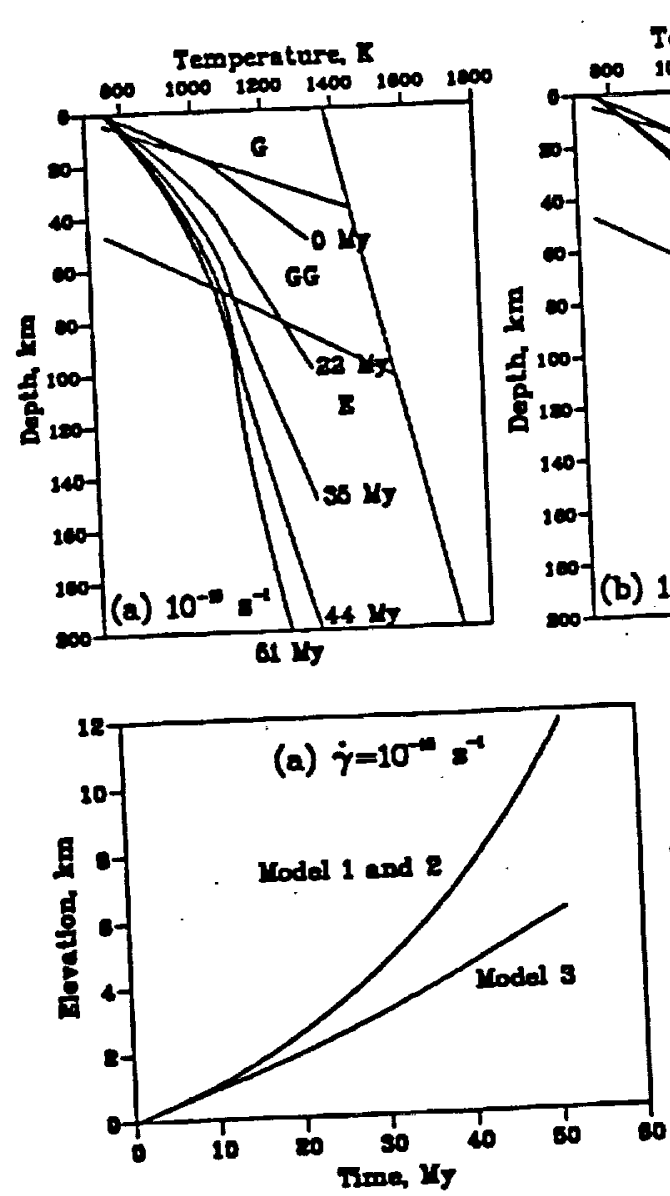
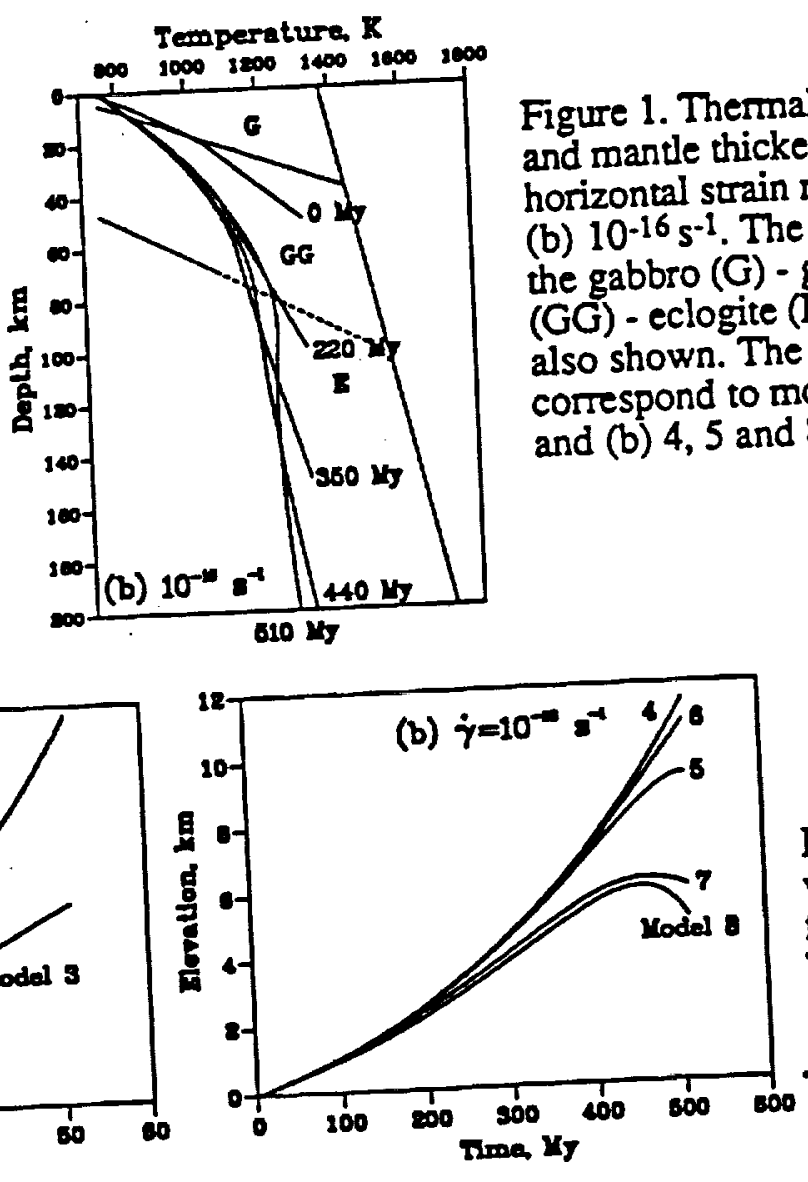

Figure 1. Thermal evolution of crust and mantle thickened by a uniform horizontal strain rate of (a) $10^{-15}$ and (b) $10^{-16} \mathrm{~s}^{-1}$. The phase diagram of the gabbro $(G)$ - garnet granulite (GG) - eclogite (E) transition [13] is also shown. The models shown correspond to models (a) 1,2 and 3, and (b) 4, 5 and 8 in Table 1 .
Figure 2. Temporal variation of elevation for the models in Table 1. 


\title{
The Gabbro - Eclogite Phase Transition and The Elevation of Mountain Belts on Venus
}

\author{
NORTYUKI NAMIKI \\ Department of Earth, Atmospheric, and Planetary Sciences, Massachusetts Institute of \\ Technology, Cambridge
}

SEAN C. SOLOMON

Department of Terrestrial Magnetism, Carnegie Institution of Washington, Washington, D.C.

Submitted to Jownal of Geophysical Research

November 1992 


\begin{abstract}
Maxwell Montes, standing up to $7 \mathrm{~km}$ above the adjacent highland plateaus, constitute the highest mountain belt on Venus. Because the thickness of the crust is likely to be limited by the gabbro - gamet granulite - eclogite phase transitions, this relief is difficult to reconcile with the assumption of thermodynamic equilibrium and a standard Airy isostatic model. We explore the hypothesis that the crust-mantle boundary is not in phase equilibrium, but rather is rate-limited by the temperature-dependent diffusion of the slowest ionic species. Under the simplifying assumption that the mountains formed by uniform horizontal shortening of the crust and lithospheric mantle at a constant rate, we solve the one-dimensional thermal evolution problem. The time-dependent density structure and surface elevation are calculated by assuming a temperature-dependent reaction rate and local Airy isostatic compensation. For a rate of horizontal strain of $10^{-15} \mathrm{~s}^{-1}$ or greater, the rise in temperature at the base of the crust during mountain formation is modest to negligible, the deepening lower crust is metastable, and surface elevation increases as the crust is thickened. For strain rates less than $10^{-16} \mathrm{~s}^{-1}$, in contrast, crustal temperature increases with time because of internal heat production, and the lower crust is more readily transformed to the dense eclogite assemblage. For such models a maximum elevation is reached during crustal shortening. While this maximum relief is $7 \mathrm{~km}$ or more for some models, a smaller density contrast between crust and mantle than assumed here $\left(500 \mathrm{~kg} \mathrm{~m}^{-3}\right)$ and incorporation of horizontal heat transport would lessen this value. We therefore favor formation of the mountain belt at a strain rate at least of order $10^{-15} \mathrm{~s}^{-1}$. By this reasoning, Maxwell Montes must be comparatively young, of order $50 \mathrm{My}$.
\end{abstract}




\section{INTRODUCTION}

The linear mountain belts of westem Ishtar Terra on Venus are notable for their topographic relief and slope and for the intensity of surface deformation [Barsukov et al., 1986; Solomon et al., 1991, 1992]. These four mountain belts, including Akna, Freyja, Maxwell, and Danu Montes (Figure 1), are generally regarded as products of large-scale compression and horizontal shortening of the crust and lithosphere [Crumpler et al., 1986; Solomon et al., 1991, 1992; Kaula et al., 1992]. Among these mountain belts, Maxwell Montes is the highest and stands up to $11 \mathrm{~km}$ above mean planetary radius and $7 \mathrm{~km}$ above the highland plain Lakshmi Planum (Figure 1). Volcanism is rare to absent in Maxwell, Freyja, and Akna Montes, but a number of magmatic features are evident in Danu Montes [Solomon et al., 1991; Head et al., 1991; Kaula et al., 1992], the mountain range least elevated above Lakshmi Planum.

The bulk composition and radioactive heat production of the crust on Venus, where measured, are similar to those of terrestrial basalts [Surkov et al., 1984, 1987]. Because basalt transforms to eclogite at high pressure and because eclogite is likely to be denser than mantle material, the thickness of the crust may be limited by the gabbro - gamet granulite - eclogite phase transitions [Anderson, 1981; Turcotte, 1989]. The phase transition depth depends on the temperature structure of the crust beneath the mountains. If the thermal gradient is low and thermodynamic equilibrium is assumed, the phase changes would take place at shallow depth, and simple isostatic models underpredict the relief [Vorder Bruegge and Head, 1991]. If the thermal gradient is high, in contrast, the base of the crust is predicted to undergo melting before a sufficiently deep root can form to support the mountains. Thus the 7-11 km maximum elevation of Maxwell Montes is difficult to understand under the assumptions of local isostasy and thermodynamic equilibrium except in the unlikely situation that the crust beneath the mountains contains a large volume of magma [Vorder Bruegge and Head, 1991].

A possible explanation for the great relief of Maxwell Montes is that the base of the crust is not in phase equilibrium. Because of the high surface temperature on Venus $(750 \mathrm{~K})$ and the very low 
water abundance of the lower atmosphere [von Zahn et al., 1983], the Venus crust is thought to contain negligible water [Kaula, 1990]. It has been suggested that under anhydrous conditions, the gabbro - eclogite phase transition takes place by solid-state diffusion and may require a geologically significant time to run to completion [Ahrens and Schubert, 1975]. Solid-state diffusion is a strongly temperature-dependent process, so that quantifying this suggestion for application to Venus requires the solution of a heat transport problem. In this paper we develop simple models for the thermal evolution of the crust beneath mountain belts on Venus in an attempt to constrain the time-dependent depth of the gabbro - eclogite transition and thus to assess this hypothesis.

Because at long wavelengths the topography of western Ishtar Terra is correlated with the gravity field, at least partial dynamical support of the regional elevation of about $4 \mathrm{~km}$ is likely [e.g., Grimm and Phillips, 1991]. We therefore adopt the 7-km elevation of Maxwell Montes above the adjacent plateau as a conservative estimate of the relief attributable to local isostasy.

\section{THERMAL MODEL}

We assume that the crustal and mantle portions of the thermal boundary layer shorten horizontally and thicken vertically with time in the manner of pure shear. The thermal structure is then governed by the one-dimensional heat equation,

$$
\frac{\partial T}{\partial t}+\dot{\gamma} z \frac{\partial T}{\partial z}=\kappa \frac{\partial^{2} T}{\partial z^{2}}+\frac{A}{C_{P}}
$$

where $T$ is temperature, $t$ is time, $\dot{\gamma}$ is the horizontal strain rate, $z$ is depth, $k$ is the thermal diffusivity, $A$ is the crustal heat production, and $C_{P}$ is the specific heat. Under the assumption that deformation is by pure shear, $\dot{\gamma}$ is constant and the vertical velocity is given by the product of $\dot{\gamma}$ and z. We solve equation (1) numerically by an explicit finite difference approximation.

\section{Model Parameters}

The thermal diffusivity is assumed to be $1.0 \times 10^{-6} \mathrm{~m}^{2} \mathrm{~s}^{-1}$ in both crust and mantle. The crustal 
heat production is assumed to equal $1.0 \times 10^{-10} \mathrm{~W} \mathrm{~kg}^{-1}$, on the basis of the $\mathrm{K}, \mathrm{U}$, and Th concentrations determined by gamma ray spectrometry by Venera and Vega landers [Surkov et al., 1987]. The specific heat is assumed to be $850 \mathrm{~kJ} \mathrm{~kg}^{-1} \mathrm{~K}^{-1}$. The other physical properties of crustal and mantle materials are assumed to be those, respectively, of tholeiitic basalt and peridotite [Basaltic Volcanism Study Project, 1981]. Temperature at the surface and the bottom of the thermal boundary layer are fixed, respectively, at $750 \mathrm{~K}$ and at a value $T_{b l}$, a free parameter in numerical models. The initial temperature profile is determined by the assumption of steady-state conditions with zero strain rate. The increase in temperature with depth due to adiabatic compression is not considered here, because compressional heating is negligible compared with crustal heat production.

$T_{b l}$ is interpreted as the temperature in an isothermal core of a thermal convection cell [Turcotte and Schubert, 1982] and is, thus, fixed at a constant. For a given $T_{b l}$, an initial temperature $T_{c}$ at the base of the crust is determined. Since temperature at the base of the crust controls the elevation of the mountains, $T_{c}$ has more importance than $T_{b l}$. Zuber [1987] analyzed wavelengths of tectonic features on Venus and found that the crustal thickness is less than about $15 \mathrm{~km}$ if the average vertical thermal gradient in the crust $\mathrm{dT} / \mathrm{dz}$ is $25 \mathrm{~K} \mathrm{~km}^{-1}$, and less than about $30 \mathrm{~km}$ if $d T / d z$ is $10 \mathrm{~K} \mathrm{~km}^{-1}$. The absence of significant viscous relaxation of impact crater relief also limits the crustal thickness in plains regions to be less than $10 \mathrm{~km}$ for $\mathrm{dT} / \mathrm{dz}=20 \mathrm{~K} \mathrm{~km}^{-1}$ and 20 $\mathrm{km}$ for $\mathrm{dT} / \mathrm{dz}=10 \mathrm{~K} \mathrm{~km}^{-1}$ [Grimm and Solomon, 1988]. These results give a maximum temperature difference across the crust of about $400 \mathrm{~K}$. Therefore $T_{b l}$ is given initially so that $T_{c}$ satisfies this upper bound.

The phase diagram is assumed to be that of tholeiitic basalt [Ito and Kennedy, 1971], and the densities of gabbro and eclogite are taken to be 2900 and $3500 \mathrm{~kg} \mathrm{~m}^{-3}$. The density of garnet granulite is assumed to increase linearly from that of gabbro to that of eclogite as pressure increases at a given temperature. The density of the mantle is assumed to be $3400 \mathrm{~kg} \mathrm{~m}^{-3}$. The elevations calculated by an assumption of local Airy isostatic compensation are sensitive to the density difference between crust and mantle. We have adopted a relatively large value of $500 \mathrm{~kg} \mathrm{~m}^{-3}$. 
Because a large density difference results in a higher elevation for a given root thickness, this assumption permits a conservative lower bound on horizontal strain rate. We discuss later the consequence of a lesser density contrast.

\section{Diffusion Rates}

The micromechanism of the gabbro - eclogite transition is not well understood. In this study we assume that volume diffusion of cations is the process most likely to limit the rate of the transformation, which involves chemical as well as phase changes. The volume fraction of reacted components, $\psi$, is given by,

$$
\dot{\psi} \Psi=\mathrm{D} / \mathrm{r}^{2}
$$

where $r$ is the typical grain radius and $D$ is the diffusion coefficient [Ahrens and Schubert, 1975]. For each parcel of shortening thermal lithosphere, $\psi$ is obtained by integration over time. The density at a given depth is determined from the volume fractions of reacted and unreacted components.

There are several reactions occurring among constituent minerals in the garnet granulite stability field [Ringwood, 1975]. The rate of each reaction is difficult to assess, because of a paucity of experimental data. We focus on the diffusion rates of ionic species in pyroxene, garnet, and olivine, because those minerals characterize the phase assemblages and therefore play important roles in the phase transitions. Plagioclase is possibly another important mineral for this assessment, but no data for self diffusion in plagioclase are available. The data for volume diffusion in silicates show that silicon and oxygen diffuse much more slowly than divalent and trivalent cations. Thus the Si-O groups provide a static framework through which the cations diffuse [Freer, 1981]. We examine the diffusion rates of four major cations, $\mathrm{Mg}^{2+}, \mathrm{Fe}^{2+}, \mathrm{Ca}^{2+}$, and $\mathrm{Al}^{3+}$ (Figure 2). The slowest diffusion rate is likely to limit the reaction rate.

Diffusion rates of $\mathrm{Fe}^{2+}$ and $\mathrm{Mg}^{2+}$ in gamet and olivine [Chakraborty and Ganguly, 1991; Morioka and Nagasawa, 1991], of $\mathrm{Mg}^{2+}$ in pyroxene [Cygan and Lasaga, 1985], and of $\mathrm{Ca}^{2+}$ in olivine [Morioka and Nagasawa, 1991] have been experimentally determined (Figure 2). Of these 
the diffusion rate of $\mathrm{Mg}^{2+}$ in gamet $\left(D_{\mathrm{Mg}, G \mathrm{G}}\right.$ ) is the lowest. Of course, if the diffusion rate of any unmeasured major species is slower than that of $\mathrm{Mg}^{2+}$ in garnet, then the phase change rate will be limited by this slower cation. We therefore take the diffusion coefficient $\mathrm{D}_{\mathrm{Mg}, \mathrm{Gt}}$ for this process as an upper bound on $D$ in equation (2).

Other diffusion rates, while not well-determined experimentally, have been estimated, either from measurements at a single temperature, or from observed compositional gradients. While all such estimates include large uncertainties, we take the minimum value of these estimates as a lower bound on $\mathrm{D}$ in equation (2). This minimum is for diffusion of $\mathrm{Al}$ in orthopyroxene (Figure 2), estimated from an analysis of compositional gradients in natural assemblages [Smith and Barron, 1991]. The estimated rate depends on assumptions of cooling rate and pressure. While neither data nor estimates are available for the diffusion coefficients of $\mathrm{Al}^{3+}$ in olivine and gamet, cation diffusion in olivine and gamet is generally faster than in pyroxene [Freer, 1981; Smith and Brown, 1988], and thus is not likely to be rate-limiting. The diffusion of $\mathrm{Ca}^{2+}$ in garnet has been estimated by numerical simulation only at $1200^{\circ} \mathrm{C}$ [Chakraborty and Ganguly, 1991] and is faster than that of $\mathrm{Al}^{3+}$ in orthopyroxene at that temperature (Figure 2). The mobilities of $\mathrm{Ca}^{2+}$ and $\mathrm{Fe}^{2+}$ are held to be comparable in garnet and pyroxene, because neither garnet nor pyroxene in natural assemblages is consistently homogeneous in those elements [Smith and Barron, 1991]. These considerations reinforce the view that $\mathrm{D}_{\mathrm{Al}, \mathrm{Opx}}$ gives a reasonable lower bound on $\mathrm{D}$ in equation (2). The two bounds on $D$ are

$$
\begin{aligned}
\mathrm{D} \leq \mathrm{D}_{\mathrm{Mg}, \mathrm{Gt}} & =2.8 \times 10^{-8} \exp \left[-\left(270 \mathrm{~kJ}+3.2 \times 10^{-6} \mathrm{P}\right) /(\mathrm{RT})\right] \\
\mathrm{D} & \geq \mathrm{D}_{\mathrm{A}, \mathrm{Opx}}=1.1 \times 10^{-5} \exp [-400 \mathrm{~kJ} /(\mathrm{RT})]
\end{aligned}
$$

where $\mathrm{P}$ is in $\mathrm{Pa}$ [Morioka and Nagasawa, 1991; Smith and Barron, 1991].

There is some possibility that the assumed lower bound on D is too large. Sautter et al. [1988] and Sautter and Harte [1990] reported a diffusion rate of $\mathrm{Al}^{3+}$ in clinopyroxene less than the lower bound given above (Figure 2), while Freer et al. [1988] experimentally obtained a maximum diffusion rate as great as the upper bound given above (Figure 2). Further, the diffusion rates in 
plagioclase are generally less than in pyroxene [Smith and Brown, 1988], and interdiffusion of CaAl-NaSi in plagioclase is several orders of magnitude slower than the lower bound on D [Grove et al., 1984]. If $D$ is as low as suggested by these last results, no phase transition is expected to occur during the formation of mountains on Venus. However, the reaction rate is unlikely to be much slower than as given by the lower bound on $\mathrm{D}$, because if volume diffusion is too slow, the reaction rate will be limited by grain-boundary diffusion.

Grain-boundary diffusion, in fact, has been proposed as a possible governing process in metamorphic reactions, because grain-boundary diffusion coefficients can be several orders of magnitude greater than those for volume diffusion [Joesten, 1991]. Whether the phase change proceeds by volume diffusion or grain-boundary diffusion will be governed by the process that is most efficient for mass transport. Grain-boundary diffusion coefficients can be misleading, however, because mass transport by such a process is confined to a thin layer, i.e., the grain boundary. Unfortunately, grain-boundary diffusion data for the minerals involved in the gabbro garnet granulite - eclogite reactions are few and generally not well determined [Joesten, 1991]. Reliable experimental data for grain-boundary diffusion of oxygen in forsterite, for instance, have been reported only at two temperatures [Condit et al., 1985]. These measurements suggest that grain-boundary diffusion for grain sizes of $1-10 \mathrm{~mm}$ is no more efficient for bulk transport than the lower bound on volume diffusion adopted above (Figure 2).

\section{NUMERICAL RESULTS}

Temperatures in the thickening crust and mantle are calculated for rates of horizontal convergence of $10^{-15}$ (Figure 3a) and $10^{-16} \mathrm{~s}^{-1}$ (Figure 3b). For all models discussed here (Table 1), thicknesses of crust and thermal boundary layer are assumed to be initially 20 and $50 \mathrm{~km}$, respectively, and to increase to 100 and $250 \mathrm{~km}$, respectively. Temperature profiles for the strain rate of $10^{-15} \mathrm{~s}^{-1}$ are vertically stretched as the crust and mantle portion of thermal boundary layer are thickened (Figure 3a). Temperatures do not increase significantly from initial values because heat is transferred mainly by advection and the contribution of crustal heat production is minor. 
Hence gabbro remains metastable for $50 \mathrm{My}$ or more, and the elevation of shortened lithosphere can increase as much as $12 \mathrm{~km}$ above the surrounding area of undeformed lithosphere in that time interval (Model 1 in Figure 4a). Equation (2) shows that the reaction runs to completion in a shorter time for small grains than for larger grains. Also it is clear from equation (3) that a higher temperature increases the diffusion rate and promotes the reaction. For the slower diffusion rate (DAl,G), however, a strain rate of $10^{-15} \mathrm{~s}^{-1}$ is sufficiently fast to suppress these effects (Model 2). The phase transition proceeds, i.e., elevation is limited, only if grains are small, diffusion is rapid, and temperature is high (Model 3).

For a strain rate of $10^{-16} \mathrm{~s}^{-1}$, crustal heat production dominates advective heat transfer after the crust becomes as thick as $60-80 \mathrm{~km}$ (Figure $3 \mathrm{~b}$ ). The resulting increase in temperature hastens the phase transition, and the slower strain rate lengthens the formation time of the mountains. For larger grains ( $r=10 \mathrm{~mm}$ ) and a diffusion constant given by equation (3a) the elevation reaches 11 $k m$ or more even if $T_{c}$ is as great as $1120 \mathrm{~K}$ (Model 4 in Figure $4 \mathrm{~b}$ ). For the same value of $T_{c}$ the elevation is at most $7 \mathrm{~km}$ for grains of $1 \mathrm{~mm}$ radius (Model 5). If $T_{c}$ is greater than $1120 \mathrm{~K}$, the model gives a maximum elevation lower than $7 \mathrm{~km}$, that is, the model fails to explain the observed relief of Maxwell Montes. Therefore this result provides an upper bound on $T_{c}$ for small grain size. If $\mathrm{D}$ is given by equation (3b), that upper bound is lowered to $1030 \mathrm{~K}$ (Model 6). Thus the combination of the longer formation time due to the lesser value of $\dot{\gamma}$ and the faster reaction due to higher temperature yields constraints on the range of parameters controlling the phase change if the elevation of the mountains is to reach $7 \mathrm{~km}$ or more above the adjacent plateaus.

\section{DISCUSSION}

The thermal model described above is simple, but significant constraints on the strain rate governing mountain building and the temperature at the base of the crust are nonetheless obtained. In this section, we first consider how the results would differ if key parameters were varied or the models were modified. We then discuss some implications of the numerical results given above.

The thermal evolution results are insensitive to the assumed initial thickness of the crust. At a 
strain rate of $10^{-15} \mathrm{~s}^{-1}$, the advection-dominated thermal profile indicates that the temperature of each parcel of crust changes little as the parcel deepens. For a given value of $T_{c}$, the thermal structure at a given crustal thickness is not affected by initial crustal thickness, or, equivalently, initial thermal gradient. Only the time required for the crust to reach that thickness depends on the initial thickness. At a strain rate of $10^{-16} \mathrm{~s}^{-1}$, in contrast, the thermal profile is close to steady state, that is, the geotherm is nearly the same as that for zero strain rate and thus does not depend on the initial crustal thickness. The initial crustal thickness is still important for the maximum relief, however, because by assumption it is identical to the crustal thickness beneath surrounding areas, taken here to be undergoing negligible rates of horizontal strain. By the assumption of Airy isostasy, at a given crustal thickness beneath the mountains a difference of $10 \mathrm{~km}$ in the thickness of the crust beneath surrounding areas results in a $1.5 \mathrm{~km}$ difference in relief.

Also important is the density difference between crust and mantle. If densities of 3000 and $3300 \mathrm{~kg} \mathrm{~m}^{-3}$ for crust and mantle are assumed, relative elevations are $\sim 40 \%$ lower than the values presented here. At a strain rate of $10^{-15} \mathrm{~s}^{-1}$, gabbroic lower crust remains metastable during the formation of mountains in most cases, as shown by models 1 and 2 . Therefore a smaller density contrast simply requires thicker crust, i.e., greater duration of shortening, and does not otherwise constrain the model parameters. In contrast, at a strain rate of $10^{-16} \mathrm{~s}^{-1}$, maximum elevations are limited in most cases by the gabbro - eclogite phase transition because of the high temperature at the base of the crust, as shown by models 5 and 6 . The lower relief resulting from a smaller density contrast lessens the upper bound on $\mathrm{T}_{\mathrm{c}}$. Thus such a lower density contrast constrains the models of thermal structure and phase transition depth more severely at low strain rates than do the density values adopted above.

At a strain rate of $10^{-16} \mathrm{~s}^{-1}$, the thermal regime is dominated by crustal heat production and diffusion of heat. Horizontal heat transfer within the shortening thermal lithosphere therefore is probably not negligible. The maximum increase in temperature at the bottom of the crust due to horizontal heat transfer can be estimated from the solution for the instantaneous heating of a semiinfinite half-space [Turcotte and Schubert, 1982], 


$$
\delta T=\Delta T \operatorname{erfc}\left(\frac{L}{2 \sqrt{k T}}\right)
$$

where $\delta \mathrm{T}$ is the increase in temperature, $\Delta \mathrm{T}$ is the temperature difference beneath the crust and an isothermal core which surrounds the shortening lithosphere, $\mathrm{L}$ is the horizontal scale of the mountains, and $t$ is the formation time. In our problem, $\Delta T$ is given by $T_{b l}-T_{c}$, and $L$ is $\sim 100$ $\mathrm{km}$. Formation times of $50 \mathrm{My}$ at a strain rate of $10^{-15} \mathrm{~s}^{-1}$ and of $500 \mathrm{My}$ at a strain rate of $10^{-16}$ $\mathrm{s}^{-1}$ result in $\delta \mathrm{T}$ of $2 \times 10^{-2}$ and $60 \mathrm{~K}$, respectively. The assumption of one-dimensional heat transfer is therefore reasonable at the higher strain rate, but horizontal diffusion of heat increases temperature significantly at the lower strain rate. If horizontal heat transport were included in the thermal models at the lower strain rate, the reaction rate of the phase change would be faster, the maximum elevation would be less, and the corresponding upper bound on $\mathrm{T}_{\mathrm{c}}$ would be lower.

These considerations favor the formation of Maxwell Montes at horizontal strain rates on the order of $10^{-15} \mathrm{~s}^{-1}$. The implied age of the mountains is of order $50 \mathrm{My}$ or less. Such an age is young compared with the average crater retention age of the surface of Venus of about $500 \mathrm{My}$ [Phillips et al., 1991]. An important question is whether such a young age is consistent with the presence of the 100-km diameter Cleopatra crater [Basilevsky et al., 1987] (Figure 1) in Maxwell Montes. The age of a single crater, of course, even a large one, is difficult to specify. The rate of formation of impact craters larger than $20 \mathrm{~km}$ in diameter on Venus has been estimated as $3.3 \pm 1.8$ $x 0^{-15} \mathrm{~km}^{-2} \mathrm{yr}^{-1}$ from the statistics of Earth-crossing and Venus-crossing asteroids and an assumed set of scaling laws [Shoemaker et al., 1991]. If Maxwell Montes, $1000 \mathrm{~km}$ long and 500 $\mathrm{km}$ wide, formed in $50 \mathrm{My}$, the expected number of craters larger than $20 \mathrm{~km}$ in diameter is $\sim 0.08$. The probability that one and only one crater larger than $20 \mathrm{~km}$ diameter formed in Maxwell Montes in $50 \mathrm{My}$ is thus $\sim 8 \%$. This value indicates that the presence of a large impact crater is not likely if the mountains formed in only $50 \mathrm{My}$, but the figure is not so low as to reject the hypothesis at high confidence.

Although Danu Montes display compressional deformational features as extensive as the other mountain belts of Ishtar Terra, their maximum relief with respect to Lakshmi Planum is as little as $1 \mathrm{~km}$ (Figure 1). The presence of magmatic features within Danu Montes [Solomon et al., 1991, 
1992; Head et al., 1991; Kaula et al., 1992] indicates that temperature beneath the mountains exceeded the solidus of crustal or shallow mantle material at least locally. Given such evidence for relatively high temperature in the lower lithosphere, the reaction of sufficiently deep lower crustal material has probably gone nearly to completion, which may account for the comparatively modest topographic relief of these mountains. It is also noteworthy that even a small amount of melting can greatly enhance grain-boundary diffusion [Condit et al., 1985; Watson, 1991]. Assessing the cause of higher temperatures beneath Danu Montes requires more detailed thermal models than the simple one-dimensional ones considered here.

\section{CONCLUSIONS}

Taking into account the temperature-dependent reaction rate of the gabbro - eclogite phase transition, horizontal strain rates of $10^{-15}$ and $10^{-16} \mathrm{~s}^{-1}$ result in significant differences in the maximum elevation of mountains on Venus, not only because of the difference in the formation time for relief, but also because of the difference in the thermal regime from advection-dominated to crustal-heat-production dominated. For a strain rate of $10^{-15} \mathrm{~s}^{-1}$, the observed maximum elevation of Maxwell Montes can be explained as a consequence of local isostasy and disequilibrium phase boundary depth for a wide range of physical parameters. For the lesser horizontal strain rate of $10^{-16} \mathrm{~s}^{-1}$, only limited parameter values for thermal models are allowed, and this limitation becomes more difficult to satisfy when a smaller density contrast between the crust and mantle is assumed or when horizontal heat transport is considered. We favor the formation of Maxwell Montes at a strain rate of $10^{-15} \mathrm{~s}^{-1}$ or greater, although the likelihood that Cleopatra crater is younger than the implied age for Maxwell Montes ( $50 \mathrm{My})$ is low. Magmatism within Danu Montes indicates higher temperatures in the crust or shallow mantle beneath those mountains than beneath the other mountains. The modest elevation of Danu Montes relative to the other mountain belts of Ishtar Terra can be understood as a consequence of near completion of the phase transition. 
Acknowledgments. We thank Paul Hess for an introduction to the literature on diffusion coefficients. This research was supported by the National Aeronautics and Space Administration under grant NAGW-1937. 


\section{REFERENCES}

Ahrens, T. J., and G. Schubert, Gabbro - eclogite reaction rate and its geophysical significance, Rev. Geophys. Space Phys., 13, 383-400, 1975.

Anderson, D. L., Plate tectonics on Venus, Geophys. Res. Lett., 8, 309-311, 1981.

Barsukov, V. L., et al., The geology and geomorphology of the Venus surface as revealed by the radar images obtained by Venera 15 and 16, Proc. Lunar Planet. Sci. Conf. 16th, J. Geophys. Res., 91, D378-D398, 1986.

Basaltic Volcanism Study Project, Basaltic Volcanism on the Terrestrial Planets, 1286 pp., Pergamon, New York, 1981.

Basilevsky, A. T., Structure of central and eastern areas of Ishtar Terra and some problems of Venusian tectonics, Geotectonics, 20, 282-288, 1986.

Basilevsky, A. T., B. A. Ivanov, G. A. Burba, I. M. Chernaya, V. P. Kryuchkov, O. V. Nikolaeva, D. B. Campbell, and L. B. Ronca, Impact cratering of Venus: A continuation of the analysis of data from Venera 15 and 16 spacecraft, J. Geophys. Res., 92, 12,869-12,901, 1987.

Bindschadler, D. L., and E. M. Parmentier, Mantle flow tectonics: The influence of ductile lower crust and implications for the formation of topographic uplands on Venus, J. Geophys. Res., 95, 21,329-21,344, 1990.

Chakraborty, S., and J. Ganguly, Compositional zoning and cation diffusion in garnets, in Diffusion, Atomic Ordering, and Mass Transport, edited by J. Ganguly, pp. 120-175, SpringerVerlag, New York, 1991.

Condit, R. H., H. C. Weed, and A. J. Piwinskii, A technique for observing oxygen diffusion along grain boundary regions in synthetic forsterite, in Point Defects in Minerals, edited by $\mathbf{R}$. N. Schrock, Geophysical Monograph, 31, 97-105, Am. Geophys. Union, Washington, D. C., 1985.

Crumpler, L. S., J. W. Head, and D. B. Campbell, Orogenic belts on Venus, Geology, 14, 1031 1034, 1986. 
Cygan, R. T., and A. C. Lasaga, Self - diffusion of magnesium in garnet at $750^{\circ} \mathrm{C}$ to $900^{\circ} \mathrm{C}, \mathrm{Am}$. J. Sci., 285, 328-350, 1985.

Freer, R., Diffusion in silicate minerals and glasses: A data digest and guide to the literature, Contrib. Mineral. Petrol., 76, 440-454, 1981.

Freer, R., M. A. Carpenter, J. V. P. Long, and S. J. B. Reed, "Null result" diffusion experiments with diopside: Implications for pyroxene equilibria, Earth Planet. Sci. Lett., 58, 285-292, 1982.

Grimm, R. E., and R. J. Phillips, Tectonics of Lakshmi Planum, Venus: Tests for Magellan, Geophys. Res. Lett., 17, 1349-1352, 1990.

Grimm, R. E., and R. J: Phillips, Gravity anomalies, compensation mechanisms, and the geodynamics of western Ishtar Terra, Venus, J. Geophys. Res., 96, 8305-8324, 1991.

Grimm, R. E., and S. C. Solomon, Viscous relaxation of impact crater relief on Venus: Constraints on crustal thickness and thermal gradient, J. Geophys. Res., 93, 11,911-11,929, 1988.

Grove, T. L., M. B. Baker, and R. J. Kinzler, Coupled CaAl-NaSi diffusion in plagioclase feldspar: Experiments and application to cooling rate speedometry, Geochim. Cosmochim. Acta, 48, 2113-2121, 1984.

Head, J. W., III, D. B. Campbell, C. Elachi, J. E. Guest, D. P. McKenzie, R. S. Saunders, G. G. Schaber, and G. Schubert, Venus volcanism: Initial analysis from Magellan data, Science, 252, 276-288, 1991.

Ito, K., and G. C. Kennedy, An experimental study of the basalt - gamet granulite - eclogite transition, in The Structure and Physical Properties of the Earth's Crust, edited by J. G. Heacock, Geophysical Monograph, 14, 303-314, Am. Geophys. Union, Washington, D. C., 1971.

Joesten, R., Grain-boundary diffusion kinetics in silicate and oxide minerals, in Diffusion, Atomic Ordering, and Mass Transport, edited by J. Ganguly, pp. 345-395, Springer-Verlag, New York, 1991.

Kaula, W. M., Venus: A contrast in evolution to Earth, Science, 247, 1191-1196, 1990. 
Kaula, W. M., D. L. Bindschadler, R. E. Grimm, V. L. Hansen, K. M. Roberts, and S. E. Smrekar, Styles of deformation in Ishtar Terra and their implications, J. Geophys. Res, 97, 16,085-16,120, 1992.

Morioka, M., Cation diffusion in olivine- $-\mathrm{I}$. Ni-Mg, $\mathrm{Mn}-\mathrm{Mg}, \mathrm{Mg}$, and Ca, Geochim. Cosmochim. Acta, 45, 1573-1580, 1981.

Morioka, M., and H. Nagasawa, Ionic diffusion in olivine, in Diffusion, Atomic Ordering, and Mass Transport, edited by J. Ganguly, pp. 176-197, Springer-Verlag, New York, 1991.

Phillips, R. J., R. E. Arvidson, J. M. Boyce, D. B. Campbell, J. E. Guest, G. G. Schaber, and L. A. Soderblem, Impact craters on Venus: Initial analysis from Magellan, Science, 252, 288 297, 1991.

Pronin, A. A., The structure of Lakshmi Planum, an indication of horizontal asthenospheric flow on Venus, Geotectonics, 20, 271-281, 1986.

Ringwood, A. E., Composition and Petrology of the Earth's Mantle, 618 pp., McGraw-Hill, New York, 1975.

Roberts, K. M., and J. W. Head, Western Ishtar Terra and Lakshmi Planum, Venus: Models of formation and evolution, Geophys. Res. Lett., 17, 1341-1344, 1990.

Sautter, V., and B. Harte, Diffusion gradients in an eclogite xenolith from the Roberts Victor kimberlite pipe: (2) kinetics and implications for petrogenesis, Contrib. Mineral. Petrol., 105, 637-649, 1990.

Sautter, V., O. Jaoul, and F. Abel, Aluminum diffusion in diopside using the ${ }^{27} \mathrm{Al}(\mathrm{p}, \mathrm{r})^{28} \mathrm{Si}$ nuclear reaction: Preliminary results, Earth Planet. Sci. Lett., 89, 109-114, 1988.

Shoemaker, E. M., R. F. Wolfe, and C. S. Shoemaker, Asteroid flux and impact cratering rate on Venus (abstract), Lunar Planet. Sci., 22, 1253-1254, 1991.

Smith, D., and B. Barron, Pyroxene - garnet equilibration during cooling in the mantle, Am. Mineral., 76, 1950-1963, 1991.

Smith, J. V., and W. L. Brown, Feldspar Minerals, 828 pp., Springer-Verlag, Berlin, 1988.

Solomon, S. C., J. W. Head, W. M. Kaula, D. McKenzie, B. Parsons, R. J. Phillips, G. 
Schubert, and M. Talwani, Venus tectonics: Initial analysis from Magellan, Science, 252, 297$312,1991$.

Solomon, S. C., et al., Venus tectonics: An overview of Magellan observation, J. Geophys. Res., 97, 13,199-13,255, 1992.

Surkov, Y. A., V. L. Barsukov, L. P. Moskalyeva, V. P. Kharyukova, and A. L. Kemurdzhian, New data on the composition, structure, and properties of Venus rock obtained by Venera 13 and Venera 14, Proc. Lunar Planet. Sci. Conf. 14th, J. Geophys. Res., 89, B393-B402, 1984.

Surkov, Y. A., F. F. Kirnozov, V. N. Glazov, A. G. Dunchenko, L. P. Tatsy, and O. P. Sobornov, Uranium, thorium, and potassium in the Venusian rocks at the landing sites of. Vega 1 and 2, Proc. Lunar Planet. Sci. Conf. 17th, J. Geophys. Res., 92, E537-E540, 1987.

Turcotte, D. L., A heat pipe mechanism for volcanism and tectonics on Venus, J. Geophys. Res., 94, 2779-2785, 1989.

Turcotte, D. L., and G. Schubert, Geodynamics: Applications of Continuum Physics to Geological Problems, 450 pp., Wiley, New York, 1982.

von Zahn, U., S. Kumar, H. Niemann, and R. Prinn, Composition of the Venus atmosphere, in Venus, edited by D. M. Hunten, L. Colin, T. M. Donahue, and V. I. Moroz, pp. 299-430, University of Arizona Press, Tucson, 1983.

Vorder Bruegge, R. W., and J. W. Head, Processes of formation and evolution of mountain belts on Venus, Geology, 19, 885-888, 1991.

Watson, E. B., Diffusion in fluid-bearing and slightly-melted rocks: Experimental and numerical approaches illustrated by iron transport in dunite, Contrib. Mineral. Petrol., 107, 417-434, 1991.

Zuber, M. T., Constraints on lithospheric structure of Venus from mechanical models and tectonic surface features, Proc. Lunar Planet. Sci. 17th, J. Geophys. Res., 92, E541-E551, 1987. 
N. Namiki, Building 54-521, Department of Earth, Atmospheric, and Planetary Sciences, Massachusetts Institute of Technology, Cambridge, MA 02139.

S. C. Solomon, Department of Terrestrial Magnetism, Carnegie Institution of Washington, 5241 Broad Branch Road, N.W., Washington, DC 20015. 


\section{FIGURE CAPTIONS}

Figure 1. Topographic map of western Ishtar Terra. Contour map of Magellan altimetry data gridded at $0.5^{\circ}$ intervals of latitude and longitude; $1-\mathrm{km}$ contour interval; polar stereographic projection. Cross symbol shows the location of Cleopatra crater $\left(65.9^{\circ} \mathrm{N} 7.0^{\circ} \mathrm{E}\right)$.

Figure 2. Diffusion constants for ionic species in olivine, pyroxene, and garnet. Solid lines show diffusion constants that were experimentally determined ( 1 is for $\mathrm{Fe}$ in garnet [Chakraborty and Ganguly, 1991]; 2 is for $\mathrm{Mg}$ in gamet [Chakraborty and Ganguly, 1991]; 3 is for Fe in olivine [Morioka and Nagasawa, 1991]; 4 is for Mg in olivine [Morioka and Nagasawa, 1991]; 5 is for $\mathrm{Mg}$ in clinopyroxene [Cygan and Lasaga, 1985]; and 6 is for Ca in olivine [Morioka and Nagasawa, 1991]). The shaded area shows the range of estimates for $\mathrm{D}_{\mathrm{Al}, \mathrm{Opx}}$, including maximum and minimum (7) values [Smith and Barron, 1991]. Cross symbols show the values determined at a single temperature ( 8 is for Ca in garnet [Chakraborty and Ganguly, 1991]; 9 is an upper bound on the diffusion constant of $\mathrm{Al}$ in clinopyroxene [Freer et al., 1988]; 10 and 11 are values for Al in clinopyroxene from Sautter et al. [1988] and Sautter and Harte [1990], respectively). The constants for grain-boundary diffusion of $O$ in forsterite [Condit et al., 1985] are converted to equivalent volume diffusion by multiplying by the ratio of grain boundary width to grain diameter (12); the grain boundary width was taken to be $3 \mu \mathrm{m}$ [Condit et al., 1985], and the grain diameters were taken to be $1-10 \mathrm{~mm}$.

Figure 3. Thermal evolution of crust (solid) and mantle (dashed) thickened at a uniform horizontal strain rate of (a) $10^{-15}$ and (b) $10^{-16} \mathrm{~s}^{-1}$. The phase boundary of the gabbro (G), gamet granulite (GG), and eclogite (E) assemblages and the solidus (S) [Ito and Kennedy, 1971] are shown by dotted lines. The models shown correspond to models (a) 1 and (b) 4 and 5 in Table 1.

Figure 4. Temporal variation of elevation for the thermal models in Table 1. 
TABLE 1. Parameters for Thermal Models

\begin{tabular}{cccccc}
\hline Model & $\mathrm{r}, \mathrm{mm}$ & $\dot{\gamma}, \mathrm{s}^{-1}$ & $\mathrm{D}$ & $\mathrm{T}_{\mathrm{c}}, \mathrm{K}$ & $\mathrm{T}_{\mathrm{bl}}, \mathrm{K}$ \\
\hline 1 & 10 & $10^{-15}$ & $\mathrm{D}_{\mathrm{AL}, \mathrm{Opx}}$ & 1050 & 1321 \\
2 & 1 & $10^{-15}$ & $\mathrm{D}_{\text {Al, Opx }}$ & 1120 & 1461 \\
3 & 1 & $10^{-15}$ & $\mathrm{D}_{\mathrm{Mg}, \mathrm{Gt}}$ & 1130 & 1481 \\
4 & 10 & $10^{-16}$ & $\mathrm{D}_{\text {AL,Opx }}$ & 1120 & 1461 \\
5 & 1 & $10^{-16}$ & $\mathrm{D}_{\mathrm{AL}, \mathrm{Opx}}$ & 1120 & 1461 \\
6 & 10 & $10^{-16}$ & $\mathrm{D}_{\mathrm{Mg}, \mathrm{Gl}}$ & 1030 & 1281 \\
\hline
\end{tabular}




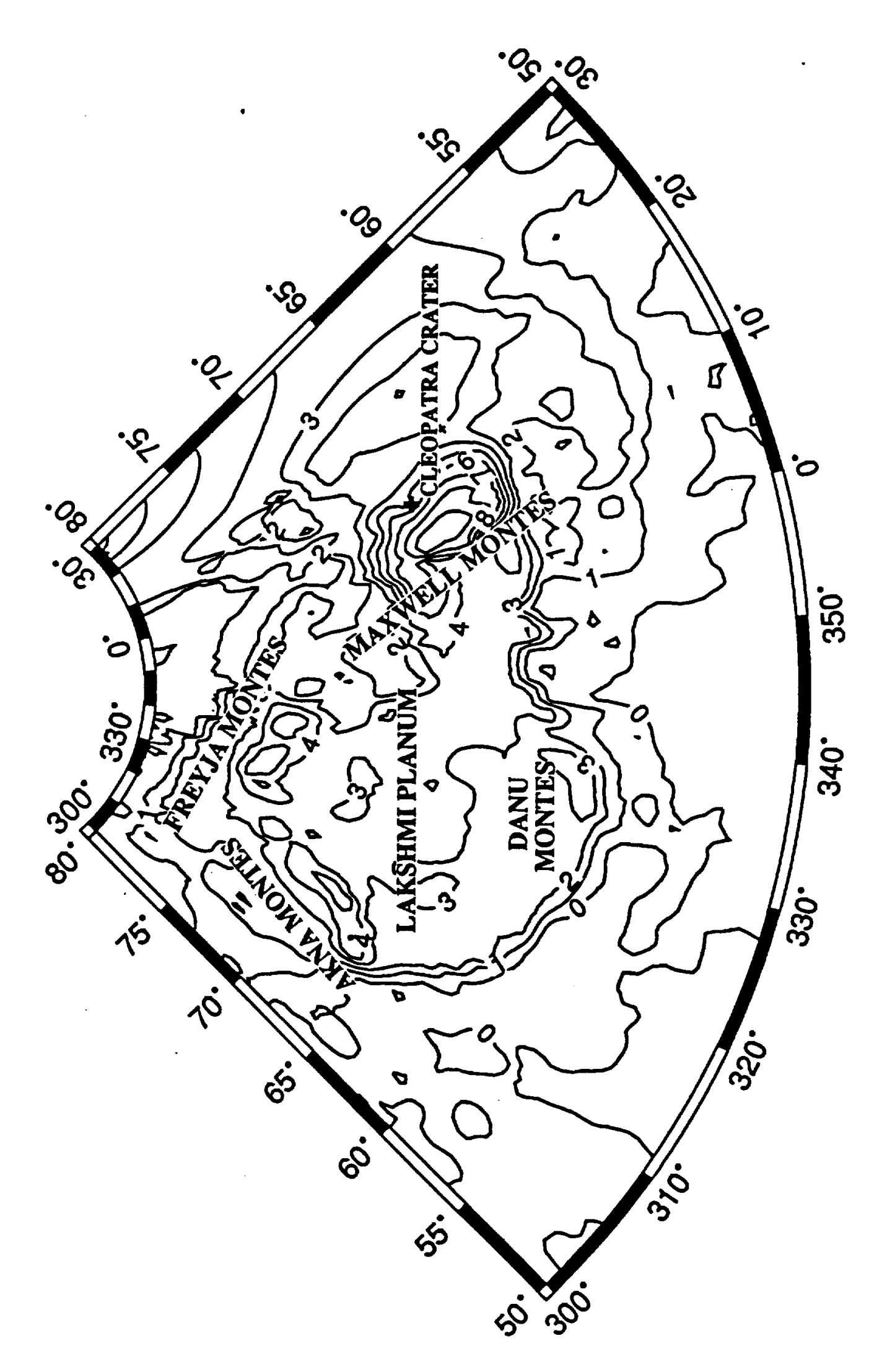


Fig. 2

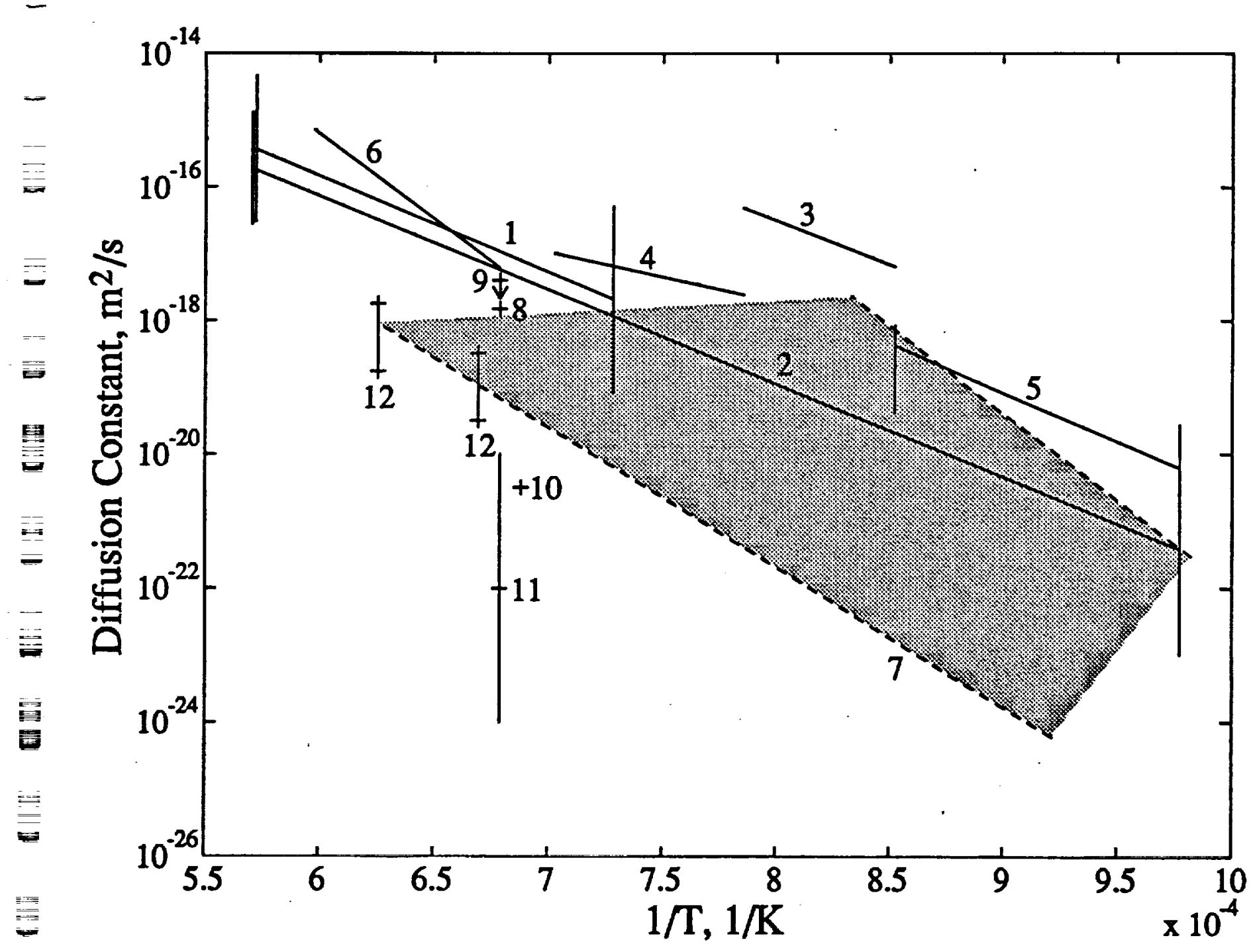




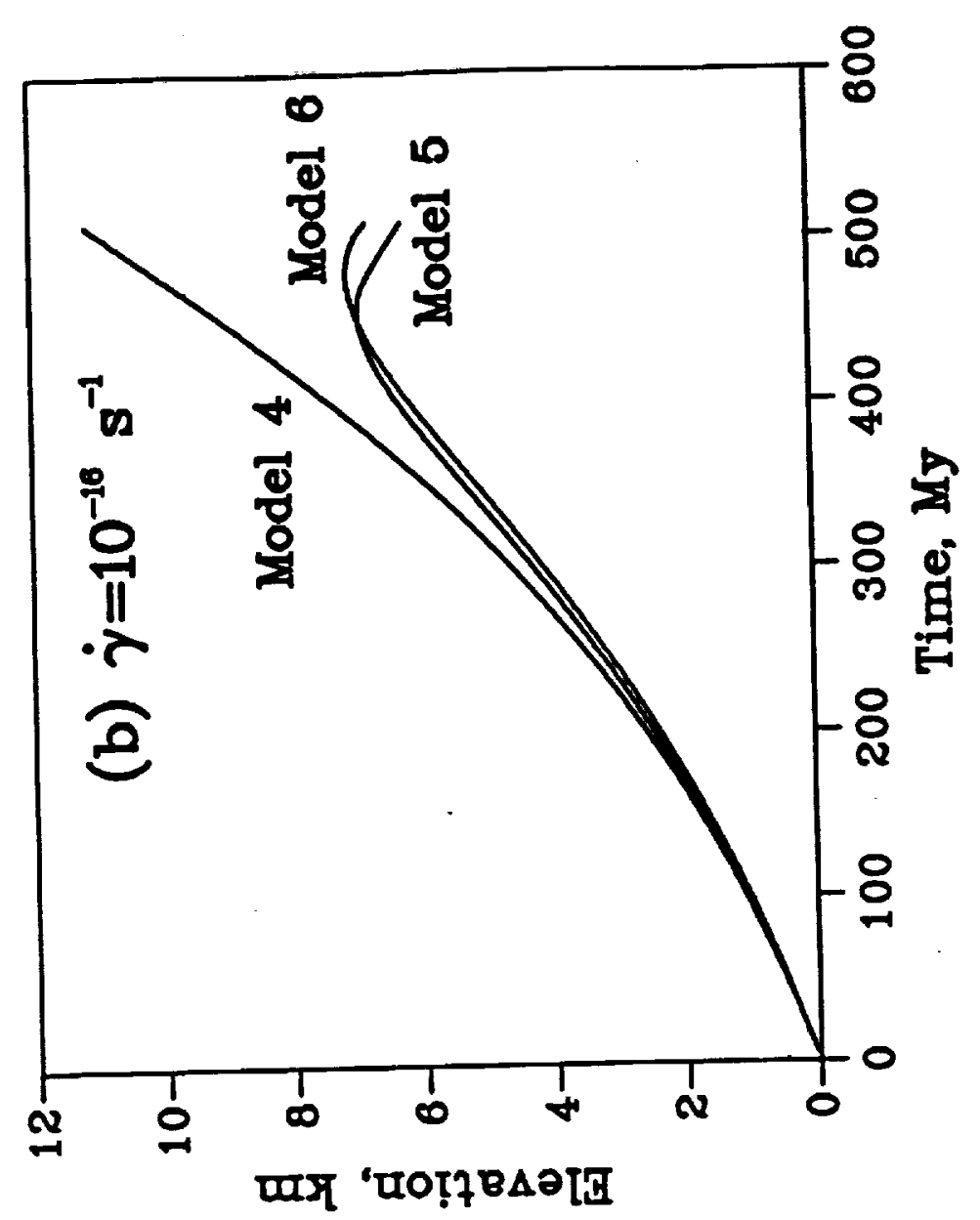

- $\quad \dot{\square}$

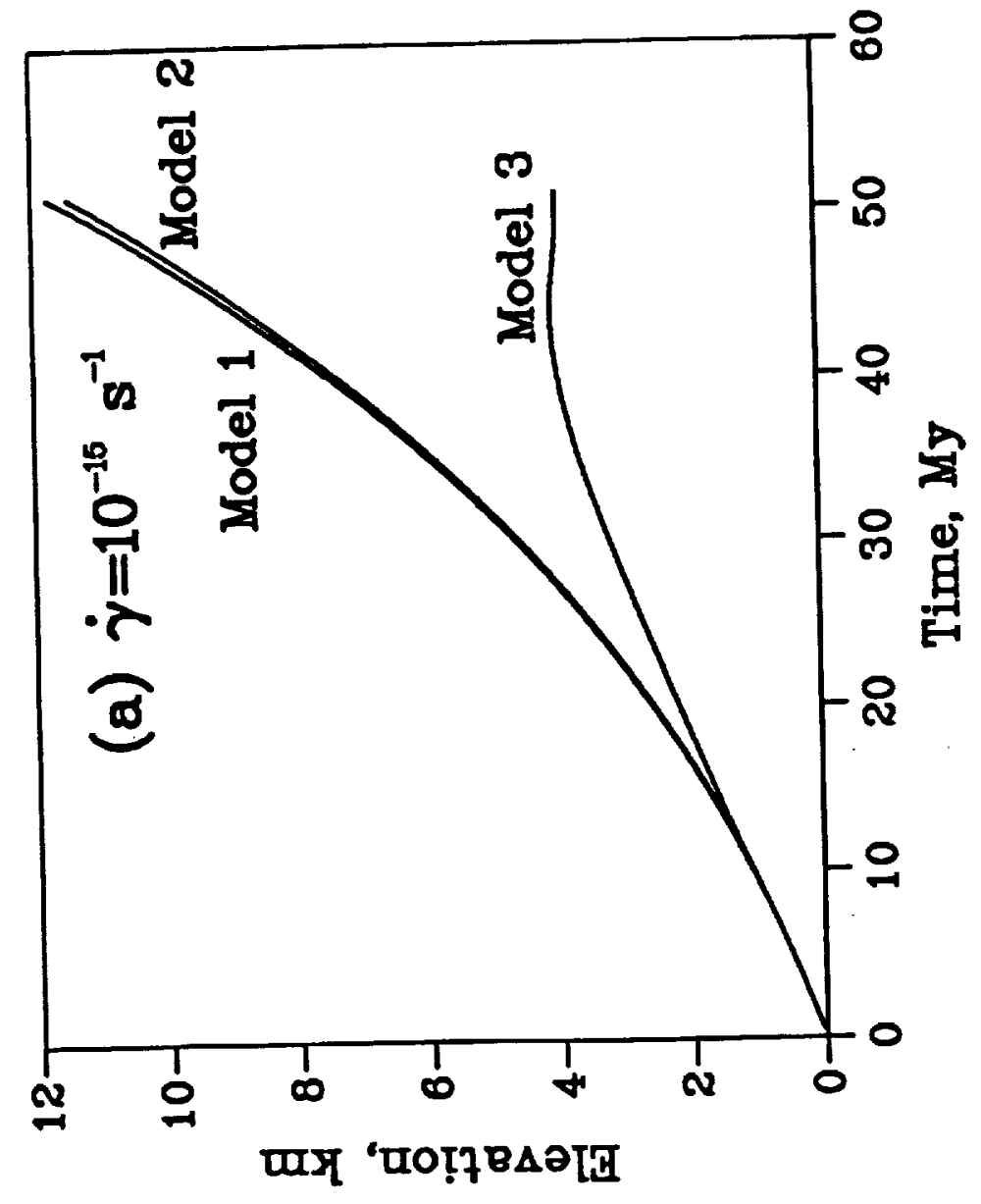

